Ann. Abeille, I965, 8 (3), 205-263.

\title{
ORGANISATION DU TRAVAIL D'EXTRACTION DU MIEL
}

\author{
J. PIEL-DESRUISSEAUX \\ Laboratoire d'Organisation scientifique du Travail (1) \\ Station centrale d'Économie et de Sociologie rurale, Paris
}

SOMMAIRE

Les travaux d'apiculture sont essentiellement saisonniers et doivent être réalisés dans le minimum de temps ; il est nécessaire de préciser les moyens et les méthodes de travail les plus rationnels, c'est-à-dire les plus rapides et les plus efficaces.

L'étude d'organisation du travail d'extraction du miel a porté sur les opérations d'enlèvement des opercules et de centrifugation des cadres, ainsi que sur les travaux accessoires de manutention et de stockage du matériel et des produits.

Pour chacune de ces tâches élémentaires ont été déterminés les moyens (outils, machines et locaux) et les méthodes de travail les plus efficaces en tenant compte des effectifs disponibles de personnel.

\section{INTRODUCTION}

L'exploitation apicole comporte une variété de travaux relevant des disciplines biologiques et des techniques industrielles dont l'efficacité dépend, non seulement des conditions naturelles qui président à leur réalisation mais aussi du choix et de 1'emploi des moyens et des méthodes de travail.

L'apiculture, comme les autres activités agricoles, présente une grande variété de matériels et de procédés résultant plus souvent d'une routine empirique que d'une recherche systématique et il est parfois difficile à l'apiculteur d'orienter son choix devant la multiplicité des solutions proposées.

L'organisation du travail a pour objet, dans une activité donnée, de rechercher les techniques les plus rationnelles permettant d'obtenir les meilleurs résultats quantitatifs et qualitatifs.

La présente étude est limitée au travail d'extraction du miel, mais elle fait partie

(1) Étude réalisée par le Laboratoire d'Organisation scientifique du Travail de l'I. N. R. A. en collaboration avec la Station de Recherches sur l'Abeille et les Insectes sociaux et la Station expérimentale d'Apiculture. 
d'un programme de recherches portant sur toutes les activités apicoles dans les domaines de la technique et de la gestion de l'entreprise.

La méthode adoptée consiste à analyser des chantiers sur lesquels on applique des moyens de travail (outils et machines) différents et des procédés variés dans l'aménagement des locaux et dans le déroulement des opérations. Cette analyse permet de calculer des normes concernant les caractéristiques des matériels et de comparer les temps, le rendement et la productivité du travail.

A partir de ces normes et de ces comparaisons, il est possible d'élaborer des modèles de processus opérationnels et d'implantations d'ateliers et de postes de travail, ainsi que des études économiques de prix de revient et de rentabilité.

L,e travail d'extraction du miel comporte chronologiquement les phases élémentaires suivantes :

- réception, manutention et stockage des hausses provenant des ruchers,

- enlèvement des opercules des cadres,

- extraction du miel par centrifugation,

- manutention et stockage du miel.

Chacune de ces phases a fait l'objet d'une étude particulière en vue de comparer l'efficacité des outils et des machines utilisés et de déterminer avec des effectifs variables de personnel, leurs conditions d'emploi avec le souci d'alléger l'effort des exécutants et d'assurer leur sécurité.

\section{I. - MANUTENTION E'T STOCKAGE DES HAUSSES}

L,es hausses venant du rucher sont transportées à l'aide de camionnettes et déchargées dans la miellerie oì elles sont stockées en attendant l'extraction. Du lieu de stockage au poste d'extraction les hausses pleines sont reprises sur une distance plus ou moins longue. Enfin après extraction du miel, les hausses contenant les cadres vides sont stockées en magasin en attendant leur révision et leur utilisation ultérieure. Ces opérations de manutention et de stockage nécessitent, pour être exécutées rationnellement, l'emploi d'un matériel bien adapté et des locaux judicieusement aménagés.

\section{A. Matériel utilisé}

Le matériel utilisé comprend les hausses, les palettes de stockage et les appareils de manutention.

\section{a) Les hausses.}

Les hausses sont du type Dadand-Blatt. Elles mesurent $50,2 \mathrm{~cm}$ de long, $42,8 \mathrm{~cm}$ de large et $\mathrm{r} 7 \mathrm{~cm}$ de hauteur (dimensions extérieures). Elles sont garnies de 9 ou de ro cadres supportés par des rateliers permettant leur mise en place correcte et rapide.

Une hausse vide équipée de ses cadres pèse $6,500 \mathrm{~kg}$. Le poids des hausses pleines dépend de l'importance de la miellée. 
Par contre lorsque les palettes sont chargées de hausses vides à stocker, on peut monter les piles à to hausses ce qui économise le nombre des palettes à utiliser sans pour autant compromettre la stabilité des piles.

Les palettes garnies de 40 hausses vides (4 piles de Io) pèsent $265 \mathrm{~kg}$ et lorsqu'elles sont garnies de 28 hausses pleines, leur poids varie de $600 \mathrm{~kg}$ à I $000 \mathrm{~kg}$.

Ces palettes sont déplacées à l'aide de transrouleurs-élévateurs à fourches.

c) Appareils de manutention.

On utilise généralement dans les mielleries trois types d'appareils de manutention :

Io Des tables roulantes.

En cornière d'acier, mesurant $55 \mathrm{~cm}$ de long, $47,5 \mathrm{~cm}$ de large et présentant un plan de travail à $70 \mathrm{~cm}$ du sol. Ces tables peuvent être chargées de deux hausses dont le bord supérieur se trouve alors à $103 \mathrm{~cm}$ du sol.

I, e plan supérieur des tables est constitué par des plateaux métalliques munis de petits bords permettant de recueillir le miel qui s'écoule des cadres désoperculés dans les hausses placées en attente d'extraction.

Certains constructeurs fabriquent des tablettes roulantes munies d'un plateau de hauteur variable, réglée par des ressorts. I a capacité de ces tablettes peutêtre de 4 hausses, de manière qu'avec un dégagement de $10 \mathrm{~cm}$ au-dessus du sol, la partie supérieure de la hausse en chargement ou en déchargement soit à $78 \mathrm{~cm}$ de hauteur, c'est-à-dire au niveau optimum de préhension des cadres.

Ces tables roulantes sont utilisées pour effectuer les petites manipulations au cours des opérations d'extraction du miel.

\section{$2^{\circ}$ Des transrouleurs.}

Les transrouleurs sont des chariots permettant de soulever les palettes à quelques centimètres au-dessus du sol et de les déplacer horizontalement. Les manœuvres sont exécutées manuellement (élévation et translation).

Ces appareils ont généralement une force de $500 \mathrm{~kg}$ suffisante pour manutentionner des petites palettes chargées de $\mathrm{I} 8$ hausses pleines.

\section{$3^{\circ}$ Des transrouleurs-élévateurs.}

Les transrouleurs-élévateurs (fig. I) sont des appareils permettant de lever les charges et de les gerber, ainsi que de les déplacer horizontalement. Dans une miellerie on peut se contenter d'utiliser des transrouleurs-élévateurs manœuvrés à la main qui permettent de surélever des charges de l'ordre d'une tonne, à une hauteur de $2,50 \mathrm{~m}$. On peut alors gerber trois palettes de 28 hausses chacune, soit 84 hausses avec une hauteur sous plafond de $4 \mathrm{~m}(3,75 \mathrm{~m}$ de hauteur de charge et $0,25 \mathrm{~m}$ de débattement supérieur).

\section{B. Temps de travail}

Les opérations de manutention des hausses pleines à la réception comportent 3 opérations élémentaires :

- déchargement des hausses du véhicule et leur chargement sur palette,

- manœuvre des palettes : approche du véhicule et remise en place de stockage,

- manœuvre de gerbage des palettes. 
Nous avons dans cette étude admis quatre charges moyennes de cadres: $\mathbf{1}, \mathbf{5}$, $2,2,5$ et $3 \mathrm{~kg}$, ce dernier poids étant rarement atteint comme moyenne. Ces chiffres sont théoriques et adoptés pour faciliter les calculs et les comparaisons de rendements de travail en particulier.

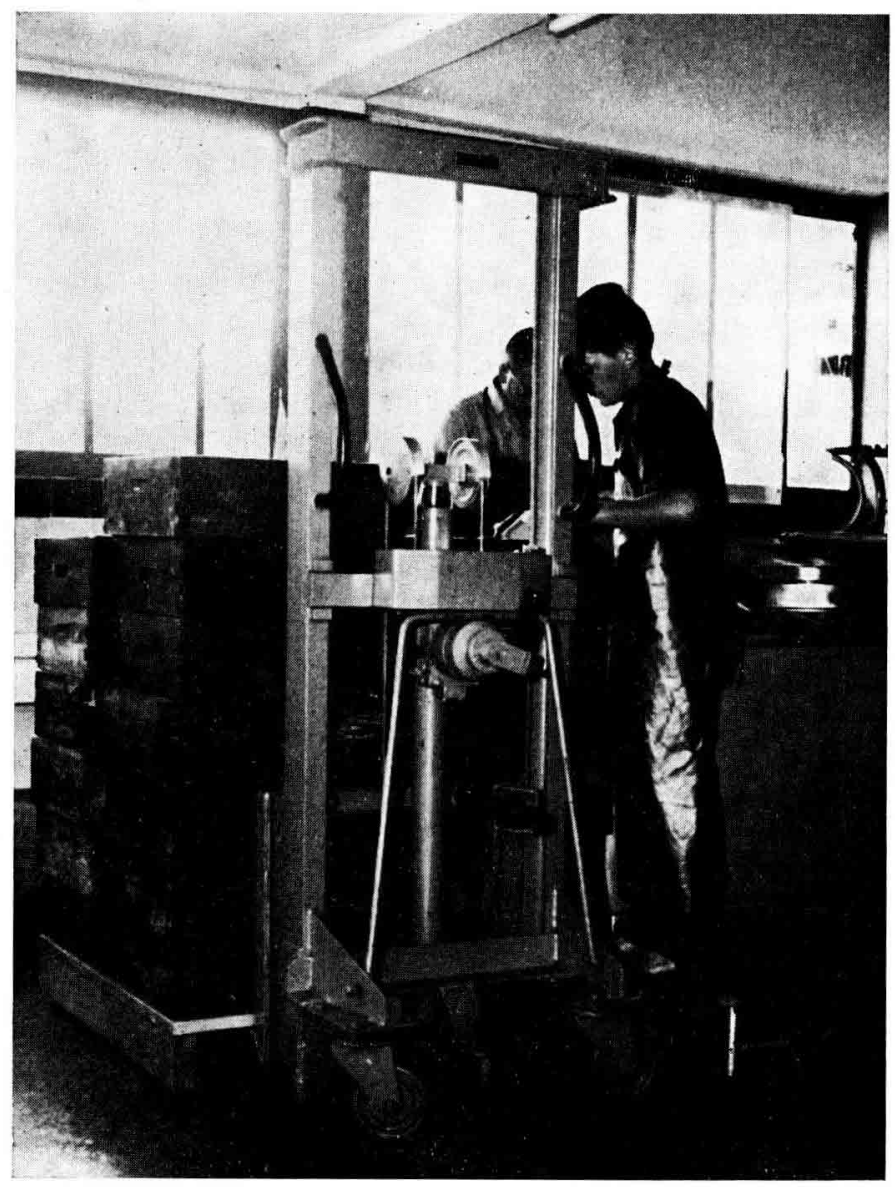

FIG. I. - Transrouleur-élévateur

En considérant ces différentes charges, le poids des hatisses pleines, à raison de Io cadres par hausse, est de :

$$
\begin{aligned}
& 2 I, 5 \mathrm{~kg} \text { avec des cadres de I,5 kg } \\
& 26,5 \mathrm{~kg} \text { avec des cadres de } 2 \mathrm{~kg} \\
& 31,5 \mathrm{~kg} \text { avec des cadres de } 2,5 \mathrm{~kg} \\
& 36,5 \mathrm{~kg} \text { avec des cadres de } 3 \mathrm{~kg} \text {. }
\end{aligned}
$$

b) Palettes de stockage.

Les palettes sont constituées par un simple plancher isolé du sol par des supports et sur lequel sont posées les hausses. Elles ne comportent ni côtés, ni ridelles, les charges étant suffisamment rigides et résistantes. 
On utilise généralement deux types de palettes suivant le dispositif de manutention dont on dispose et permettant de déplacer des charges différentes.

I,e tableau I indique les principales caractéristiques des deux types de palettes.

TABLEAU I

Caractéristiques des palettes de stockage

\begin{tabular}{|c|c|c|c|c|c|c|c|c|c|c|}
\hline \multirow{3}{*}{ Palettes } & \multicolumn{3}{|c|}{ Dimensions } & \multirow{3}{*}{$\begin{array}{c}\text { Surface } \\
\left(\mathrm{m}^{2}\right)\end{array}$} & \multicolumn{3}{|c|}{ Nombre de } & \multirow{3}{*}{$\begin{array}{l}\text { Haut, } \\
\text { chargée } \\
\text { (cm) }\end{array}$} & \multicolumn{2}{|c|}{ Poids avec hausses } \\
\hline & \multirow{2}{*}{$\begin{array}{l}\text { Long. } \\
\text { (cm) }\end{array}$} & \multirow{2}{*}{$\begin{array}{l}\text { Larg. } \\
(\mathrm{cm})\end{array}$} & \multirow{2}{*}{$\begin{array}{l}\text { Haut. } \\
\text { (cm) }\end{array}$} & & \multirow{2}{*}{ piles } & \multicolumn{2}{|c|}{ hausses } & & vides & pleines \\
\hline & & & & & & pleines & vides & & $(\mathrm{kg})$ & \\
\hline Petites & 85 & 65 & 20 & 0,55 & 2 & 18 & 18 & 173 & 122 & $400-600$ \\
\hline Grandes & 102 & 102 & 15 & $1,0^{\prime}$ & 4 & 28 & 36 & $\begin{array}{l}134 \\
168\end{array}$ & 245 & $600 \cdot 1000$ \\
\hline
\end{tabular}

Les petites palettes permettant de recevoir 2 piles de 9 hausses, soit un total de 18 hausses ce qui représente une charge de $122 \mathrm{~kg}$ en hausses vides et de 400 à $600 \mathrm{~kg}$ en hausses pleines sont utilisées lorsqu'on emploie pour les déplacer un transrouleur. La hauteur de leur chargement est limitée à la zone de préhension supérieure maximum (1).

L es grandes palettes dont la surface est double de celle des précédentes ont naturellement une capacité plus importante, on peut y disposer 4 piles de hausses. Comme les palettes sont utilisées au poste d'enlèvement des opercules, ainsi que nous le verrons plus loin, on n'a pas intérêt à augmenter la hauteur des piles au-dessus de la zone de préhension optimum soit $\mathrm{x}, 20 \mathrm{~m}$ et c'est la raison pour laquelle les piles ne comportent que 7 hausses.

\section{a) Manutention des hausses.}

Cette opération pour être réalisée dans le minimum de temps exige deux personnes : l'une dans le véhicule et l'autre au sol entre le véhicule et la palette.

Les temps de manutention des hausses sont relativement constants car c'est une opération exécutée d'une manière pratiquement identique d'un chantier à un autre.

Pour manipuler $x 6 x$ hausses, le temps total chronométré est de $2739 \mathrm{cmn}$ représentant une moyenne de :

I7 cmn par hausse $\left({ }^{2}\right)$ avec un écart absolu compris entre 15,9 et $19,5 \mathrm{cmn}$.

(1) Cette zone correspond à la hauteur à laquelle il est possible de saisir manuellement un objet sans geste ni effort anormaux.

( $\left.{ }^{2}\right)$ Toutes les mesures de temps ont été effectuées en prenant la minute (mn) comme unité et le centiminute $(\mathrm{cmn})$ comme sous-multiple de cette unité. 
b) Mancuvre des palettes.

Les cinq mesures qui ont été faites sont assez homogènes, elles donnent un temps total de $592 \mathrm{cmn}$ soit une moyenne de II $8 \mathrm{cmn}$ avec des écarts compris entre IIo et $125 \mathrm{cmn}$.

Ce temps est variable d'un poste à un autre car il dépend des distances à parcourir et de la plus ou moins grande facilité de circulation dans les locaux.

c) Gerbage des palettes.

Le temps de manœuvre du transrouleur-élévateur pour gerber une palette est compris entre $3 \mathrm{mn}$ et $3,50 \mathrm{mn}$ suivant qu'on gerbe à $\mathbf{I}, 25 \mathrm{~m}$ ou à $2,50 \mathrm{~m}$.

d) Temps global de déchargement.

Pour décharger un véhicule de type camionnette transportant 84 hausses soit une charge nette de $\mathrm{x} 800$ à $3000 \mathrm{~kg}$, le temps de travail de deux ouvriers est de $25 \mathrm{mn}$.

Le diagramme de la figure 2 représente la répartition des différentes opérations entre les deux exécutants. L'un des ouvriers est affecté à la manœuvre d'approche des palettes vides, l'autre aux manœuvres de retrait et de gerbage des palettes pleines. Les deux hommes travaillent ensemble à l'opération de déchargement des hausses.

On remarque sur le graphique que l'ouvrier $\mathrm{A}$ affecté aux palettes pleines, travaille sans interruption pendant $24,22 \mathrm{mn}$, alors que l'ouvrier $B$ est occupé pendant $20,82 \mathrm{mn}$ pour un temps de travail effectif de I7,82 $\mathrm{mn}$ et un arrêt d'attente de $3 \mathrm{mn}$.

Ce temps théorique de $25 \mathrm{mn}$ a été confirmé par des chronométrages portant sur des déchargements de véhicules qui transportaient 90 à 98 hausses pleines et pour lesquels on a enregistré des temps variant de 25 à $30 \mathrm{mn}$, ce qui représente un faible écart par rapport à la moyenne calculée et si l'on tient compte de l'irrégularité des opérations effectuées au cours d'un tel travail.

\section{Surface de déchargement}

Il est nécessaire pour éviter le pillage, que le déchargement des hausses venant du. rucher, soit effectué dans un endroit parfaitement clos interdisant l'accès des abeilles.

Les véhicules généralement utilisés pour le transport des hausses sont des fourgonnettes ou des camionnettes dont les dimensions varient de :

$$
\begin{aligned}
& 3,60 \mathrm{~m} \text { à } 4 \mathrm{~m} \text { de longueur, } \\
& \mathrm{I}, 80 \mathrm{~m} \text { à } 2 \mathrm{~m} \text { de largeur, } \\
& \mathrm{I}, 50 \mathrm{~m} \text { à } 2 \mathrm{~m} \text { de hauteur. }
\end{aligned}
$$

Il est donc nécessaire de disposer pour la zone de déchargement d'une surface brute maximum de $8 \mathrm{~m}^{2}$ soit $4 \mathrm{~m}$ de long et $2 \mathrm{~m}$ de large et pour tenir compte des surfaces nécessaires à l'évolution du personnel et du matériel de manutention, il faut prévoir une surface nette maximum de $18 \mathrm{~m}^{2}$ soit $6 \mathrm{~m}$ de long et $3 \mathrm{~m}$ de large. 

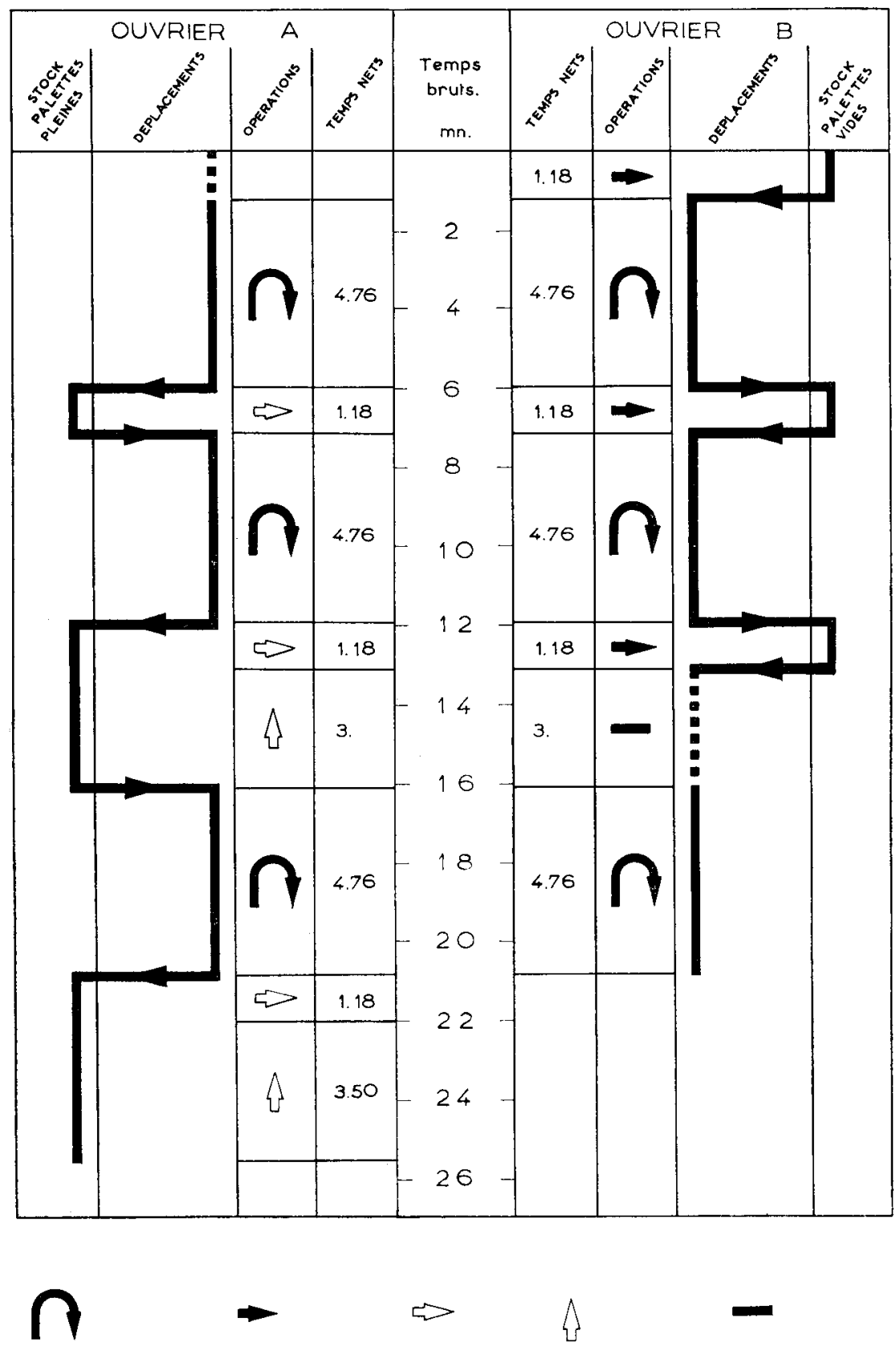

Décharger
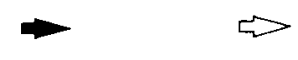

Transporter en charge

Déplacement

à vide

Gerber les palettes

Déplacements

Fig. 2. - Diagramme de temps de déchargement de 84 hausses stockées sur trois palettes gerbées 


\section{Surface de stockage des hausses}

Dans l'évaluation des besoins en surface de stockage des hausses, il faut tenir compte de la surface brute représentée par l'encombrement des palettes au sol et de la surface de circulation permettant le transport des palettes et l'évolution des moyens de manutention. I a surface nette est constituée par le total de la surface brute et de la surface de circulation.

a) Calcul de la surface brute

$I_{1}$ es dimensions permettant de calculer la surface brute dépendent :

du nombre de palettes à stocker,

de la dimension des palettes (petites ou grandes),

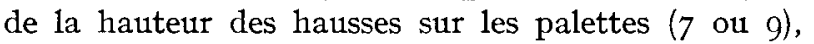

de la hauteur de gerbage (un, deux, ou trois niveaux).

ro Cas des petites palettes.

Les petites palettes de $0,85 \times 0,65 \mathrm{~m}$ manipulées au transtouleur et non gerbées sont chargées de deux piles de 9 hausses soit $\mathrm{r} 8$ hausses par palette avec une hauteur d'encombrement de $1,73 \mathrm{~m}$.

Le tableau 2 indique les capacités de stockage en fonction de la longueur de celui-ci allant de 0,90 à $4,5 \mathrm{~m}$ (on pourrait prolonger au-delà de cette mesure) et du nombre de rangs de palettes en largeur (ici on a adopté $I, 2$ et 3 rangs).

TABLEAU 2

Dimensions et capacité de stockage des petites palettes

\begin{tabular}{|c|c|c|c|}
\hline \multicolumn{3}{|c|}{ Dimensions du stockage } & \multirow{2}{*}{$\begin{array}{l}\text { Nombre } \\
\text { de } \\
\text { hausses }\end{array}$} \\
\hline $\begin{array}{l}\text { Largeur } \\
(\mathrm{cm})\end{array}$ & $\begin{array}{l}\text { Longueur } \\
\text { (cm) }\end{array}$ & $\begin{array}{c}\text { Surface } \\
\left(\mathrm{m}^{2}\right)\end{array}$ & \\
\hline $\begin{array}{l}1 \text { rang } \\
90\end{array}$ & $\begin{array}{r}70 \\
140 \\
210 \\
280 \\
350\end{array}$ & $\begin{array}{l}0,63 \\
1,26 \\
1,89 \\
2,52 \\
3,15\end{array}$ & $\begin{array}{l}18 \\
36 \\
54 \\
72 \\
90\end{array}$ \\
\hline $\begin{array}{c}2 \text { rangs } \\
180\end{array}$ & $\begin{array}{r}70 \\
140 \\
210 \\
280 \\
350\end{array}$ & $\begin{array}{l}1,26 \\
2,52 \\
3,78 \\
5,04 \\
6,30\end{array}$ & $\begin{array}{r}36 \\
72 \\
108 \\
144 \\
180\end{array}$ \\
\hline $\begin{array}{c}3 \text { rangs } \\
270\end{array}$ & $\begin{array}{r}70 \\
140 \\
210 \\
280 \\
350\end{array}$ & $\begin{array}{l}1,89 \\
3,78 \\
5,67 \\
7,56 \\
9,45\end{array}$ & $\begin{array}{r}54 \\
108 \\
162 \\
216 \\
270\end{array}$ \\
\hline
\end{tabular}


Par exemple si l'on doit stocker 360 hausses, soit $\frac{360}{18}=20$ palettes, il est nécessaire de disposer de $6,30 \times 2=\mathrm{I} 2,60 \mathrm{~m}^{2}$ représentant une longueur de stockage de $4,50 \mathrm{~m}$ (soit 5 palettes) et une largeur de $\mathrm{I}, 40 \times 2=2,80 \mathrm{~m}$ ce qui représente 4 rangées de palettes. On doit majorer cette surface de celle de l'aire de circulation.

\section{$2^{\circ}$ Cas des grandes palettes.}

Les grandes palettes de $102 \times$ I02 $\mathrm{cm}$ manipulées au transrouleur-élévateur, peuvent être gerbées et sont chargées de 4 piles de 7 hausses pleines ou de 4 piles de 9 hausses vides soit une capacité unitaire de 28 hausses pleines ou 36 hausses vides.

Le tableau 3 indique les dimensions et les capacités de stockage pour les palettes chargées de 28 et de 36 hausses.

\section{TABLEAU 3}

Dimensions el capacité de stockage des grandes palettes

\begin{tabular}{|c|c|c|c|c|c|c|c|c|}
\hline \multicolumn{3}{|c|}{ Dimensions du stockage } & \multicolumn{3}{|c|}{ Nombre de hausses pleines } & \multicolumn{3}{|c|}{ Nombre de hausses vides } \\
\hline \multirow{2}{*}{$\begin{array}{l}\text { Largeur } \\
(\mathrm{m})\end{array}$} & \multirow{2}{*}{$\begin{array}{l}\text { Longueur } \\
\text { (m) }\end{array}$} & \multirow{2}{*}{$\begin{array}{c}\text { Surface } \\
\left(\mathrm{m}^{2}\right)\end{array}$} & \multirow{2}{*}{$\begin{array}{c}\text { non } \\
\text { gerbées }\end{array}$} & \multicolumn{2}{|c|}{ gerbúes } & \multirow{2}{*}{$\begin{array}{c}\text { non } \\
\text { gerbées }\end{array}$} & \multicolumn{2}{|c|}{ gerbées } \\
\hline & & & & 2 haut. & 3 haut. & & 2 haut. & 3 haut. \\
\hline \multirow{5}{*}{$\begin{array}{c}1 \mathrm{rang} \\
1,10\end{array}$} & 1,10 & 1,21 & 28 & 56 & $8 \prime$ & 36 & 72 & 108 \\
\hline & 2,20 & 2,42 & 56 & 112 & 168 & 72 & 194 & 216 \\
\hline & 3,30 & 3,63 & $8^{\prime}$ & 168 & 252 & 108 & 216 & $32 x^{\prime}$ \\
\hline & 4,40 & $4,8_{t}^{\prime}$ & 11: & $2 \cdot 24$ & 336 & lát & 288 & 432 \\
\hline & 5,50 & 6,05 & $11^{\prime} 0$ & 280 & 420 & 180 & 360 & 5.10 \\
\hline \multirow{5}{*}{$\begin{array}{c}2 \text { rangs } \\
2,20\end{array}$} & 1,10 & $2,4 \div 2$ & 56 & 112 & 168 & $7:$ & 144 & 216 \\
\hline & 2,20 & 4,84 & 112 & 224 & $3: 36$ & 1't' & 288 & 432 \\
\hline & 3,30 & 7,26 & 168 & 336 & 504 & 216 & 432 & 648 \\
\hline & 4,40 & 9,68 & $22^{\prime}$ & 448 & 672 & 288 & 576 & 864 \\
\hline & 5,50 & 12,10 & 280 & 560 & 840 & 360 & $7: 20$ & 1080 \\
\hline \multirow{5}{*}{$\begin{array}{c}3 \text { rangs } \\
3,30\end{array}$} & 1,10 & 3,63 & 84 & 168 & 252 & 108 & 216 & 324 \\
\hline & 2,20 & 7,26 & 168 & 336 & $50^{\prime}$ & 216 & 432 & 648 \\
\hline & 3,30 & 10,89 & 252 & $50^{\prime}$ & 756 & $32 \%$ & 648 & 972 \\
\hline & 4,40 & 14,52 & 336 & 672 & 1008 & 432 & $866^{\prime}$ & 1296 \\
\hline & 5,50 & 18,15 & 420 & 840 & 1260 & 540 & 1080 & 1620 \\
\hline
\end{tabular}

Par exemple si l'on doit stocker I ooo hausses pleines sur des grandes palettes il faut disposer d'une surface de $14,52 \mathrm{~m}^{2}$ soit une longueur de stockage de $4,40 \mathrm{~m}$ et une largeur de $3,30 \mathrm{~m}$. En gerbant les palettes sur trois niveaux, cela représente une hauteur de gerbage de $\mathrm{I}, 34 \times 3=4,02 \mathrm{~m}$.

Lorsque les I ooo hausses sont vides, elles occupent une surface de $\mathrm{I} 2, \mathrm{IO} \mathrm{m}^{2}$ soit une longueur de $5,50 \mathrm{~m}$ et une largeur de $2,20 \mathrm{~m}$, mais il faut disposer d'une hauteur supérieure à $\mathrm{I}, 68 \times 3=5,04 \mathrm{~m}$ pour permettre le gerbage sur trois niveaux. 
b) Surfaces de circulation.

Les surfaces de circulation dépendent de la dimension des palettes, du moyen mécanique de manutention et des manœuvres à faire exécuter à celui-ci.

Lorsqu'on utilise des petites palettes de $0,985 \times 0,65 \mathrm{~m}$, qui sont déplacées à l'aide d'un transrouleur dans le sens de leur longueur, il est nécessaire de prévoir des allées de circulation d'une largeur de :

- $\mathrm{r}, 50 \mathrm{~m}$ pour le simple passage ;

- 2,50 m lorsqu'il faut effectuer des manœuvres latérales (virage et alignement de la palette transportée sur une ligne de stockage).

Avec les palettes de grandes dimensions $(\mathrm{I}, 02 \times \mathrm{I}, 02 \mathrm{~m})$, manutentionnées et gerbées avec un transtouleur-élévateur, il est alors nécessaire de prévoir des largeurs d'allées de circulation de :

- $2 \mathrm{~m}$ lorsqu'il s'agit d'un simple passage sans manceuvre;

- $3 \mathrm{~m}$ si l'on doit effectuer des manœuvres de virage d'alignement et de gerbage des palettes.

\section{Exemples de calcul de stockage.}

Une entreprise doit stocker 560 hausses sur petites palettes, quelles sont les dimensions à donner au local de stockage?

Le nombre de 560 hausses ne figure pas sur le tableau 3. La moitié de ce nombre, 280 est trop forte pour le chiffre le plus proche indiqué sur le tableau (270), par contre le quart soit $x_{40}$ correspond au chiffre de I $_{44}$ figurant au tableau.

Pour stocker I 44 hausses, il faut une surface brute de $5,04 \mathrm{~m}^{2}$ et pour 576 hausses i1 est nécessaire de disposer de 4 fois plus de place soit $20,16 \mathrm{~m}^{2}$, surface limitée par des côtés de $3,60 \mathrm{~m}$ de large $(\mathrm{r}, 80 \times 2)$ et $5,60 \mathrm{~m}$ de long $(2,80 \times 2)$.

La zone de circulation doit permettre d'effectuer les manœuvres du transrouleur et on adopte à cet effet une largeur de $2,50 \mathrm{~m}$ et la longueur de l'allée sera de $5,60 \mathrm{~m}$ soit une surface de circulation de $\mathrm{I} 4 \mathrm{~m}^{2}$.

La surface nette de stockage est égale à $20, \mathrm{I} 6+\mathrm{I} 4=34, \mathrm{I} 6 \mathrm{~m}^{2}$. Avec une dimension de $5,60 \mathrm{~m}$, le local doit avoir une longueur de $\frac{34, \mathrm{I} 6}{5,60}=6$, Io.

Il faut donc disposer d'un emplacement de $5,60 \times 6$, Io $\mathrm{m}$ de côtés avec allée centrale de $2,50 \mathrm{~m}$ de large et disposer les palettes sur deux rangées de part et d'autre de 1'allée.

Deuxième exemple :

Dans une entreprise, on doit stocker I ooo hausses sur grandes palettes qui peuvent être gerbées sur trois niveaux, quelle surface de stockage doit-on prévoir pour stocker les hausses vides?

Il est admis qu'au cours du travail d'extraction du miel, les hausses pleines ne sont jamais stockées en totalité, on ne tient compte que du stockage des hausses vides.

L'examen du tableau 3 montre que dans le cas des hausses vides et du gerbage sur trois hauteurs, le nombre de hausses supérieur et le plus rapproché de I ooo est celui de I 296, correspondant à un stockage sur 3 rangs $(3,30 \mathrm{~m})$ et une longueur de $4,40 \mathrm{~m}$ soit $\mathrm{I} 4,5^{2} \mathrm{~m}^{2}$, qui sont les dimensions de la surface brute.

L'allée de circulation doit permettre l'évolution et les manœuvres d'un trans- 
rouleur-élévateur, il faut donc lui donner une largeur de $3,00 \mathrm{~m}$ avec la même longueur que celle de la surface brute soit $4,40 \mathrm{~m}$. La surface de circulation est de $13,20 \mathrm{~m}^{2}$ et la surface nette est de $14,52+\mathrm{I} 3,20=27,72 \mathrm{~m}^{2}$.

Pour une dimension de $4,40 \mathrm{~m}$, l'autre côté doit mesurer $\frac{27,72}{4,40}=6,30 \mathrm{~m}$.

On peut dans ce cas envisager le stockage des palettes à raison d'une rangée d'un côté de l'allée de circulation et de deux rangées de l'autre côté.

\section{II. - ENI,L̀VEMENT DES OPERCULES}

Le travail d'extraction du miel comprend deux phases principales : l'enlèvement des opercules qui obturent les cellules des cadres et la centrifugation qui a pour but d'expulser le miel des cellules.

\section{A. Définition du travail}

Les hausses garnies de cadres provenant du rucher sont approchées du poste où se déroule le travail. L'opérateur saisit les cadres un à un et procède à l'enlèvement des opercules sur les deux faces à l'aide d'un couteau ou d'une machine. Les opercules tombent dans un bac et les cadres terminés sont placés dans une hausse vide lorsqu'on utilise un extracteur à axe horizontal, ou sur un tourniquet d'attente si l'on utilise un extracteur à axe vertical.

L'opérateur se tient en position debout, en raison des mouvements de préhension et de dépôt des cadres à effectuer et de l'effort à appliquer sur le couteau à désoperculer.

Le déroulement du travail peut indifféremment se dérouler de droite à gauche, c'est-à-dire saisir les cadres à désoperculer à droite et pour les cadres terminés à gauche ou inversement, quel que soit le matériel utilisé.

\section{B. Matériel utilisé}

a) Outils.

L'outillage utilisé au cours des études de chantiers comprend : le couteau ordinaire, le couteau électrique, la machine.

Le couteau ordinaire (fig. 3) est une lame d'acier de $30 \mathrm{~cm}$ de long et $4 \mathrm{~cm}$ de large munie d'un manche, il doit être parfaitement aiguisé sur ses deux bords et pour faciliter le glissement de la lame sur le miel, il est nécessaire de la tremper dans de l'eau chaude à environ $50^{\circ}$. Certains opérateurs utilisent deux couteaux qu'ils placent alternativement dans un seau d'eau chaude.

Le couteau électrique (fig. 4) dont l'emploi a fait l'objet des observations est de fabrication américaine. Il comporte une lame de mâmes dimensions que celles du couteau ordinaire mais à l'intérieur de laquelle est logée une résistance électrique chauffante. La température de la lame est limitée par un thermostat qui est lui-même réglé à l'aide d'une petite vis disposée au milieu d'un des côtés de la lame. Le courant électrique est amené par un fil qui pénètre dans le couteau à l'extrémité libre de 
la poignée. La température de la lame facilite son glissement en réalisant la fonte partielle de la cire et en empêchant le miel d'adhérer à la lame.

I a machine à désoperculer observée est essentiellement formée d'une boîte métallique de $53 \mathrm{~cm}$ de long, $30 \mathrm{~cm}$ de large et $24 \mathrm{~cm}$ de haut sur un côté de laquelle est installée une lame métallique de $40 \mathrm{~cm}$ de longueur et $\mathrm{I} 5 \mathrm{~mm}$ de largeur (fig. 5). Cette lame est animée d'un mouvement vibratoire de très faible amplitude et elle est chauffée par une résistance électrique réglable.

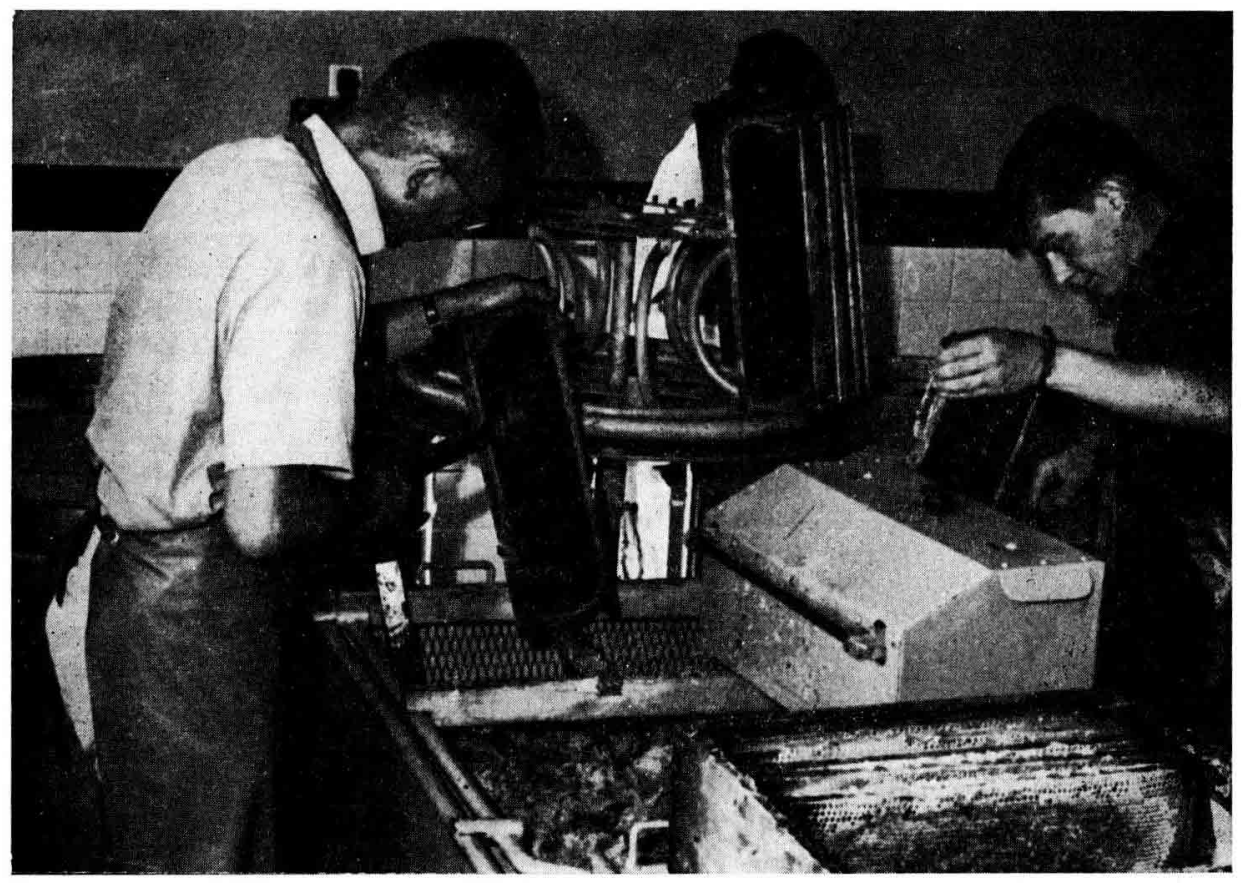

FIG. 3. - Couleau ordinaire de désoperculer

La machine à clésoperculer étudiée présente trois inconvénients :

- la lame enlève les opercules sur la face du cadre opposée à l'opérateur et celui-ci ne voit pas le travail :

- la température de la lame est difficile à maintenir constante car le réglage est manuel et comme il est nécessaire d'interrompre souvent le travail, la lame a tendance à trop chauffer et à provoquer la caramélisation du miel.

- I orsque les cadres ne sont pas parfaitement garnis et si les opercules ne font pas nettement saillie par rapport au plan du cadre, l'enlèvement des opercules n'est pas possible et il faut finir à l'aide d'un couteau ce qui entraine un ralentissement important de la vitesse du travail et l'échauffement de la lame.

b) Bac à désoperculer.

Le bac à désoperculer est un récipient métallique destiné à recevoir les opercules détachés des cadres. Il doit être muni d'un dispositif permettant de maintenir le cadre pendant le travail d'enlèvement. 
Deux modèles de bacs ont été observés :

I $\mathrm{Le}$ bac à cuve.

Cet appareil est une cuve parallélipipédique de $\mathrm{I}, \mathrm{I} 5 \mathrm{~m}$ de long, I $\mathrm{m}$ de large et $0,80 \mathrm{~m}$ de profondeur (fig. 6). Il est construit en métal, de préférence en acier inoxydable, les angles sont arrondis pour faciliter le nettoyage.

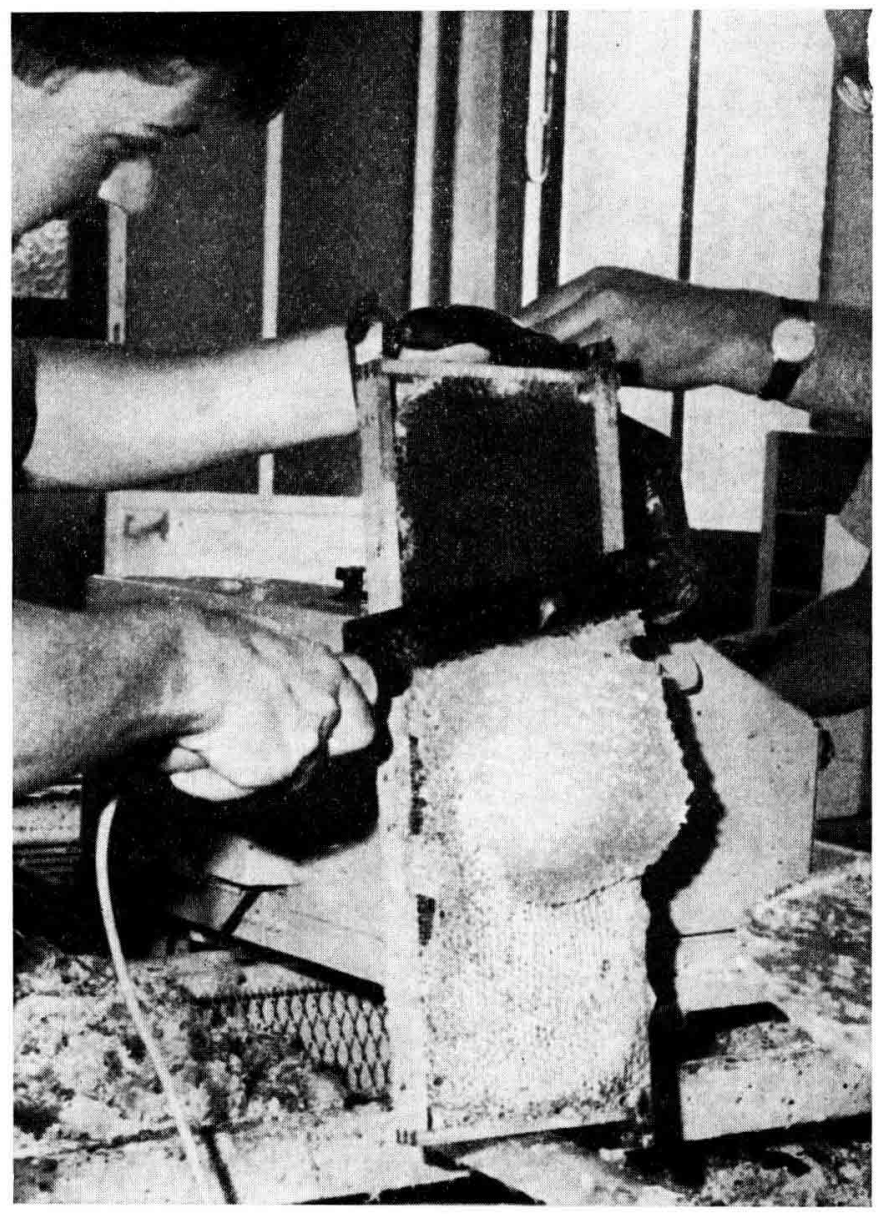

Fig. 4. - Couleau électrique à désoperculer

Les opercules tombent en vrac dans la cuve. Un orifice inférieur permet l'écoulement du miel et de l'eau de lavage. Les opercules chargés de miel sont soumis à un égouttage ou une pression à l'aide d'un petit pressoir.

La cuve est montée sur quatre roulettes orientables pour faciliter son déplacement.

Le fond est à $20 \mathrm{~cm}$ du sol ce qui porte le bord supérieur à $\mathrm{I} \mathrm{m}$. Pour permettre une attitude confortable de l'ouvrier qui désopercule, on dispose sous ses pieds un caillebotis recouvert d'une grille métallique et de $20 \mathrm{~cm}$ de hauteur. 
$2^{\circ}$ Table à désoperculcr.

Cette table est constituée par un bâti en cornières d'acier de $\mathrm{r}, 80 \mathrm{~m}$ de long, $0,80 \mathrm{~m}$ de large et $0,78 \mathrm{~m}$ de hauteur (fig. 7). Fille permet à deux opérateurs de travailler côte à côte ou face à face

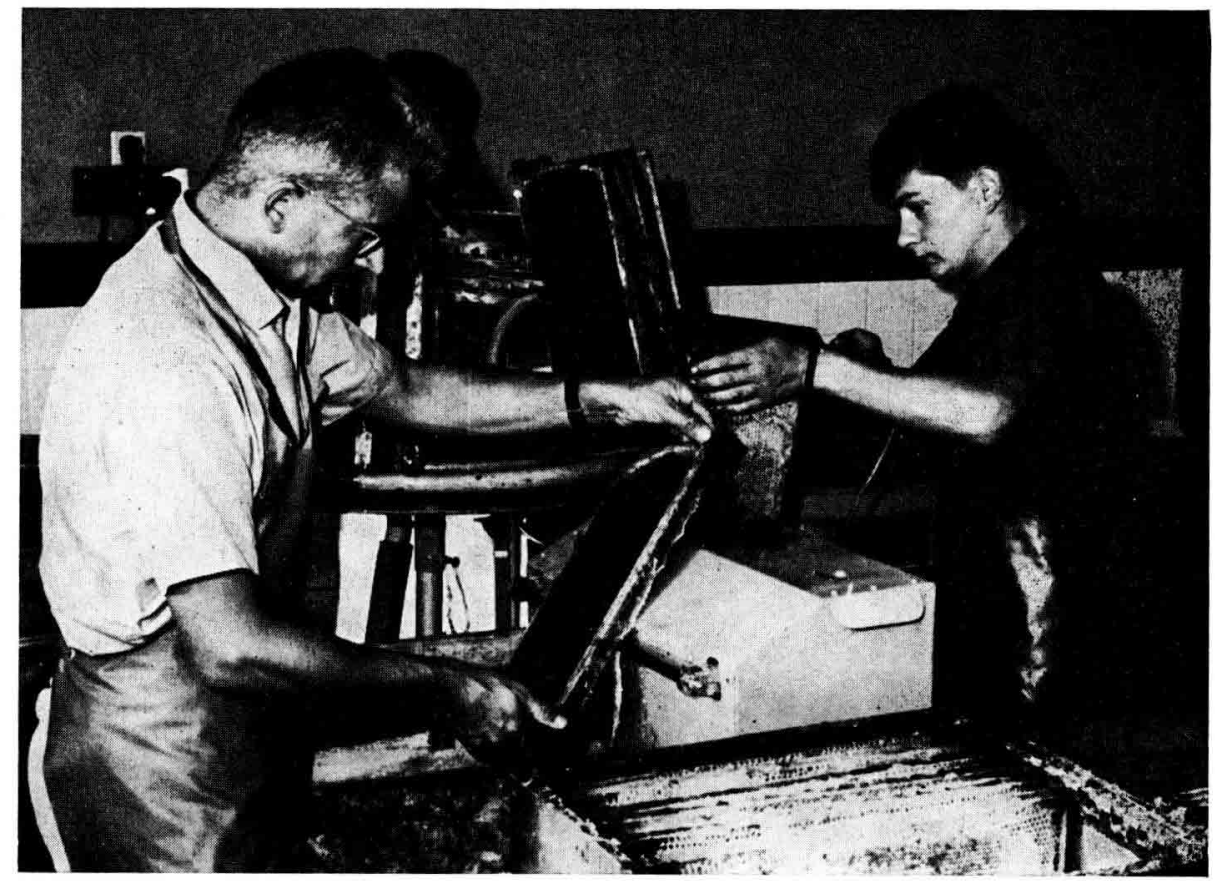

Fig. 5. - Machine à désopercaler
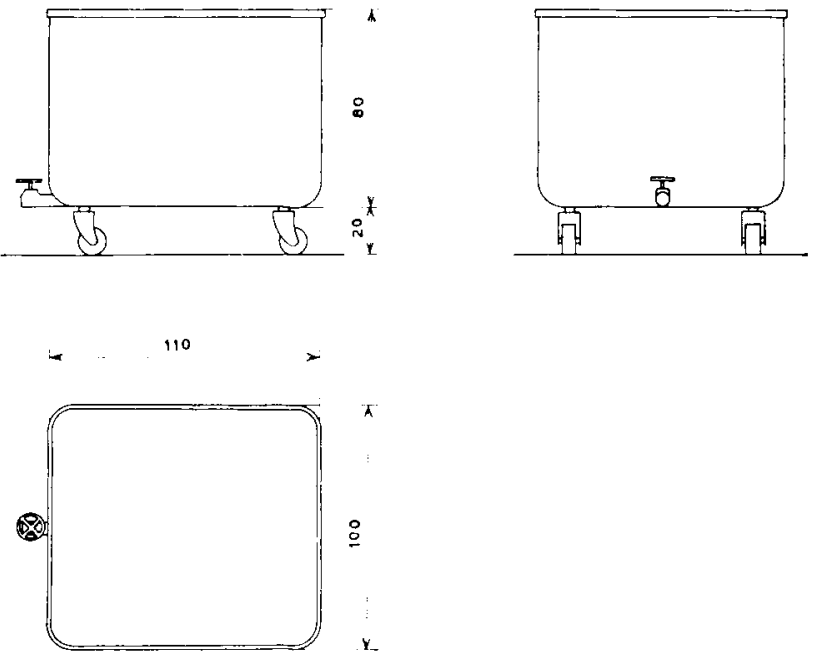

Hig. 6. - Bac à désoperculer 
Des caisses de mêmes dimensions que les hausses et dont le fond est en tôle perforée, reçoivent les opercules et sont posées sur des barreaux métalliques. Ces barreaux sont disposés au-dessus d'un bac d'acier inoxydable aménagé à la partie inférieure du bâti et à $30 \mathrm{~cm}$ au-dessus du sol. Les opercules s'égouttent et le miel tombe dans le bac, puis, grâce à une goulotte, dans la cuve de réception de l'extracteur. Cet égouttage ne serait pas suffisant, aussi les caisses perforées sont passées à l'extracteur à axe horizontal de la mème manière que les hausses.
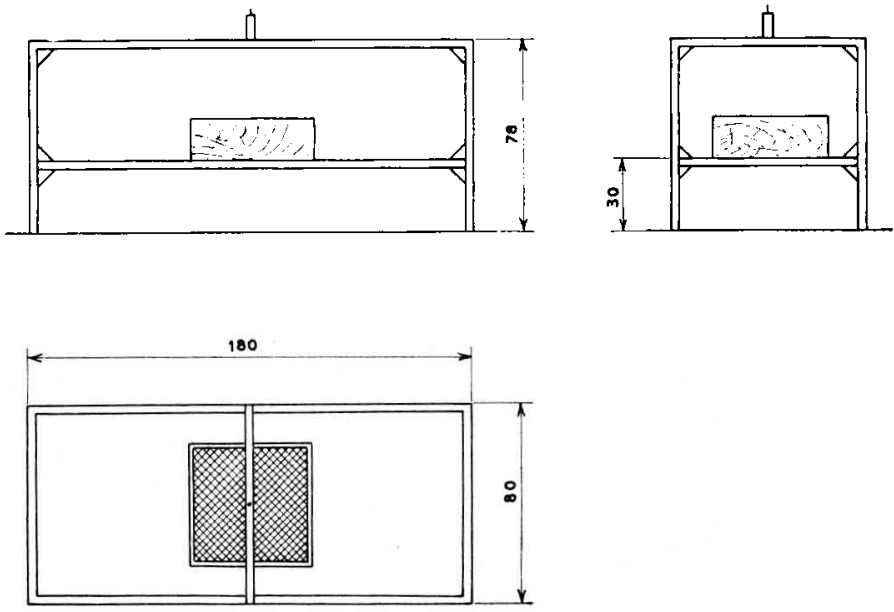

Fig. 7. - Table d désoperculer

\section{Support des cadres}

Pour réaliser facilement l'enlèvement des opercules à l'aide des couteaux ordinaire et électrique, il est nécessaire que les cadres soient solidement maintenus de la main gauche par l'opérateur et qu'ils ne risquent pas de glisser sous l'effort de pression de la lame du couteau. En face de l'opérateur, une barre transversale réglable en hauteur est posée sur les bords du bac ou de la table à désoperculer. Elle présente en son centre une pointe de $3 \mathrm{~cm}$ sur laquelle on immobilise le petit côté inférieur des cadres pendant l'opération d'enlèvement des opercules. On peut ainsi leur donne r l'inclinaison nécessaire à l'écoulement facile de la nappe d'opercules enlevée et de retourner rapidement les cadres par simple pivotement sur la pointe. L'emploi de ce dispositif allège l'effort musculaire de l'opérateur qui est appelé à effectuer plusieurs milliers de gestes au cours d'une journée de travail.

\section{c) Tourniquet d'attente.}

Lorsqu'on utilise l'extracteur à axe horizontal, les cadres désoperculés sont placés dans des hausses vides en attendant leur centrifugation. Dans l'emploi de l'extracteur à axe vertical, ils sont placés un à un dans la machine.

Pour équilibrer le travail entre le poste d'enlèvement des opercules et le poste de centrifugation, les cadres sont disposés verticalement sur un tourniquet d'attente. Cet appareil est constitué par un bâti circulaire en tubes métalliques tournant autour d'un axe vertical (fig. 8). Des logements ménagés à la périphérie du bâti maintiennent 
les cadres en position verticale et légèrement inclinés vers l'axe. Un réceptacle métallique, placé à la partie inférieure de l'appareil, reçoit le miel s'égouttant des cadres.

Le tourniquet a un diamètre de $86 \mathrm{~cm}$ à la base; $46 \mathrm{~cm}$ à la partie supérieure. La hauteur des supports est de $30 \mathrm{~cm}$. Il peut recevoir 42 cadres, nombre supérieur à la capacité de l'extracteur à axe vertical qui est de 35 cadres.

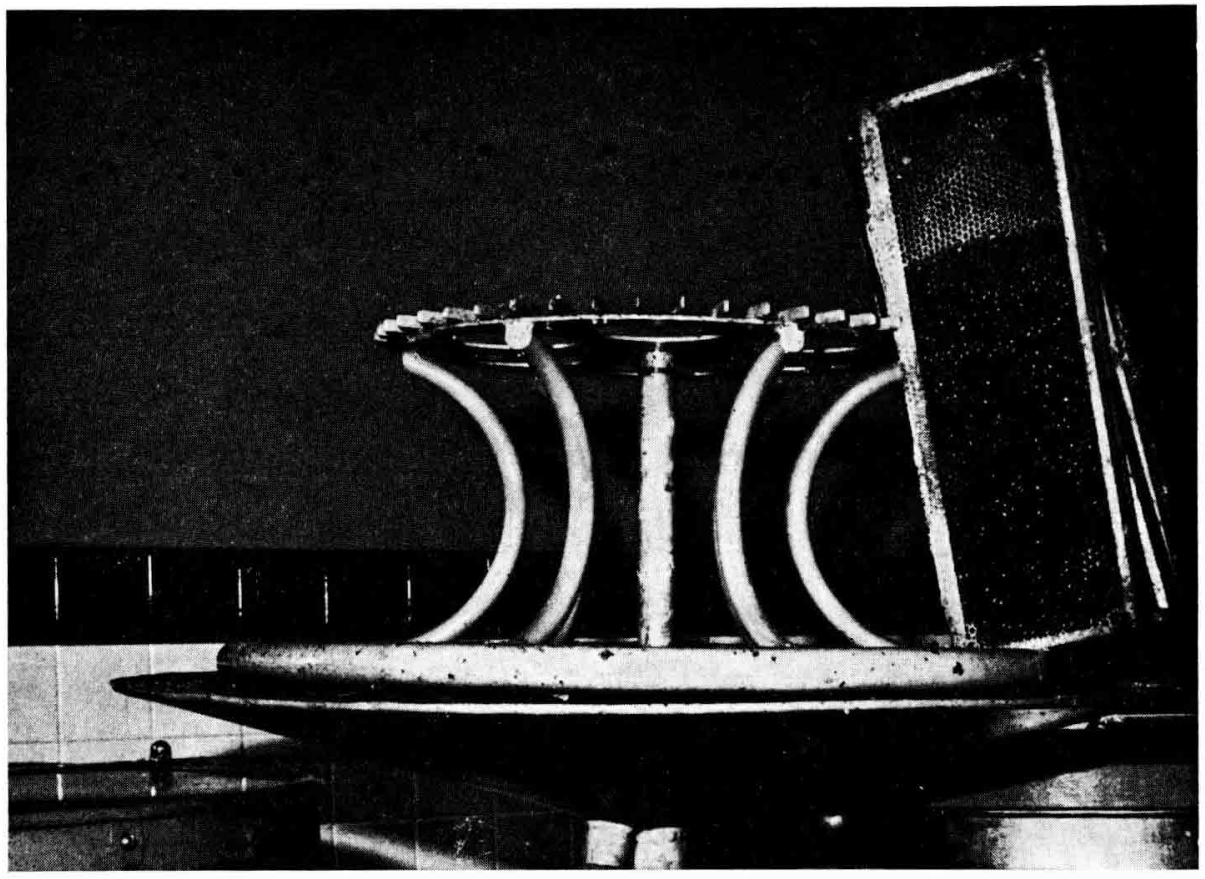

FIG. 8. - Tourniquet d'attente

\section{Déroulement du travail}

Plusieurs cas doivent être envisagés dans l'analyse du déroulement du travail d'enlèvement des opercules, soit que les hausses sont placées sur des petits chariots ou sur un transrouleur-élévateur et soit que l'opération suivante, centrifugation, est exécutée à l'aide d'un appareil à axe vertical ou à axe horizontal.

\section{Premier cas.}

La centrifugation est réalisée avec la machine à axe horizontal et les hausses sont manutentionnées à l'aide de chariots ayant une capacité de 4 hausses.

L'opérateur est debout devant le bac à désoperculer. A sa droite est placé un chariot chargé de 4 hausses et contenant chacune ro cadres à désoperculer. A sa gauche est placé un autre chariot supportant une hausse vide.

En se tournant d'un quart de tour à droite, l'ouvrier saisit un cadre à désoperculer, il pivote d'un quart de tour à gauche et pose un des petits côtés du cadre sur la pointe de la barre transversale du bac. Il passe le couteau de haut en bas (ou inversement suivant les opérateurs) pour détacher les opercules qui tombent 
dans le bac. Il fait pivoter le cadre sur la pointe et désopercule la $2^{\mathrm{e}}$ face $\mathrm{d} t 1$ cadre. Il pose le couteau sur le bord de la cuve, saisit le cadre des deux mains, se tourne d'un quart de tour à gauche et place le cadre désoperculé dans la hausse à remplir. Il fait un demi-tour, saisit un $2^{\mathrm{e}}$ cadre à désoperculer, reprend le couteaut et recommence le cycle comme précédemment.

Lorsqu'une hausse de droite est vide, il la place au-dessus de la hausse de gauche qui est alors entièrement garnie de cadres désoperculés. Cette opération est effectuée tous les ro cadres. Lorsque le chariot de droite est vide et que les 4 hausses sont passées sur le chariot de gauche, celui-ci est enlevé et mis en attente d'extraction, le chariot de droite prend sa place et un chariot chargé de 4 hausses à désoperculer est disposé à droite du poste de travail. L,es changements de chariots doivent se faire toutes les 4 hausses c'est-à-dire tous les 40 cadres.

Lorsqu'on utilise une machine à désoperculer, les opérations de manipulation des cadres sont identiques, mais pour désoperculer, l'ouvrier tenant le cadre verticalement à deux mains, fait glisser la face du cadre qu'il ne voit pas sur la lame de l'appareil. Il retourne le cadre et désopercule la $2^{\mathrm{e}}$ face. Lorsqu'une partie de la surface du cadre n'a pas été désoperculée par la machine, l'ouvrier doit compléter le travail à l'aide d'un couteau.

\section{Deuxième cas.}

L'extraction se fait avec le même matériel que précédemment mais les hausses contenant les cadres à désoperculer sont disposées à droite du poste sur une palette placée sur le chariot élévateur.

Le nombre des hausses mises à la disposition de l'ouvrier est de 28 , soit 280 cadres et la manœuvre de réapprovisionnement en cadres à désoperculer est 7 fois moins fréquente qu'avec les petits chariots. Au cours du travail, à mesure que le nombre des hausses à désoperculer diminue, on remonte la palette de manière à disposer les hausses supérieures à la hauteur de préhension optimum de l'ouvrier.

Les opérations d'enlèvement des opercules sont réalisées dans les mêmes conditions que celles décrites dans le premier cas. Les cadres désoperculés sont comme précédemment disposés dans des hausses placées sur un petit chariot, nombre correspondant à la capacité de l'extracteur.

\section{Troisième cas.}

L'extraction est maintenant réalisée à l'aide d'un extracteur à axe vertical dans lequel les cadres désoperculés sont disposés un à un sans être préalablement remis dans les hausses.

Les hausses petuvent être approchées du poste d'enlèvement des opercules soit à l'aide de chariots à 4 hausses, soit à l'aide de l'élévateur ( 28 hausses). Ces hausses remplies de cadres à désoperculer sont placées indifféremment à droite ou à gauche de l'opérateur. Les opérations élémentaires de saisie des cadres et d'enlèvement des opercules sont identiques à celles précédemment décrites. Lorsque la $2^{\mathrm{e}}$ face d'un cadre est désoperculée, l'ouvrier pivote à droite et pose le cadre sur le tourniquet d'attente disposé entre le poste d'enlèvement des opercules et le poste d'extraction. 


\section{Etude des temps}

Des chronométrages ont été réalisés dans l'emploi des trois outils le plus fréquemment utilisés pour l'enlèvement des opercules : couteau ordinaire, couteau électrique et machine à désoperculer.

\section{a) Emploi du couteau ordinaire.}

Une séquence de travail avec le couteau ordinaire comporte les gestes élémentaires suivants :

- saisir un cadre à désoperculer et le placer sur la barre à pointe,

- désoperculer la Ire face du cadre,

- faire pivoter le cadre et désoperculer la $2^{\mathrm{c}}$ face,

- poser le cadre désoperculé dans une hausse vide ou sur le tourniquet.

Les temps du premier et du dernier gestes, saisir et poser, ont été groupés, ayant été obtenus par différence entre le temps total et les temps des autres opérations. Sur 80 mesures, on a obtenu un temps total de $869 \mathrm{cmn}$, le temps moyen est de Io,86 $\mathrm{cmn}$. On observe une assez grande régularité dans l'exécution de ces gestes, l'écart absolu est de $4 \mathrm{cmn}$ (maximum I3, minimum 9) et l'écart-type portant sur l'ensemble des mesures est de $\mathrm{I}, 32$.

I,e geste de désoperculer une face a porté sur 34 mesures avec un temps total de $508 \mathrm{cmn}$, et une moyenne de $2 \mathrm{I}, \mathrm{I} 6 \mathrm{cmn}$. Ce geste est beaucoup plus irrégulier que les précédents car il dépend de la manière dont se présente la surface des cadres qui sont plus ou moins chargés de miel. L'écart absolu est pour ce geste de I7 cmn (maximum 3I, minimum I4) et l'écart-type s'élève à 4,47.

Dans le calcul des temps nets pour les trois méthodes de travail, nous avons accordé une marge de $20 \mathrm{p}$. roo du temps brut à titre de temps de repos, ce qui est normal pour une opération qui est réalisée en position debout et exige un effort musculaire prolongé des bras et des mains.

La récapitulation des temps donne pour ce travail les résultats suivants $(\mathrm{cmn})$ :

\begin{tabular}{|c|c|}
\hline Prendre et poser le cadre. & Io,86 \\
\hline Désoperculer la Ire face & $2 I, I 6$ \\
\hline Désoperculer la $2^{\mathrm{e}}$ face & $2 I, I$ \\
\hline Temps brut .. & 53 \\
\hline emps brut & Io \\
\hline$-7+5+2+5$ & \\
\hline
\end{tabular}

Suivant qu'on utilise pour la centrifugation un appareil à axe vertical ou à axe horizontal, on doit désoperculer dans le $\mathrm{I}^{\mathrm{er}}$ cas 36 cadres ce qui nécessite un temps d'enlèvement des opercules de $2297 \mathrm{cmn}$, temps arrondi à $23 \mathrm{mn}$ et dans le $2^{\mathrm{e}}$ cas un temps de $2552 \mathrm{cmn}$, temps arrondi à $26 \mathrm{mn}$.

b) Emploi du couteau électrique.

I a séquence de travail avec le couteau électrique est exactement la même qu'avec le couteau ordinaire.

L,es temps d'exécution des gestes de saisie des cadres à désoperculer et de pose des cadres désoperculés sont les mêmes que précédemment, soit en moyenne Io,86 cmn. 
Les mesures d'enlèvement des opercules sur une face ont porté sur 300 opérations qui ont donné un temps total de $486 \mathrm{I} \mathrm{cmn}$ soit une moyenne de $\mathrm{I} 6,20 \mathrm{cmn}$ par geste.

Comme avec le couteau ordinaire, les écarts enregistrés sont importants car il s'agit toujours d'un temps technologique soumis à l'irrégularité des cadres à désoperculer. L'écart absolu est ici de $22 \mathrm{cmn}$ (minimum 8 , maximum 30) et un écarttype de 5,08 .

La récapitulation des temps donne pour ce travail les résultats suivants:

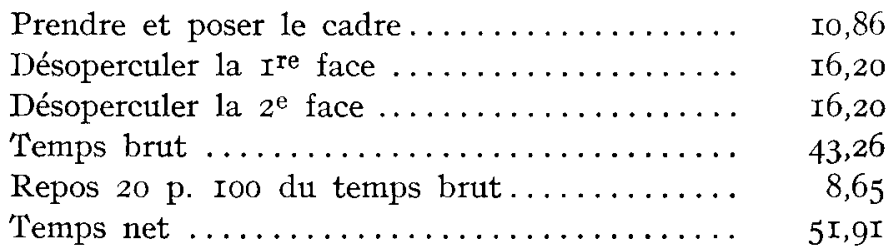

Le temps pour désoperculer au couteau électrique 36 cadres, s'élève à $\mathrm{I} 868 \mathrm{~cm}$, chiffre arrondi à $\mathrm{I} 9 \mathrm{mn}$ et pour 40 cadres il s'élève à $2076 \mathrm{cmn}$, chiffre arrondi à $2 \mathrm{I} \mathrm{mn}$.

\section{c) Emploi de la machine à désoperculer.}

Les gestes de saisie des cadres à désoperculer et de pose des cadres désoperculés restent les mêmes que dans les méthodes précédentes.

Avec cette méthode, un geste nouveau apparaît qui consiste à passer éventuellement les grands côtés des cadres sur la lame de la machine pour les débarrasser des débris de cire ou de propolis. Sur 57 opérations enregistrées, ce geste a été observé I2 fois avec un total de temps de $163 \mathrm{cmn}$ soit une moyenne de $13,5^{8} \mathrm{cmn}$.

Le geste élémentaire pour désoperculer une face a fait l'objet de II4 mesures avec un total de temps de $24 \mathrm{IO} \mathrm{cmn}$ et une moyenne de $2 \mathrm{I}, \mathrm{I} 3 \mathrm{cmn}$. Les écarts sont ici très importants pour la même raison que celle évoquée précédemment. L'écart absolu est de $25 \mathrm{cmn}$ (minimum 9, maximum 34) et l'écart-type est de 5,34. Il est intéressant de constater la constance des écarts-types observés sur la même opération réalisée avec des outils différents et des moyennes de temps variées.

Enfin, l'emploi de la machine introduit une opération supplémentaire : lorsque la surface du cadre à désoperculer n'est pas régulière, la lame laisse des opercules et il est nécessaire de terminer le travail à l'aide d'un couteau ordinaire à désoperculer.

Sur 57 opérations nous avons observé 44 interventions au couteau avec un temps total de $936 \mathrm{cmn}$ soit une moyenne de $21,20 \mathrm{cmn}$ et un écart absolu1 très important : $38 \mathrm{cmn}$ (minimum 9, maximum 47) et un écart-type égal à ro.

Pour calculer le temps moyen d'une séquence, il est nécessaire de pondérer les moyennes des gestes élémentaires, pour tenir compte de leur fréquence variable.

Pour 57 séquences, il a été observé :

57 opérations de prendre et poser d'une durée moyenne de Io,86 soit 6rg,02 cmn I2 opérations de passage des côtés d'une durée moyenne de 13,58 soit I $62,96 \mathrm{cmn}$ 57 opérations de désoperculer la $\mathrm{I}^{\mathrm{re}}$ face d'une durée moyenne $2 \mathrm{I}, \mathrm{I} 3$, total I $204,4 \mathrm{I}$ 57 opérations de désoperculer $1 \mathrm{a} 2^{\text {e }}$ face d'une durée moyenne $2 \mathrm{I}, \mathrm{I} 3$, total $\mathrm{I} 204,4 \mathrm{I}$ 44 opérations de finition au couteau d'une durée moyenne $2 \mathrm{I}, 2 \mathrm{O}$, total 932,80. 
Soit pour les 57 séquences un total de 4 I23,60 $\mathrm{cmn}$ et un temps brut moyen de $72,34 \mathrm{cmn}$.

Le temps de repos égal à $20 \mathrm{p}$. Ioo du temps brut est de $\mathrm{I} 4,46 \mathrm{cmn}$ et le temps net moyen ressort à $86,80 \mathrm{cmn}$.
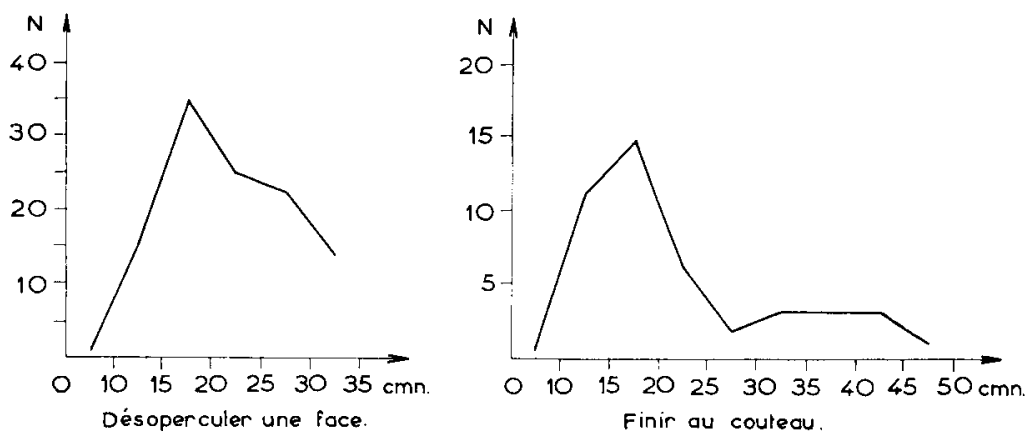

Emploi de la machine à désoperculer.

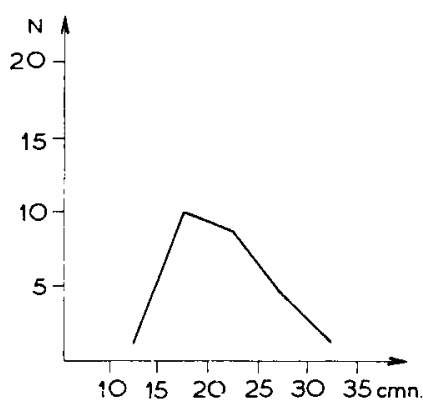

Désoperculer au couleau ordinaire.

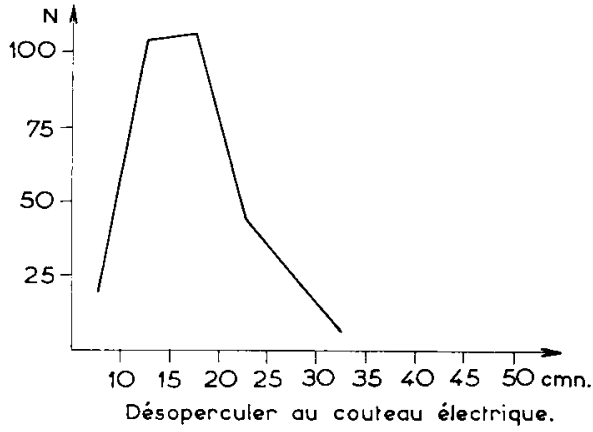

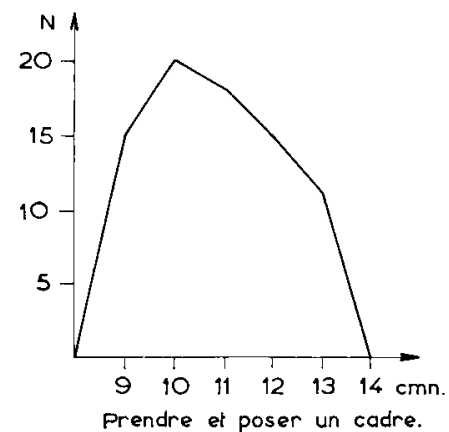

FIG. 9. - Courbes de fréquence des opérations élémentaires. (désoperculation)

Pour désoperculer 36 cadres à la machine, il faut $3 \mathrm{r} 24 \mathrm{cmn}$, temps arrondi à $32 \mathrm{mn}$, et pour désoperculer 40 cadres, il faut $3472 \mathrm{cmn}$, temps arrondi à $35 \mathrm{mn}$. 
TABLEAU 4

Temps d'enlevement des opercules

\begin{tabular}{|c|c|c|c|c|c|}
\hline \multirow[b]{2}{*}{ Méthodes } & \multicolumn{3}{|c|}{ Temps pour 1 cadre } & \multicolumn{2}{|c|}{ Temps pour } \\
\hline & $\underset{\text { (cmn) }}{\text { Temps brut }}$ & $\underset{(\mathrm{cmn})}{\text { Repos } 20 \%}$ & $\begin{array}{l}\text { Temps net } \\
\text { (cmn) }\end{array}$ & $\begin{array}{l}36 \text { cadres } \\
(\mathrm{mn})\end{array}$ & $\begin{array}{l}40 \text { cadres } \\
\text { (mn) }\end{array}$ \\
\hline Machine. & 72,34 & 14,46 & 86,80 & 32 & 35 \\
\hline Couteau ordinaire ....... & 53,18 & 10,63 & 63,81 & 23 & 26 \\
\hline Couteau électrique ...... & 43,26 & 8,63 & 51,91 & 19 & 21 \\
\hline
\end{tabular}

d) Comparaison des méthodes.

Les graphiques de la figure 9 représentent les fréquences des temps observés pour les différentes opérations élémentaires du travail d'enlèvement des opercules avec les trois moyens étudiés.

On remarque sur ces graphiques la grande régularité des gestes prendre et poser un cadre dont la courbe de fréquence se rapproche d'une courbe gaussienne, le mode étant très rapproché de la moyenne.

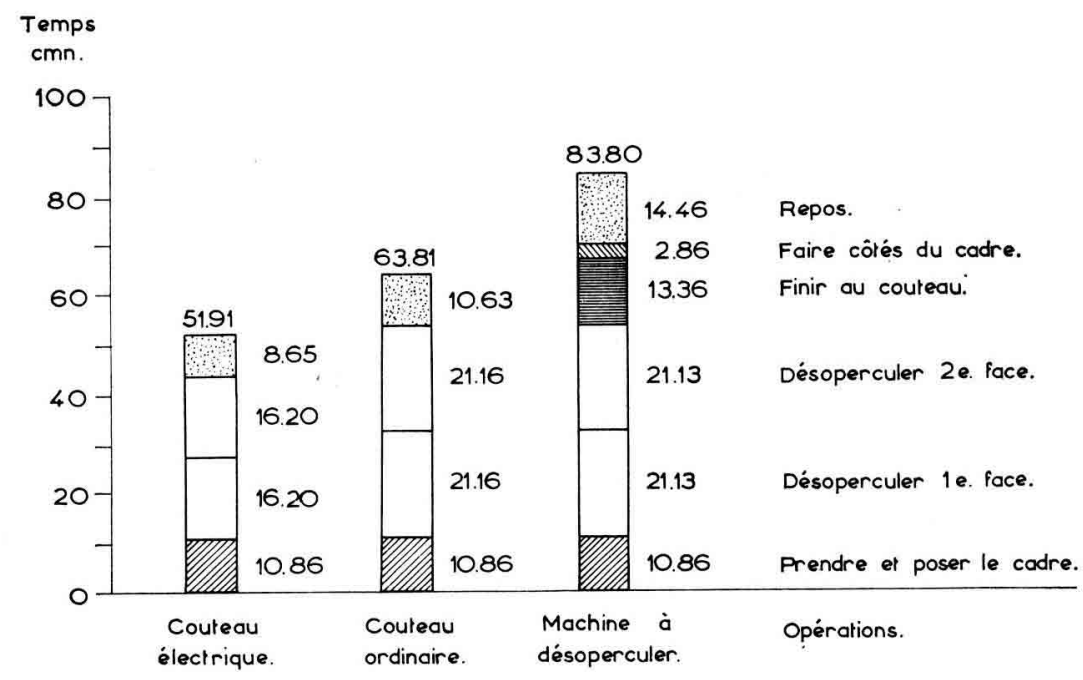

FIG. Io. - Comparaison des temps moyens pour désoperculer

Les opérations d'enlèvement des opercules sur une face de cadre sont beaucoup moins régulières et la plus faible dispersion est obtenue avec le couteau électrique, sur la courbe de fréquence de cette opération, le mode correspond à la moyenne.

Enfin, c'est l'opération de finition au couteau dans l'emploi de la machine à désoperculer qui donne la courbe de fréquence la plus irrégulière, comme nous l'avons dit précédemment, cette opération est réalisée avec une périodicité extrêmement aléatoire et les durées enregistrées sont très dispersées. 
Le graphique de la figure Io et le tableau 9 permettent de comparer les temps moyens calculés pour chaque méthode d'enlèvement des opercules.

C'est l'emploi du couteau électrique qui fournit les meilleurs temps avec un total net de $5 \mathrm{r}, 9 \mathrm{r} \mathrm{cmn}$ par cadre.

L'emploi du couteat ordinaire est moins rapide, il exige un temps net de $63,8 \mathrm{I} \mathrm{cmn}$ par cadre soit une augmentation de 22,88 p. Ioo.

L'utilisation de la machine à désoperculer exige quelques remarques. Lorsque la récolte est abondante, c'est-à-dire que les cadres sont normalement chargés de miel, l'enlèvement des opercules est exécuté avec la machine à la même vitesse qu'avec le couteau ordinaire. Par contre, si les cadres sont irrégulièrement chargés et présentent des zones où l'épaisseur des cellules est plus faible, la machine ne peut désoperculer celles-ci et il est nécessaire de reprendre le travail au couteau ordinaire, ce qui augmente le temps moyen de l'opération.

Au cours des observations, alors que la técolte était satisfaisante, le temps net moyen par cadre avec la machine s'est élevé à $86,80 \mathrm{cmn}$, soit une augmentation de 67,22 p. Ioo par rapport au travail effectué avec le couteau électrique et de $36 \mathrm{p}$. Ioo par rapport au travail avec le couteau ordinaire.

\section{III. - CENTRIFUGATION A L'EXTRACTEUR}

\section{A. Définition du travail et matériel utilisé}

Après enlèvement des opercules, les cadres doivent être soumis à un mouvement de rotation rapide pour libérer le miel des cellules par l'action de la force centrifuge. Dans les mielleries d'une certaine importance, on utilise d'une façon générale l'extracteur à axe vertical qui est le plus anciennement employé. Plus récemment, la Station expérimentale d'Apiculture s'est attachée à perfectionner un extracteur à axe horizontal dont un exemplaire existant chez M. Cholin à Meaux (Seine-etMarne) a servi de modèle.

\section{a) Extracteur à axe vertical.}

Cet appareil est constitué par une cuve cylindrique verticale de $\mathrm{I}, \mathrm{I} 3 \mathrm{~m}$ de hauteur et $92 \mathrm{~cm}$ de diamètre. Le fond de la cuve est situé à $33 \mathrm{~cm}$ du sol (fig. II).

A l'intérieur de la cuve un panier rotatif soutenu par un axe vertical et entraîné par un moteur électrique peut recevoir 36 cadres disposés verticalement et radialement par rapport à l'axe de l'appareil.

Une goulotte disposée à la partie inférieure permet l'évacuation du miel et de l'eau de lavage.

Cet appareil occupe une surface brute au sol de $0,66 \mathrm{~m}^{2}$.

b) Extracteur à axe horizontal.

L'extracteur à axe horizontal est constitué par un support monté sur un axe horizontal permettant d'introduire dans 1'appareil 4 hausses chargées chacune de Io cadres désoperculés ce qui représente une capacité de 40 cadres (fig. I2).

Le mouvement de rotation est obtenu à l'aide d'un moteur électrique de $0,75 \mathrm{cv}$ avec variateur de vitesse permettant d'obtenir de o à 300 tours par mn. 
Cet extracteur occupe une surface brute de $\mathrm{I}, 68 \mathrm{~m}^{2}$ représentant une longueur de $\mathrm{r}, 40 \mathrm{~m}$ et une largeur de $\mathrm{r}, 20 \mathrm{~m}$.

La hauteur de la porte latérale de chargement a été calculée de manière à travailler en position debout.

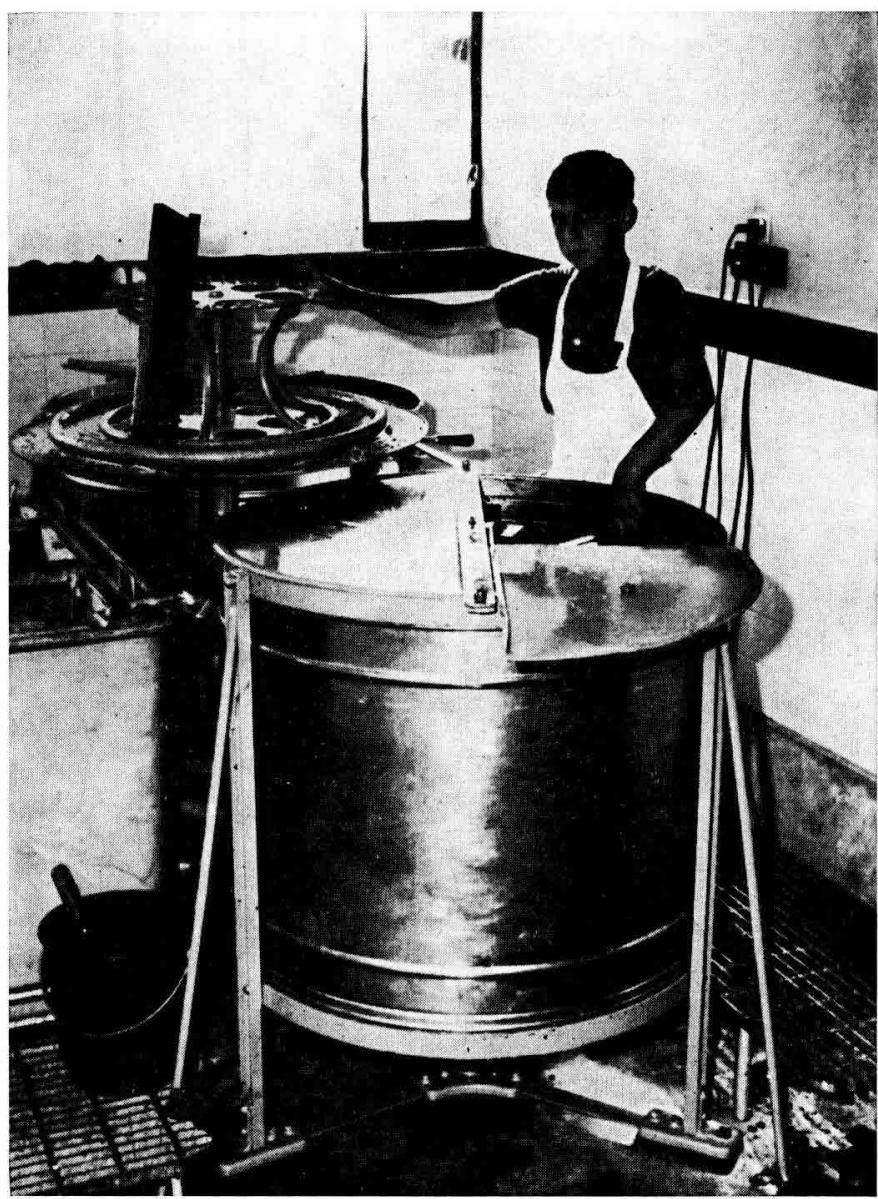

FIG. II. - Extracteur à axe vertical

c) Fosse de réception.

Le miel s'égouttant de la table à désoperculer et s'écoulant de l'extracteur est reçu dans un bac de réception en tôle ou en acier inoxydable et mesurant $\mathrm{I}, 20$ à $\mathrm{I}, 40 \mathrm{~m}$ de longueur, $0,40 \mathrm{~m}$ de largeur et 0,27 à $0,30 \mathrm{~m}$ de hauteur. Pour permettre l'élimination des plus grosses particules de cire, le miel est filtré à son entrée dans le bac à travers une tôle perforée à trous de $5 \mathrm{~mm}$ de diamètre et on augmente la longueur séparant l'arrivée du miel de sa sortie du bac par l'aménagement de 3 chicanes en tôle dont la hauteur est réglable.

A l'extrémité du bac de réception opposée à celle de l'arrivée du miel, une pompe refoule le miel vers les bacs de stockage appelés maturateurs à travers une canalisation en verre Pyrex de $40 \mathrm{~mm}$ de diamètre. 
Le débit de la pompe doit être calculé très largement par rapport au volume théorique à manutentionner pour obtenir le maximum de sécurité de travail à ce poste. On utilise pour un extracteur de 36 ou de 40 cadres une pompe de $\mathrm{r} 800$ à $2000 \mathrm{~kg} /$ heure alors que la production théorique maximum n'est que de $650 \mathrm{à} 750 \mathrm{~kg}$ de miel.

Bac de réception et pompe sont placés dans une fosse de $0,70 \mathrm{~m}$ de profondeur et mesurant I,30 à I,50 m de longueur et $0,50 \mathrm{~m}$ de largeur à l'emplacement de la cuve et $\mathrm{I} \mathrm{m}$ à l'emplacement de la pompe. Cette fosse est aménagée à proximité immédiate du ou des extracteurs.

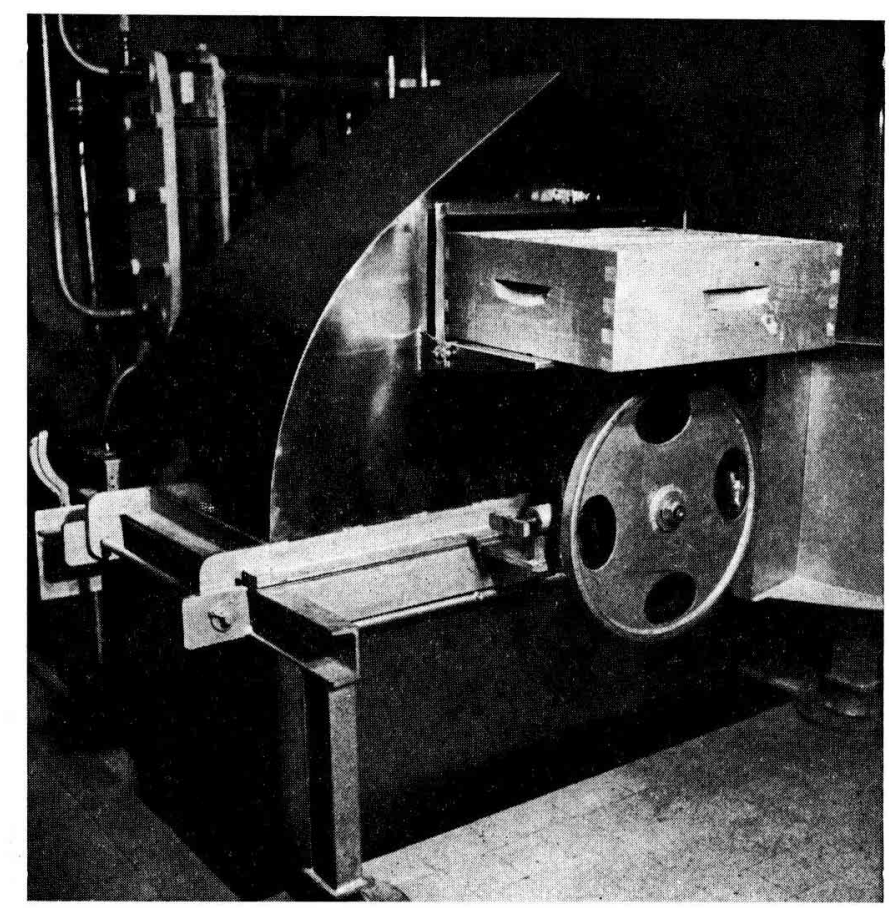

Fig. I2. - Extracteur à axe horisontal

\section{B. Opérations et temps élémentaires}

Le déroulement et la durée du travail varient suivant la nature du matériel utilisé. a) Extracteur à axe vertical.

Lorsqu'on utilise l'extracteur à axe vertical, les cadres sont manipulés isolément, il est donc nécessaire de disposer entre le poste d'enlèvement des opercules et l'extracteur d'un tourniquet d'attente qui a été décrit au chapitre précédent. Ce tourniquet permet de stocker les cadres désoperculés pendant que l'extracteur fonctionne. La capacité du tourniquet est de 42 cadres, nombre supérieur à la capacité de l'extracteur qui est de 36 cadres.

L'ouvrier affecté au poste d'extraction saisit un à un les cadres disposés sur le tourniquet et les introduit dans le panier de l'extracteur. Lorsque les 36 cadres 
garnissent l'extracteur, celui-ci est mis en route. L'ouvrier est alors libéré pendant la durée de fonctionnement de l'appareil soit to $\mathrm{mn}$, temps pendant lequel il peut participer à l'enlèvement des opercules des cadres ou à des opérations de manutention des hausses pleines et vides.

Après la durée normale de centrifugation, l'appareil est arrêté rapidement grâce à un dispositif de freinage. Les cadres sont sortis un à un du panier de centrifugation et disposés dans des hausses vides qui sont ensuite transportées à leur lieu de stockage.

L'ouvrier a intérêt à dissocier les deux dernières opérations élémentaires de manière à libérer le plus rapidement possible l'extracteur et à procéder immédiatement à son rechargement. Nous verrons en effet que l'opération de rangement des cadres dans les hausses est trois fois plus longue que celle de déchargement de l'extracteur.

Les temps nécessaires (cmn) à ces opérations sont les suivants :

chargement de l'extracteur $\ldots \ldots \ldots \ldots \ldots \ldots \ldots$

centrifugation $\ldots \ldots \ldots \ldots \ldots \ldots \ldots \ldots \ldots \ldots$

déchargement de l'extracteur $\ldots \ldots \ldots \ldots \ldots \ldots$

rangement des cadres dans les hausses
I 20

$\mathrm{I} 000$

I 20

300

soit un total de $\mathrm{I} 540 \mathrm{cmn}$ ce qui représente $\mathrm{I} 5,40 \mathrm{mn}$, temps arrondi à $\mathrm{I} 6 \mathrm{mn}$ Ces temps comprennent Io $\mathrm{mn}$ de travail machine et $6 \mathrm{mn}$ d'opérations manuelles réparties en deux périodes l'une de $\mathrm{I}, 5 \mathrm{mn}$ avant centrifugation et l'autre de 4,5 $\mathrm{mn}$ après centrifugation.

\section{b) Extracteur à axe horizontal.}

Dans l'emploi de l'extracteur à axe horizontal, le travail est exécuté en utilisant des hausses garnies de cadres désoperculés. Ces hausses, au nombre de 4 par séquence de travail sont disposées à proximité de la machine sur un chariot à roulettes. L'opération de chargement consiste à ouvrir la porte de l'extracteur, à introduire la première hausse sur le support, imprimer à celui-ci un mouvement d'un quart de tour, à la main, introduire la $2^{\mathrm{e}}$ hausse, faire tourner le support d'un quart de tour et ainsi de suite jusqu'à l'introduction de la $4^{\text {e }}$ hausse ; fermer la porte et mettre le moteur en marche.

Durant la rotation de la machine, l'ouvrier est libéré et peut comme dans le cas précédent, être employé à désoperculer des cadres ou à effectuer des travaux de manutention de hausses. Après le temps normal de centrifugation, 1'appareil est arrêté par freinage, la porte est ouverte et les hausses sont sorties et placées sur un chariot pour être ensuite transportées à leur lieu de stockage.

Les temps chronométrés ont donné pour les différentes opérations les moyennes suivantes :

chargement de 4 hausses $\ldots \ldots \ldots \ldots$

centrifugation $\ldots \ldots \ldots \ldots \ldots \ldots \ldots$.

déchargement de 4 hausses
I minute

Io minutes

I minute

soit un temps total de $\mathrm{I} 2 \mathrm{mn}$ comprenant Io $\mathrm{mn}$ de temps machine et $2 \mathrm{mn}$ de temps de travail manuel réparti en deux périodes, de même durée (une minute) l'une avant et l'autre après la centrifugation. 


\section{Organisation du travail}

L'organisation du travail consiste à rechercher la combinaison optimum des moyens d'action : hommes, matériels, produits en vue d'obtenir le meilleur rendement de chacun d'eux.

I)ans le travail d'extraction du miel, trois opérations sont exécutées: manutention des hausses et des cadres, enlèvement des opercules et centrifugation des cadres avec ou sans hausse.

Au point de vue du matériel, nous avons vu qu'il est possible d'utiliser des moyens de manutention différents : chariots, transrouleurs et transrouleurs-élévateurs, étant donnée l'importance relative dans le temps de ces opérations, par rapport aux deux autres, il n'en est pas tenu compte dans l'étude d'organisation, il suffit de prévoir des temps disponibles d'ouvrier pour les effectuer, ainsi que celles ayant trait au rangement et au nettoyage du matériel et du local.

Pour l'enlèvement des opercules, trois méthodes peuvent être utilisées suivant la nature des outils, enfin la centrifugation peut être réalisée suivant deux méthođes compte tenu du matériel adopté.

Le personnel est variable, il a semblé intéressant pour les différentes méthodes d'étudier l'organisation du travail exécuté avec une seule personne, réalisant alternativement la récolte au rucher et l'extraction à la miellerie.

Dans le cas de deux personnes, deux méthodes peuvent être appliquées : 1'une des personnes travaille à la récolte au rucher et l'autre opère seule à la miellerie ou bien elles travaillent ensemble alternativement au rucher et à la miellerie. Enfin le cas d'entreprises plus importantes, susceptibles d'employer 3 ou 4 personnes à la miellerie, a été envisagé.

\section{a) Emploi de l'extracteur à axe vertical.}

L'extracteur à axe vertical a une capacité de 36 cadres manipulés un à un et la durée de la séquence du travail de centrifugation est de $16 \mathrm{mn}$ dont ro de travailmachine. L'ouvrier appelé à ce poste, doit effectuer :

- le chargement de l'extracteur pendant I,5 minute ;

- participer à l'opération d'enlèvement des opercules pendant $8 \mathrm{mn}$, tandis que l'extracteur fonctionne ( Io mn), et enfin décharger l'extracteur et placer les cadres vides dans les hausser pendant $4,5 \mathrm{mn}$.

Nous envisagerons au poste d'enlèvement des opercules les trois solutions suivantes : utilisation du couteau ordinaire, du couteau électrique et de la machine à désoperculer.

Rappelons à cet effet que pour désoperculer 36 cadres, c'est-à-dire le nombre correspondant à la capacité de l'extracteur à axe vertical, il faut :

$23 \mathrm{mn}$ avec le couteau ordinaire

I9 $\mathrm{mn}$ avec le couteau électrique

$32 \mathrm{mn}$ sur la machine à désoperculer.

Pour chaque solution d'enlèvement des opercules, nous examinerons différents cas suivant le nombre d'ouvriers participant au travail.

Pour chaque cas sera calculé le temps nécessaire à l'exécution d'une séquence c'est-à-dire l'enlèvement des opercules et la centrifugation de 36 cadres. 
On déterminera le nombre de séquences susceptibles d'être réalisées au cours d'une séance de travail de $4 \mathrm{~h}$ et d'une journée de $8 \mathrm{~h}$. La différence entre le temps total de $8 \mathrm{~h}$ et le temps théorique du travail d'extraction indiquera le temps disponible pour l'exécution des opérations accessoires de manutention et de nettoyage.

\section{Io Solution du couteau ordinaire.}

$1^{\text {er }}$ cas : un homme travaille seul :

Le temps de centrifugation est de $16 \mathrm{mn}$, pendant la marche de la machine, 1 'ouvrier dispose de $8 \mathrm{mn}$ pendant lesquelles il peut désoperculer au couteau ordinaire $\frac{36 \times 8}{23}=\mathrm{I} 2,5$ soit $\mathrm{I} 2$ cadres.

Entre deux opérations de centrifugation, 1'ouvrier doit désoperculer $36-$ I $2=24$ cadres, ce qui exige un temps de $\frac{23 \times}{36} \frac{24}{36}=$ I5,3I mn, temps arrondi à 16 mn.

Une séquence aura donc : I6 + I6 = $32 \mathrm{mn}$ (voir graph. I du tabl. 5).

$\mathrm{Au}$ cours d'une demi-journée de travail, c'est-à-dire pendant $240 \mathrm{mn}$, l'ouvrier peut effectuer :

$$
\frac{24^{\circ}}{32}=7,5 \text { soit } 7 \text { séquences }
$$

ce qui représente I4 séquences par jour.

Le temps d'extraction est pour la journée $(480 \mathrm{mn})$ de $32 \times \mathrm{I} 4=448 \mathrm{mn}$.

L'ouvrier dispose donc d'un reliquat de temps de $480-448=32 \mathrm{mn}$ pour effectuer les opérations accessoires.

$2^{\text {e }}$ cas : deux ouvriers travaillent simultanément :

L'ouvrier affecté à la centrifugeuse peut comme précédemment pendant la marche de la machine, désoperculer i2 cadres.

L'ouvrier chargé uniquement de l'enlèvement des opercules doit traiter : $36-$ I $2=24$ cadres ce qui exige :

$$
\frac{23 \times 24}{36}=15,33 \mathrm{mn} \text {, chiffre arrondi à } 16 \mathrm{mn} \text {. }
$$

La séquence de travail est donc de I6 mn (voir graph. 2 du tabl. 5).

Au cours d'une demi-journée $(240 \mathrm{mn})$ le nombre de séquences est de $\frac{240}{\mathrm{I} 6}=\mathrm{I} 5$.

Comme dans ce cas les deux ouvriers sont employés à plein temps pendant les opérations d'enlèvement des opercules et de centrifugation, on ne retient que I3 séquences par demi-journée et 26 séquences par jour. On dispose alors d'un reliquat de temps de :

$480-(\mathrm{I} 6 \times 26)=64 \mathrm{mn}$ par ouvrier et de $2,08 \mathrm{~h}$ pour les deux ouvriers pour les opérations accessoires.

3e cas : trois hommes, deux extracteurs :

Dans ce cas, deux ouvriers sont affectés à l'enlèvement des opercules. Pour traiter 36 cadres, il leur faut $\frac{23}{2}=\mathrm{II}, 5 \mathrm{mn}$, la durée d'un cycle de machine étant de $16 \mathrm{mn}$, si 1'on ne veut pas que l'équipe d'enlèvement des opercules attende, 
il faut disposer de deux centrifugeuses desservies par un ouvrier qui ne fait que ce travail (fig. 3 du tabl. 5).

La durée de la séquence est alors de I I,5 mn.

Le nombre de séquences par demi-journée de travail est de $\frac{240}{\text { II }, 5}=20,86$, soit 20 séquences et donc 40 séquences par jour.

\section{TABLEAU 5}

Séquences de travail avec extracteur à axe vertical et couteau ordinaire

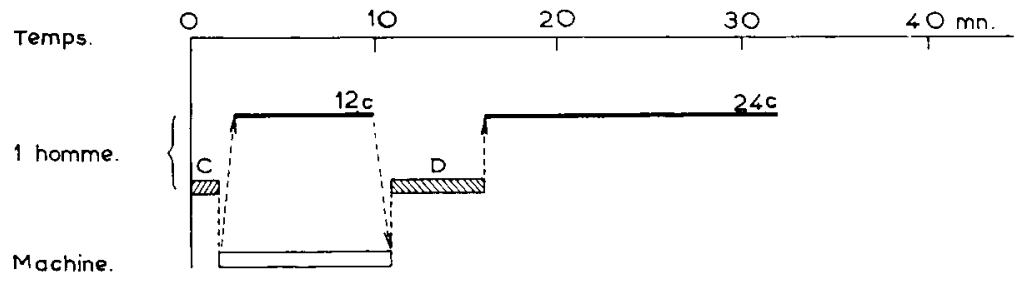

Fig. 1. Un homme seul.

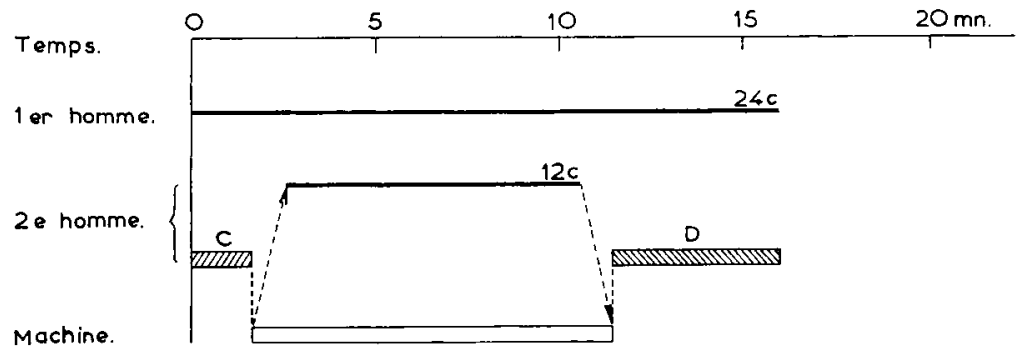

Fig. 2 - Deux hommes.

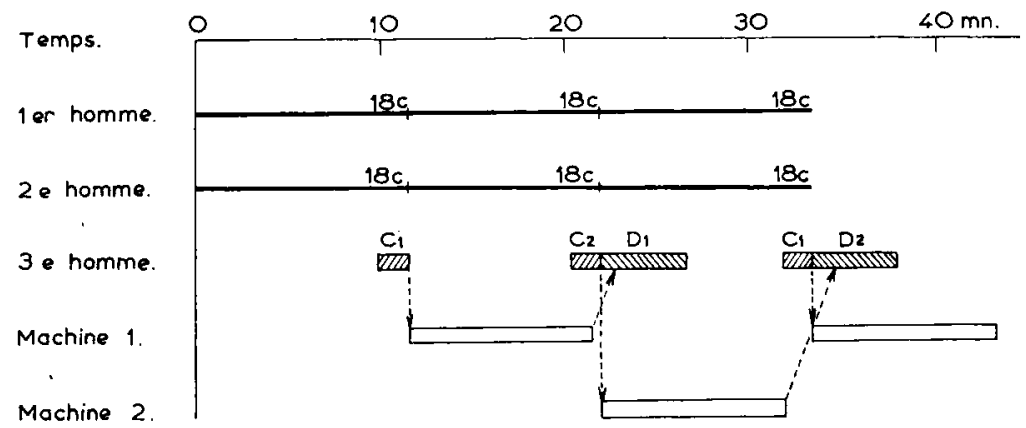

Fig. 3 - Trois hommes el deux mochines.

$c$ cadres désoperculés, $C$ chargement extracteur, $D$ déchargement extracteur, $C_{1} C_{2} \quad D_{1} D_{2}$ chargement et déchargement avec 2 extracteurs, Trait plein : enlèvement des opercules, Trait double : extraction machine, Traits hachurés : chargement et déchargement extracteur. 
Le temps de travail des deux ouvriers désoperculeurs est complet à leur poste, par contre le temps de travail de l'ouvrier affecté aux centrifugeuses, est de :

$$
6 \times 40=240 \mathrm{mn}
$$

il dispose par journée de travail de $480-240=240 \mathrm{mn}$ soit $4 \mathrm{~h}$ pour effectuer les opérations accessoires.

\section{TABLEAU 6}

Séquences de travail avec extracteur à axe verical et couteau électrique

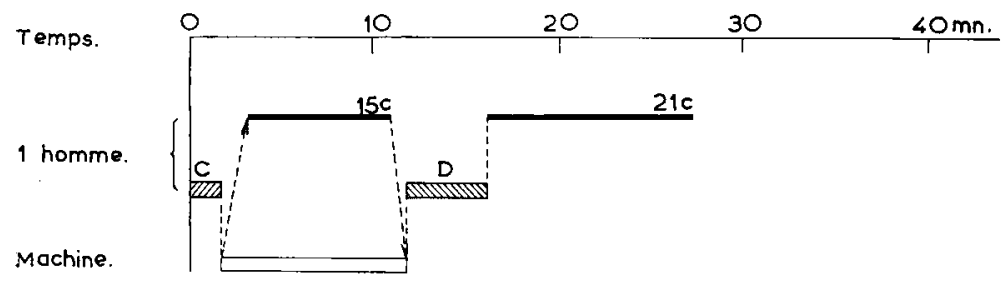

Fig. 1 - Un homme seul.

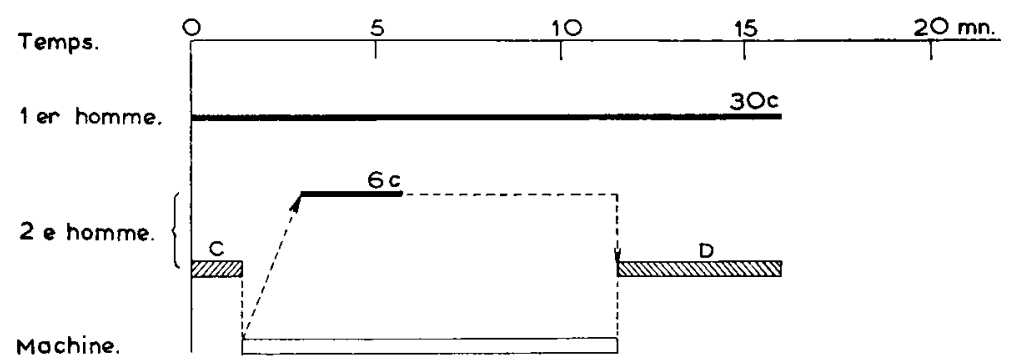

Fig. 2 - Deux hommes.

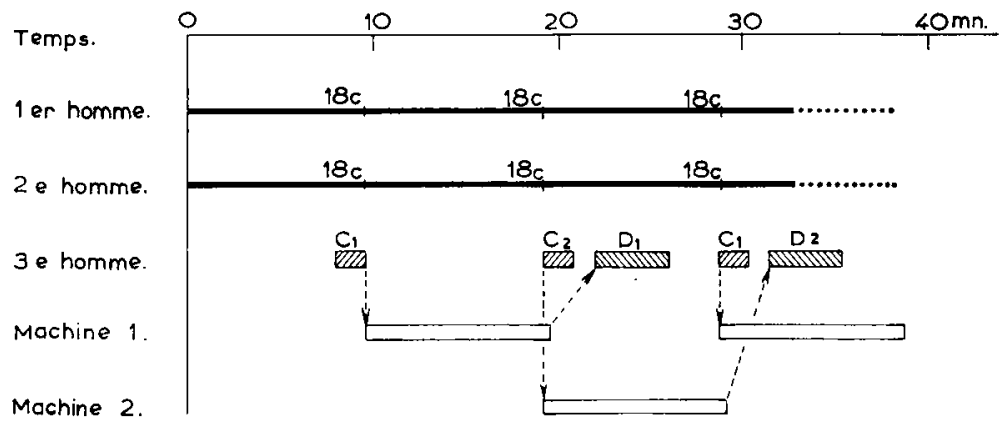

Fig. 3 - Trois hommes el deux machines.

$c$ cadres désoperculés, $C$ chargement extracteur, $D$ déchargement extracteur, $C_{1} C_{2} D_{1} D_{2}$ chargement et déchargement avec 2 extracteurs, Trait plein : enlevement des opercules, Trait double : extraction machine Traits hachurés : chargement et déchargement extracteur. 


\section{$2^{\circ}$ Solution du couteau électrique.}

La durée du temps de travail de la centrifugeuse reste la même que précédemment soit $\mathrm{I} 6 \mathrm{mn}$ pour traiter 36 cadres dont Io $\mathrm{mn}$ de travail machine, $\mathrm{I}, 5 \mathrm{mn}$ de chargement manuel et $4,5 \mathrm{mn}$ de déchargement manuel.

Avec l'emploi du couteau électrique, il faut I $\mathrm{mn}$ pour désoperculer 36 cadres. $1^{\text {er }}$ cas : un homme travaille seul (fig. I du tabl. 6).

Pendant le fonctionnement de la machine qui dure ro mn, il peut consacrer $8 \mathrm{mn}$ à désoperculer et traiter $\frac{36 \times 8}{\mathrm{I} 9}=\mathrm{I} 5$ cadres. I1 reste donc à désoperculer $36-\mathrm{I} 5=2 \mathrm{I}$ cadres ce qui nécessite un temps de $\frac{\text { Ig } \times 2 \mathrm{I}}{36}=$ II $\mathrm{mn}$.

La durée d'une séquence de travail est donc de I $6+$ II $=27 \mathrm{mn}$.

Au cours d'une demi-journée, l'ouvrier peut exécuter $\frac{240}{27}=8,88$ soit 8 séquences. mais pour permettre de disposer de temps pour les travaux accessoires, nous adoptons 7 séquences, soit $\mathrm{I}_{4}$ séquences par jour.

I,e temps de travail d'extraction est đe $27 \times \mathrm{I}_{4}=378 \mathrm{mn}$, soit un temps à consacrer aux opérations de manutention et de nettoyage de $480-378=102 \mathrm{mn}$ ou $\mathrm{I}, 42 \mathrm{~h}$.

2 e cas : deux hommes et une centrifugeuse (fig. 2 du tabl. 6).

Pendant la durée de fonctionnement de la centrifugeuse qui est de $16 \mathrm{mn}$, l'ouvrier affecté à l'enlèvement des opercules peut traiter $\frac{36 \times \text { I6 }}{\mathrm{I} 9}=3^{\circ}$ cadres.

Il reste donc à l'ouvrier chargé de la manœuvre de la centrifugeuse à désoperculer 6 cadres soit $3 \mathrm{mn}$ de travail pendant que la machine fonctionne.

La séquence de travail est ici de $16 \mathrm{mn}$ ce qui représente $\frac{240}{\mathrm{I} 6}=\mathrm{I} 5$ séquences par demi-journée et 30 séquences par jour.

L'ouvrier préposé à l'enlèvement des opercules travaille à plein temps, celui affecté à la centrifugeuse travaille :

$$
(6+3) 30=270 \mathrm{mn}
$$

il dispose de $480-270=210 \mathrm{mn}$ soit $3 \mathrm{~h} 30 \mathrm{mn}$ pour effectuer les travaux accessoires.

$3^{\mathrm{e}}$ cas : trois hommes et deux centrifugeuses (fig. 3 du tabl. 6).

Detıx hommes désoperculent et traitent chacun I 8 cadres en $\frac{\text { I9 } \times \text { I8 }}{36}=9,5 \mathrm{mn}$.

La durée de la phase d'enlèvement des opercules étant nettement plus courte que celle de l'extraction ( $\mathrm{I} 6 \mathrm{mn}$ ) il faut utiliser deux appareils servis par un $3^{\text {e }}$ ouvrier qui, en outre, effectue les opérations accessoires de manutention et de nettoyage.

La durée de la séquences de travail est de $9,5 \mathrm{mn}$ et on exécute $\frac{240}{9,5}=25$ séquences par demi-journée et 50 séquences par jour.

Les deux ouvriers qui enlèvent les opercules travaillent à roo $\mathrm{p}$. Ioo du temps, l'ouvrier aux centrifugeuses travaille à ce poste $6 \times 5^{0}=300 \mathrm{mn}$ et il dispose de $480-300=180 \mathrm{mn}$ soit $3 \mathrm{~h}$ pour les travaux accessoires. 


\section{$3^{\circ}$ Solution de la machine à désoperculer.}

Avec la machine à désoperculer, le temps d'enlèvement des opercules de 36 cadres exige $32 \mathrm{mn}$.

$1^{\text {er }}$ cas : un homme travaille seul (fig. I du tab1. 7).

Pendant le fonctionnement de la centrifugeuse, l'ouvrier peut désoperculer pendant $8 \mathrm{mn}$ et il traite $\frac{36 \times 8}{3^{2}}=9$ cadres.

\section{TABLEAU 7}

Séquences de travail avec extracteur à axe vertical et machine à désoperculer

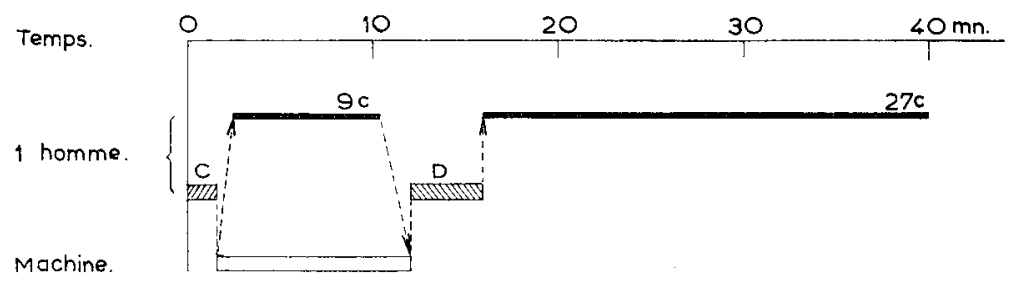

Fig. 1 - un homme seul.

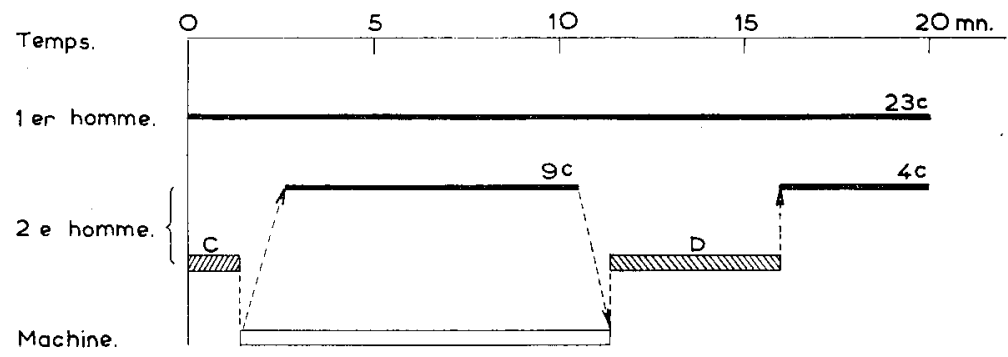

Fig. 2 - Deux hommes.

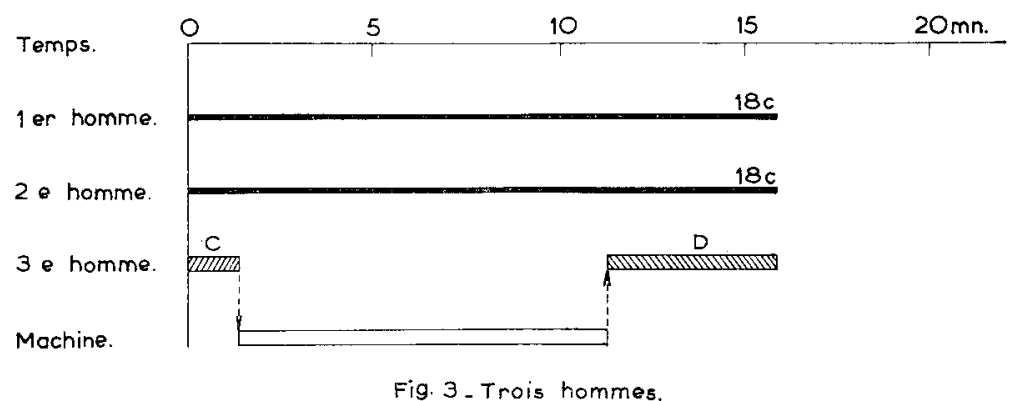

$c$ cadres désoperculés, $\mathrm{C}$ chargement extracteur, $\mathrm{D}$ déchargement extracteur, $\mathrm{C}_{1} \mathrm{C}_{2} \mathrm{D}_{1} \mathrm{D}_{2}$ chargement et déchargement avec 2 extracteurs, Trait plein : enlevement des opercules, Trait double: extraction machine, Traits hachurés : chargement et déchargement extracteur. 
I1 reste à désoperculer $3^{6}-9=27$ cadres ce qui exige un temps de

$$
\frac{32 \times 27}{3^{6}}=24 \mathrm{mn} \text {. }
$$

La durée (mn) d'une séquence de travail se décompose comme suit :

Extraire et désoperculer 9 cadres ...... I6

Désoperculer 27 cadres ............. 24

Total ............... $\quad \overrightarrow{40}$

Au cours d'une demi-journée, il peut effectuer $\frac{240}{40}=6$ séquences, mais pour lui permettre de procéder aux opérations de manutention et de nettoyage, nous retenons seulement 5 séquences, soit ro pour une journée de travail.

Le temps de travail pour désoperculer et centrifuger au cours d'une journée est de $40 \times$ Io $=400 \mathrm{mn}$, il reste disponible $480-400=80 \mathrm{mn}$ soit I h 20 pour les opérations accessoires.

2e cas : detux hommes, deux machines à désoperculer (fig. 2 du tabl. 7).

I'ouvrier affecté à la centrifugeuse peut, durant la marche de la machine, désoperculer pendant $8 \mathrm{mn} \frac{36 \times 8}{32}=9$ cadres.

I1 reste à désoperculer $36-9=27$ cadres ce qui exige $24 \mathrm{mn}$ de travail, soit $20 \mathrm{mn}$ pour l'ouvrier qui ne fait que ce travail et $4 \mathrm{mn}$ pour celui de la centrifugeuse qui dispose de temps libre entre le déchargement et le rechargement de la machine.

$\mathrm{L}$ a séquence de travail est de $20 \mathrm{mn}$, permettant de réaliser $\frac{240}{20}=\mathrm{I} 2$ séquences par demi-journée, nous ramenons ce chiffre à II, soit 22 séquences par jour pour permettre d'effectuer les opérations accessoires.

Le temps de travail d'extraction est de $20 \times 22=440 \mathrm{mn}$ par jour et par ouvrier, soit $480-440=40 \mathrm{mn}$ de temps disponible par ouvrier et $80 \mathrm{mn}$ soit I h $20 \mathrm{mn}$ pour les deux ouvriers.

3e cas : Deux hommes pour désoperculer, un homme à l'extracteur (fig. 3, tabl. 7).

Pour désoperculer 36 cadres, deux hommes mettent $\frac{32}{2}=\mathrm{I} 6 \mathrm{mn}$ temps correspondant à un cycle d'extracteur auquel est affecté un ouvrier à plein temps.

La durée de la séquence de travail étant de $\mathrm{I} 6 \mathrm{mn}$, on effectue $\frac{240}{\mathrm{I} 6}=\mathrm{I} 5$ séquences par demi-journée et 30 par jour.

Les deux ouvriers employés à l'enlèvement des opercules travaillent à ce poste pendant Ioo p. IOO du temps. L'ouvrier qui sert la centrifugeuse travaille à ce poste $6 \times 30=\mathrm{I} 8 \mathrm{o} \mathrm{mn}$, il dispose donc de $480-\mathrm{I} 8 \mathrm{o}=300 \mathrm{mn}$, soit $5 \mathrm{~h}$ pour effectuer les opérations accessoires.

b) Emploi de l'extracteur à axe horizontal.

Rappelons que la durée du cycle de travail de cet appareil est de 12 mn comprenant:

chargement de 4 hausses .......... I $\mathrm{mn}$

centrifugation ................. Io $\mathrm{mn}$

déchargement de 4 hausses........ I $\mathrm{Imn}$ 
La capacité de la machine est de 4 hausses soit 40 cadres. Pour désoperculer 40 cadres avec les différents outils, il faut :

$$
\begin{aligned}
& 26 \mathrm{mn} \text { avec le couteau ordinaire, } \\
& 2 \mathrm{I} \mathrm{mn} \text { avec le couteau électrique, } \\
& 35 \mathrm{mn} \text { avec la machine à désoperculer. }
\end{aligned}
$$

Comme pour le travail avec l'extracteur à axe vertical, il est nécessaire de considérer les possibilités d'organisation en tenant compte des outils utilisés et de l'effectif de personnel employé.

\section{TABLEAU 8}

Séquences de travail avec extracteur $\dot{a}$ axe horizontal et couteau ordinaire

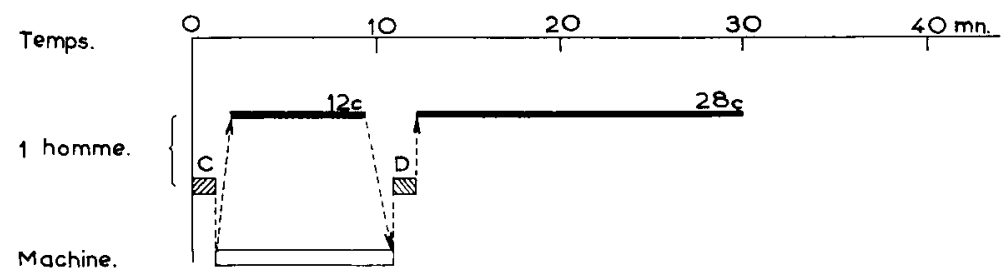

Fig. 1. Un homme seul.

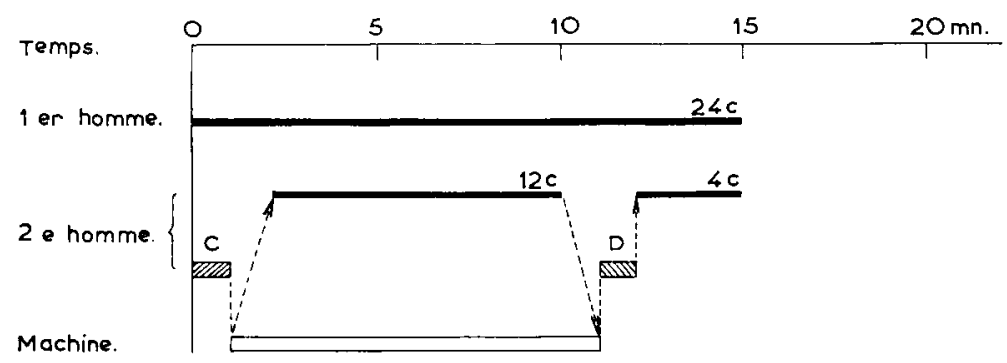

Fig. 2 . Deux hommes.

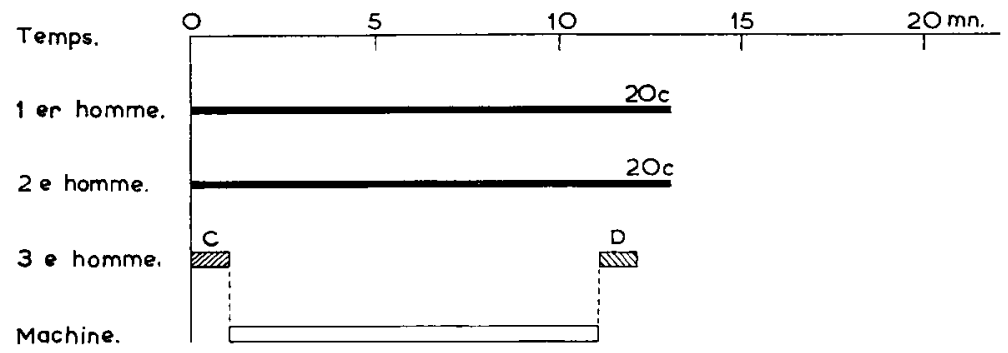

Fig. 3. Trois hommes.

$c$ cadres désoperculés, $C$ chargement extracteur, $D$ déchargement extracteur, $C_{1} C_{2} D_{1} D_{2}$ chargement et déchargement avec 2 extracteurs, Trait plein : enlèvement des opercules, Trait double : extraction machine, Traits hachurés : chargement et déchargement extracteur. 
La technique de travail et la méthode de calcul appliquées sont les mêmes que dans le cas de l'emploi de l'extracteur à axe vertical.

Lorsqu'on utilise un homme seul, il désopercule des cadres pendant la marche de la centrifugeuse et complète le nombre des cadres à désoperculer pour atteindre le nombre de 40 entre deux opérations de centrifugation.

Lorsque deux ouvriers travaillent simultanément, l'un enlève les opercules et l'autre sert la centrifugetuse (chargement et déchargement) et participe pendant son temps libre à l'enlèvement des opercules.

Dans ces deux cas le nombre de séquences de travail est réduit par rapport au nombre théorique maximum possible de manière à laisser aux ouvriers un temps disponible suffisant pour effectuer les opérations accessoires de manutention des hausses pleines et vides et les travaux de nettoyage du matériel et du local.

Lorsqu'on emploie plus de deux personnes, celle affectée à la centrifugeuse ne participe plus à l'opération d'enlèvement des opercules. En effet dans ce cas les ouvriers qui désoperculent sont employés à cette tâche à plein temps et les opérations de manutention ainsi que les travaux de nettoyage occupent le temps disponible de l'ouvrier affecté à la centrifugeuse.

Il est alors inutile d'entrer dans le détail des calculs et il suffit de rapporter les résultats obtenus :

\section{I ${ }^{o}$ Solution $d u$ couteau ordinaire.}

$1^{\text {er }}$ cas : un homme travaille seul (fig. I, tabl. 8).

Le nombre de séquences journalières de travail est de $I_{4}$ ce qui représente une durée de 420 minutes de travail d'extraction et un temps disponible de $\mathrm{I} \mathrm{h}$ pour les travaux accessoires.

\section{2e cas : deux hommes (fig. 2, tabl. 8).}

Le nombre de séquences est de 30 par jour entraînant un travail d'extraction de $45^{\circ} \mathrm{mn}$ par ouvrier et un temps disponible de $30 \mathrm{mn}$ soit $\mathrm{I} \mathrm{h}$ pour les deux personnes.

$3^{\mathrm{e}}$ cas : trois hommes (fig. 3, tabl. 8).

Deux ouvriers désoperculent d'une manière permanente et un ouvrier sert la centrifugeuse et effectue les opérations de manutention. Le nombre des séquences de travail est de 36 par jour. Le temps disponible pour les opérations accessoires est de $5 \mathrm{~h}$ o8 $\mathrm{mn}$.

\section{$2^{\circ}$ Solution du couteau électrique.}

$1^{\text {er }}$ cas : un homme travaille seul (fig. I, tab1. 9).

Le nombre de séquences est de $I 6$ par jour et le temps disponible est égal à I h $20 \mathrm{mn}$.

2 e cas : deux hommes travaillent simultanément (fig. 2, tabl. 9).

Nombre de séquences journalières: 34 avec un total de temps disponible de I h I6 $\mathrm{mn}$.

3e cas : quatre hommes et deux centrifugeuses (fig. 3, tabl. 9).

Le cas de trois hommes, c'est-à-dire deux employés à désoperculer et un à 
l'extracteur, n'est pas intéressant car l'opération d'enlèvement des opercules par deux ouvriers utilisant un couteau électrique est plus rapide que le travail de la centrifugetise et il serait nécessaire que les ouvriers attendent la machine et le rendement de l'ouvrier affecté à la centrifugeuse serait trop faible.

\section{TABLEAU 9}

Séquences de travail avec extracteur à axe horizontal et coutean électrique

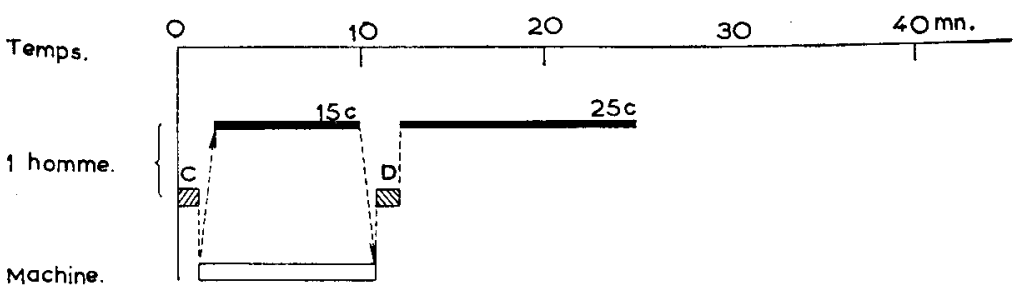

Fig. 1 - Un homme seul.

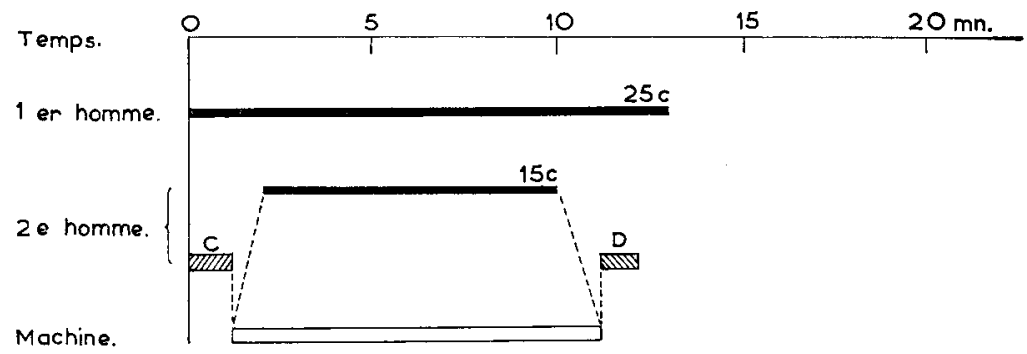

Fig. 2 - Deux hommes.

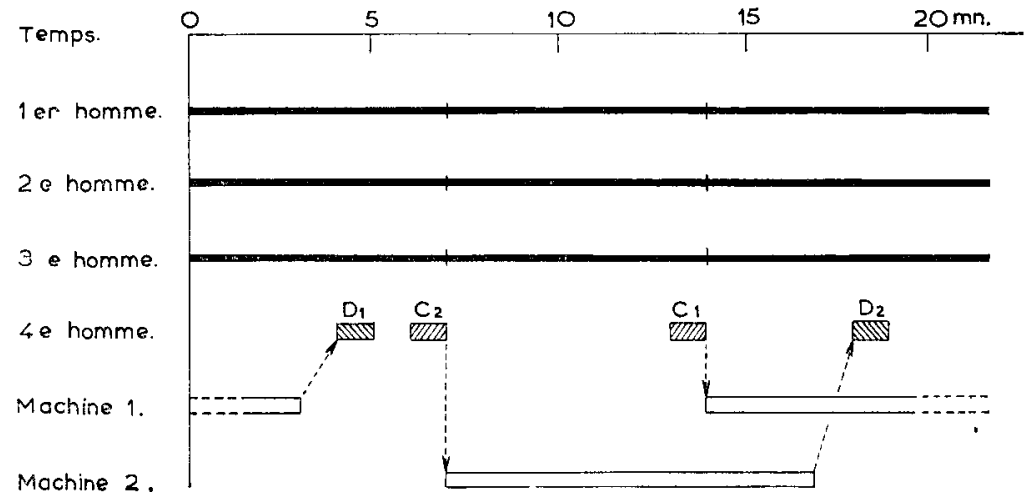

Fig. 3. Quaire hommes et deux machines.

c cadres désoperculés, $C$ chargement cxtracteur, $D$ déchargement extracteur, $C_{1} C_{2} D_{1} D_{2}$ chargement et déchargement avec 2 extracteurs, Trait plein : enlèvement des opercules, Trait double : extraction machine, Traits hachurés : chargement et déchargement extracteur. 


\section{TABLEAU IO}

Séquences de travail avec extracteur à axe horizontal et machine à désoperculer

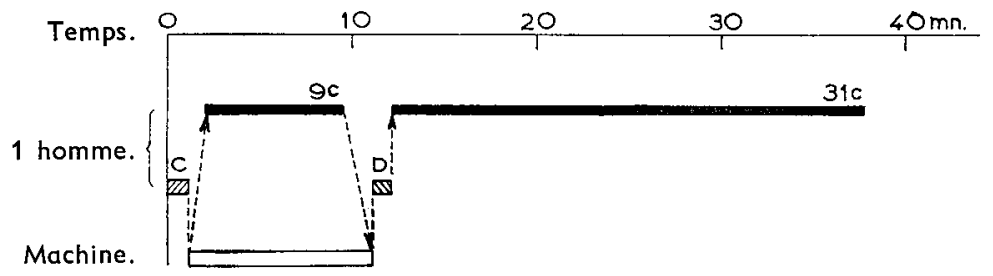

FIG. I. - Un homme sevl

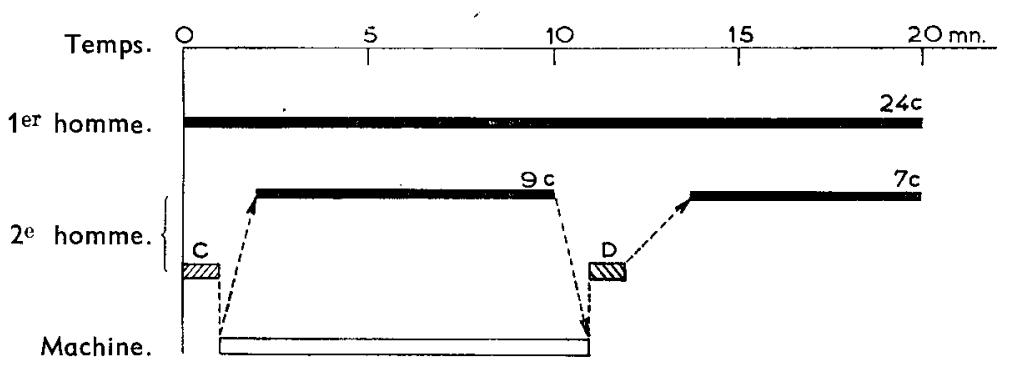

FIG. 2. - Deux hommes

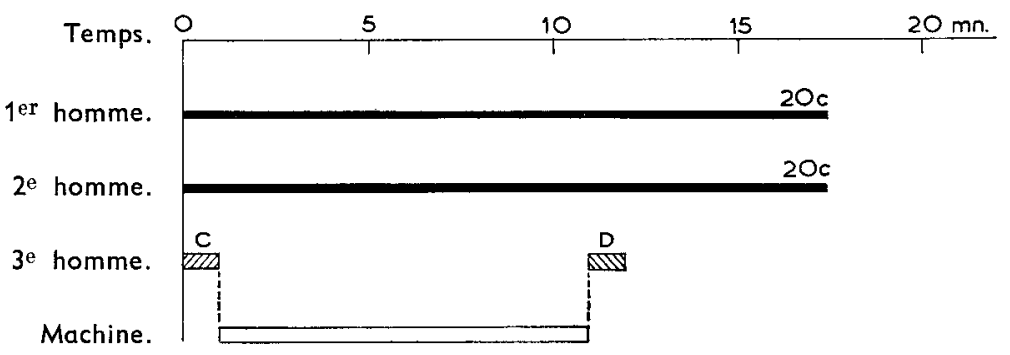

FIG. 3. - Trois hommes

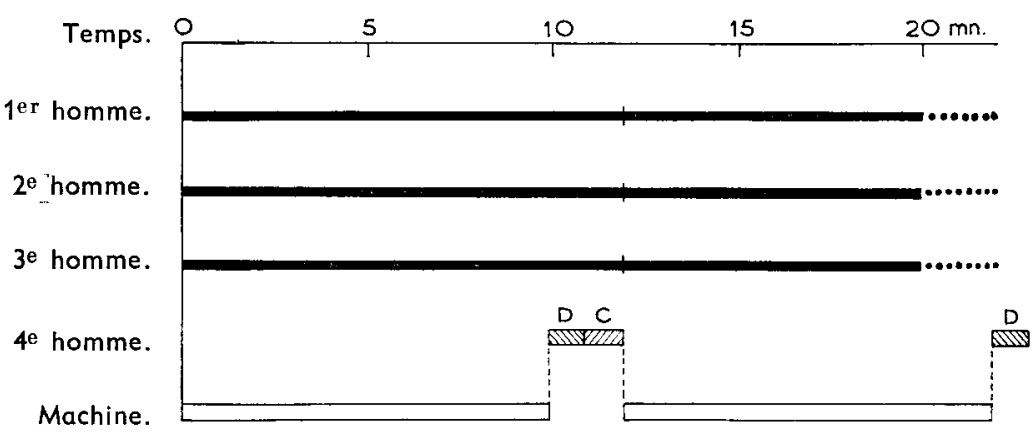

FIG. 4. - Quatre hommes

$c$ cadres désoperculés, $C$ chargement extracteur, $D$ déchargement extracteur, $C_{1} C_{2} D_{1} D_{2}$ chargement et déchargement avec 2 extracteurs, Trait plein : enlèvement des opercules, Trait double : extraction machine, Traits hachurés : chargement et déchargement extracteur. 
Par contre, dans les entreprises importantes traitant une quantité journalière de miel atteignant 4 à 5 tonnes, il est intéressant d'envisager le cas de 4 ouvriers disposant de 2 extracteurs à axe horizontal. 'Trois ouvriers sont affectés à l'enlèvement des opercules et font 40 cadres en $7 \mathrm{mn}$, temps trop court pour servir un extracteur dont la durée du cycle de travail est de $12 \mathrm{mn}$. Il est alors nécessaire de disposer de deux centrifugeuses servies par un même ouvrier, la durée de la séquence de travail reste de $7 \mathrm{mn}$ et chaque centrifugeuse est chargée toutes les deux séquences, c'est-à-dire toutes les I4 mn, laissant ainsi un battement de 2 mn entre le déchargement des hausses vides et le chargement des hausses pleines.

Dans ce cas le nombre de séquences journalières est de 60 et la durée du temps disponible pour exécuter les opérations accessoires est de I $\mathrm{h}$ pour chaque ouvrier qui désopercule et de $5 \mathrm{~h} 40 \mathrm{mn}$ pour l'ouvrier affecté aux centrifugeuses.

$3^{\circ}$ Solution de la machine à désoperculer.

$I^{\text {er }}$ cas : un homme travaille seul (fig. I, tabl. Io).

Le nombre de séquences journalières est de Io et le temps disponible pour les travaux accessoires de $\mathrm{I}$ h $30 \mathrm{mn}$.

2e cas : deux hommes (fig. 2, tabl. Io).

Il est alors nécessaire de disposer de deux machines à désoperculer. Le nombre de séquences de travail est de 22 par jour et le temps total disponible pour les deux ouvriers de I h $20 \mathrm{mn}$.

3e cas : trois hommes (fig. 3, tabl. ro).

Deux hommes désoperculent avec chacun une machine, le troisième est affecté à la centrifugeuse. Le nombre de séquences journalières est de 26 avec un temps disponible de $50 \mathrm{mn}$ pour les désoperculeurs et de $428 \mathrm{mn}$ pour l'extracteur soit au total $478 \mathrm{mn}$ ou $7 \mathrm{~h} 58 \mathrm{mn}$.

4 e cas : quatre hommes (fig. 4, tabl. Io).

Dans ce cas, trois hommes sont employés à l'enlèvement des opercules et il leur faut I2 mn pour désoperculer les 40 cadres représentant la charge de la machine. Ce temps correspond à celui de la marche de la centrifugeuse, y compris les temps de chargement et de déchargement. Les temps de travail des deux postes : enlèvement des opercules et extraction étant parfaitement équilibrés, il suffit d'une seule machine.

Le nombre de séquences de travail est de 40 par jour. Les ouvriers qui désoperculent sont employés à plein temps à cette opération, par contre, l'ouvrier chargé de la centrifugeuse dispose de $400 \mathrm{mn}$ soit $6 \mathrm{~h} 40 \mathrm{mn}$ pour effectuer les opérations de manutention et de nettoyage.

\section{I). Résultats comparés}

\section{a) Rendement brut du travail.}

Pour comparer le travail obtenu avec les différents moyens et les différentes méthodes d'organisation, on a calculé le nombre de cadres traités au cours d'une journée de travail. Les cadres ayant une charge de miel variable, celle-ci a été classée en quatre catégories allant de $I, 5 \mathrm{~kg}$ à $3 \mathrm{~kg}$ par cadre de moyenne de poids. La 
moyenne de $3 \mathrm{~kg}$ est exceptionnelle, elle permet d'aboutir à des chiffres qui doivent être considérés comme purement théoriques à l'heure actuelle.

Le tableau II résume les calculs obtenus classés par effectifs de personnel, par méthodes d'enlèvement des opercules et par extracteurs utilisés.

TABLEAU II

Travail journalier avec les divers cas d'organisatian du travail

\begin{tabular}{|c|c|c|c|c|c|c|c|c|c|}
\hline \multicolumn{2}{|c|}{ Personnel } & \multicolumn{2}{|c|}{ Matériel } & \multicolumn{2}{|c|}{ Nombre de } & \multicolumn{4}{|c|}{ Poids de miel extrait avec cadres } \\
\hline Désop. & Extr. & Désop. & Extr. & Séqu. & cadres & 1,5 & 2 & 2,5 & 3 \\
\hline 1 & & O & V & 14 & 504 & 756 & 1008 & 1260 & 1512 \\
\hline 1 & 1 & 0 & V & 26 & 936 & 1404 & 1872 & 2340 & 2808 \\
\hline 2 & 1 & 0 & $2 \mathrm{~V}$ & 40 & 1440 & 2160 & 2880 & 3600 & 4320 \\
\hline 1 & & $\mathrm{E}$ & V & 14 & $50^{\prime}$ & 756 & 1008 & 1260 & 1512 \\
\hline 1 & 1 & E & V & 30 & 1080 & 1620 & 2160 & 2700 & 3240 \\
\hline 2 & 1 & $\mathrm{E}$ & $2 \mathrm{~V}$ & 50 & 1800 & 2700 & 3600 & 4500 & 5400 \\
\hline 1 & & M & V & 10 & 360 & 540 & 720 & 900 & 1080 \\
\hline 1 & 1 & $2 \mathrm{M}$ & V & 22 & 792 & 1188 & 1584 & 1980 & 2376 \\
\hline 2 & 1 & $2 \mathrm{M}$ & V & 30 & 1080 & 1620 & 2160 & 2700 & $32 \% 0$ \\
\hline 1 & & 0 & $\mathrm{H}$ & 14 & 560 & 840 & 1120 & 1400 & 1680 \\
\hline 1 & 1 & O & H & 30 & 1200 & 1800 & 2400 & 3000 & 3600 \\
\hline 2 & 1 & 0 & $\mathrm{H}$ & 36 & 1440 & 2160 & 2880 & 3600 & 4320 \\
\hline 1 & & $\mathrm{E}$ & $\mathrm{H}$ & 16 & $6\{0$ & 960 & 1280 & 1600 & 1920 \\
\hline 1 & 1 & $\mathrm{E}$ & $\mathrm{H}$ & 34 & 1360 & 2040 & 2720 & 3400 & 4080 \\
\hline 3 & 1 & $\mathrm{E}$ & $2 \mathrm{H}$ & 60 & 2400 & 3600 & 4800 & 6000 & 7200 \\
\hline 1 & & M & HI & 10 & 400 & 600 & 800 & 1000 & 1200 \\
\hline 1 & 1 & $2 \mathrm{M}$ & $\mathrm{H}$ & 22 & 880 & 1320 & 1760 & 2200 & 2640 \\
\hline 2 & 1 & $2 \mathrm{M}$ & $\mathrm{H}$ & 26 & 1040 & 1560 & 2080 & 2600 & 3120 \\
\hline 3 & 1 & $3 \mathrm{M}$ & $\mathrm{H}$ & 40 & 1600 & 2400 & 3200 & 4000 & 4800 \\
\hline
\end{tabular}

O couteau ordinaire, $\mathbf{E}$ couteau électrique, $\mathrm{M}$ machine à désoperculer, $\mathrm{V}$ extracteur à axe vertical, $\mathrm{H}$ extracteur à axe horizontal

Le graphique de la figure $\mathbf{I} 3$ représente les quantités journalières de miel extraites avec l'extracteur à axe vertical et les différents outils d'enlèvement des opercules.

On remarque que le rendement le plus élevé est obtenu avec 3 hommes, le couteau électrique et deux extracteurs, cette organisation permet d'extraire 2700 à $4500 \mathrm{~kg}$ de miel avec des cadres chargés de $\mathrm{I}, 5$ à $2,5 \mathrm{~kg}$ en moyenne.

On remarque sur ce tableau la différence importante entre les rendements obtenus avec la machine à désoperculer et les couteaux électrique et ordinaire.

Le graphique de la figure I4 se rapporte aux rendements journaliers de miel extrait en utilisant l'extracteur à axe horizontal.

Ici le meilleur rendement : 3600 à $6000 \mathrm{~kg}$ de miel extrait est obtenu avec 4 hommes, le couteau électrique et deux extracteurs.

L'examen du tableau et des deux graphiques montre que dans tous les cas avec un même nombre d'ouvriers et les mêmes outils d'enlèvement le rendement du travail est toujours plus élevé lorsqu'on utilise l'extracteur à axe horizontal. 
b) Productivité du matériel (1) :

Les différentes méthodes d'organisation ne permettent pas un emploi identique du personnel et du matériel dans le temps.

Le tableau I 2 indique pour chaque cas le pourcentage d'utilisation du personnel

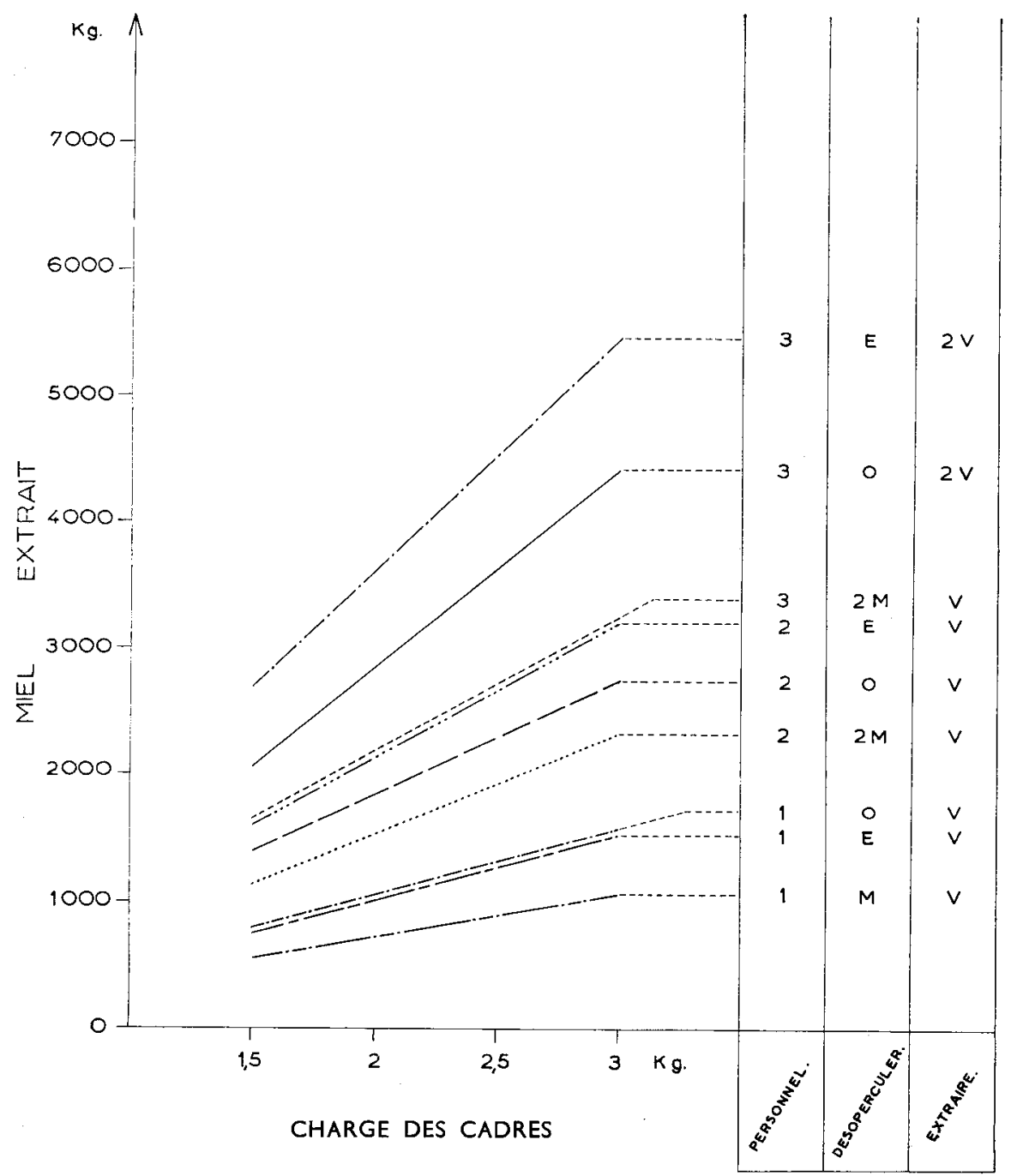

FIG. 13. - Quantités journalières de miel extraites avec l'extracteur à axe vertical (Même légende que celle du tabl. II)

aux postes d'enlèvement des opercules et d'extraction et du matériel d'extraction.

Il est normal que les extracteurs sont les plus mal employés lorsqu'un homme. travaille seul, celui-ci partageant son temps entre les opérations d'enlèvement des opercules et la centrifugation. Par contre, les meilleurs rendements-machine sont

(1) La productivité exprime la production par unité de facteurs. 
obtenus lorsque deux ou trois personnes sont employées à désoperculer, en effet dans ce cas, on constate que le temps d'attente des machines est réduit aut minimum.

I1 est intéressant de constater que la méthode qui donne le meilleur rendement machine avec le minimum de personnel est celle qui comporte l'emploi de 2.ouvriers, le couteau électrique à désoperculer et l'extracteur à axe vertical.

Le rendement-machine est alors de Ioo p. Ioo.

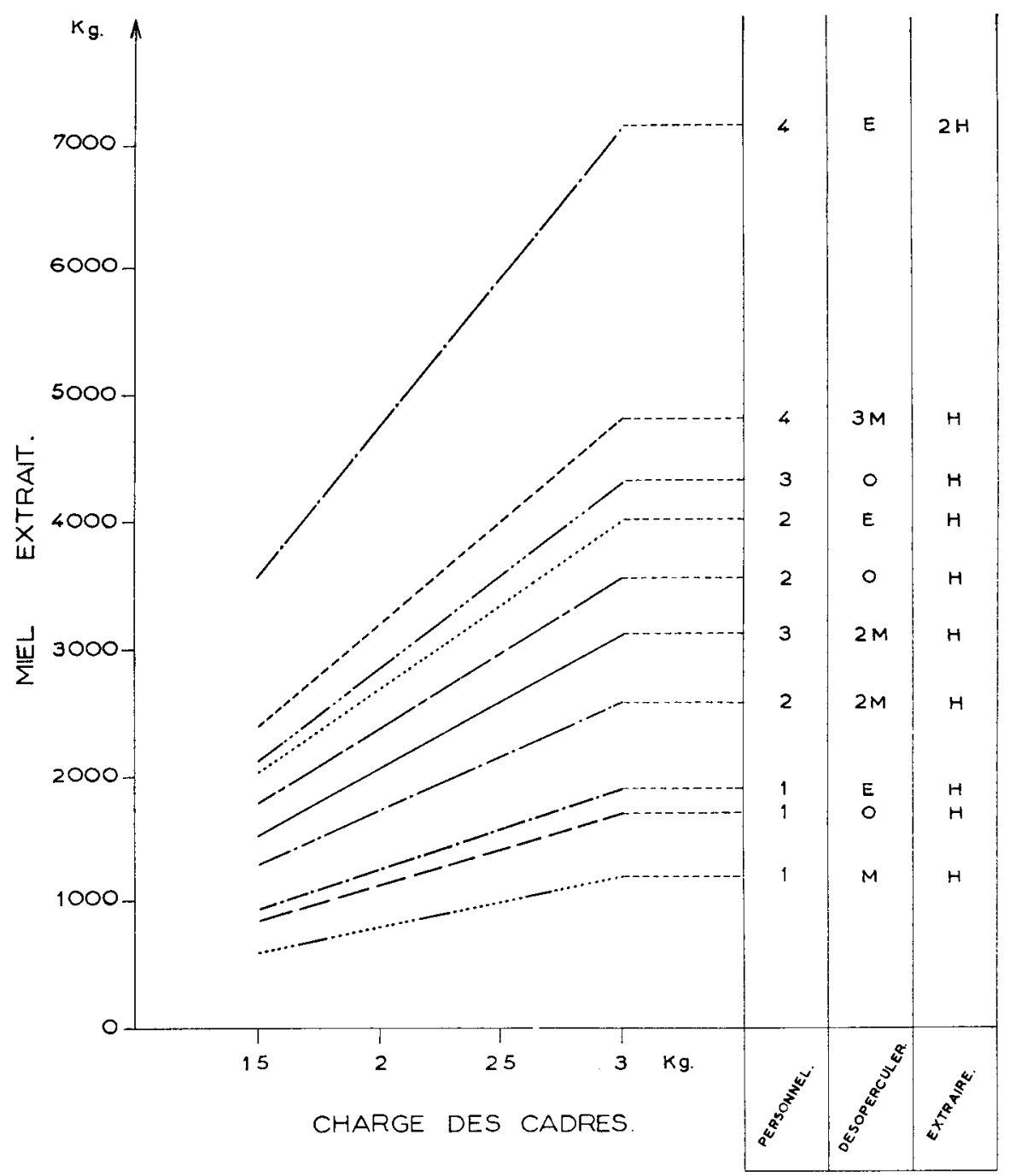

FIG. I4. -- Quantilés journalières de miel extraites avec l'extracteur à axe horizontal (Même légende que celle du tabl. I I)

c) Productivité du personnel.

Le tableau 13 indique le nombre moyen de cadres traités et les quantités de miel extraites, compte tenu de la charge des cadres, par personne suivant les différentes méthodes d'organisation. 
La meilleure productivité est obtenue avec deux hommes désoperculant au couteau électrique et utilisant un extracteur à axe horizontal. Dans ce cas un homme traite en moyenne 680 cadres par jour et extrait de I 020 à I $700 \mathrm{~kg}$ de miel suivant la charge normale des cadres.

Nous avons affecté le coefficient roo au rendement de cette méthode et les autres ont été classées par rapport à ce coefficient de référence.

La deuxième méthode qui s'avère la plus avantageuse au point de vue de la productivité est celle obtenue avec un seul homme travaillant au couteau électrique à désoperculer et avec un extracteur à axe horizontal.

I,e graphique de la figure i5 représente le classement des différentes méthodes d'organisation du travail en prenant la meilleure comme référence roo.

TABIEAU I2

Rendement du travail hommes et machines

\begin{tabular}{|c|c|c|c|c|c|c|c|}
\hline \multicolumn{2}{|c|}{ Personnel } & \multicolumn{2}{|c|}{ Matéricl } & \multirow{3}{*}{$\begin{array}{l}\text { Séquences } \\
\text { par jour }\end{array}$} & \multicolumn{3}{|c|}{ Temps travail \% } \\
\hline \multirow[b]{2}{*}{ désop. } & \multirow[b]{2}{*}{ extr. } & \multirow[b]{2}{*}{ désop. } & \multirow[b]{2}{*}{ extr. } & & \multirow[b]{2}{*}{ mach. } & \multicolumn{2}{|c|}{ ouvrier } \\
\hline & & & & & & désop. & extr. \\
\hline 1 & & 0 & V & 14 & 46,7 & 92,3 & \\
\hline 1 & 1 & 0 & V & 26 & 86,6 & 86,6 & 76 \\
\hline 2 & 1 & 0 & $2 \mathrm{~V}$ & 40 & 66,7 & 95,8 & 50 \\
\hline 1 & & $\mathrm{E}$ & V & 14 & 46,7 & 78,7 & \\
\hline 1 & 1 & F & V & 30 & 100 & 100 & 56,2 \\
\hline 2 & 1 & $\mathrm{E}$ & $2 \mathrm{~V}$ & 50 & 83,3 & 99 & 62,5 \\
\hline 1 & & M & $\mathrm{V}$ & 10 & 33,3 & 83,3 & \\
\hline 1 & 1 & $2 \mathrm{M}$ & V & 22 & 73,3 & 91,7 & 82,5 \\
\hline 2 & 1 & $2 \mathrm{M}$ & V & 30 & 100 & 100 & 37,5 \\
\hline 1 & & 0 & $\mathrm{H}$ & 1'; & 35 & 87,5 & \\
\hline 1 & 1 & 0 & H & 30 & 75 & 93,7 & 81,3 \\
\hline 2 & 1 & 0 & H & 36 & 90 & 97,5 & 15 \\
\hline 1 & & E & H & 16 & 40 & 83,3 & \\
\hline 1 & 1 & $\mathrm{E}$ & $\mathrm{H}$ & $3^{\prime}$ & 85 & 92,1 & 70,8 \\
\hline 3 & 1 & E & 2 II & 60 & 75 & 87,5 & 25 \\
\hline 1 & & M & $\mathrm{H}$ & 10 & 25 & 79,1 & \\
\hline 1 & 1 & $2 \mathrm{MI}$ & II & 22 & 55 & 91,7 & 77,9 \\
\hline 2 & 1 & $2 \mathrm{M}$ & II & 26 & 65 & 94,7 & 10,8 \\
\hline 3 & 1 & $3 \mathrm{M}$ & $\mathrm{H}$ & 40 & 100 & 100 & 16,7 \\
\hline
\end{tabular}

Nous remarquons sur ce graphique que les quatre meilleures méthodes sont obtenues avec l'extracteur horizontal.

Les rendements moyens sont obtenus avec l'emploi du couteau ordinaire à desoperculer et l'extracteur à axe vertical.

Enfin les rendements les plus faibles sont obtenus avec l'emploi de la machine à désoperculer occupant les sept dernières places du classement avec des rendements variant de 50,88 à 64,70 par rapport à la meilleure méthode de référence Ioo.

Il est naturellement nécessaire dans le choix d'un matériel de ne pas tenir compte uniquement des avantages techniques qu'il présente, mais également des

Annales de l'Abeille. - 1965. 


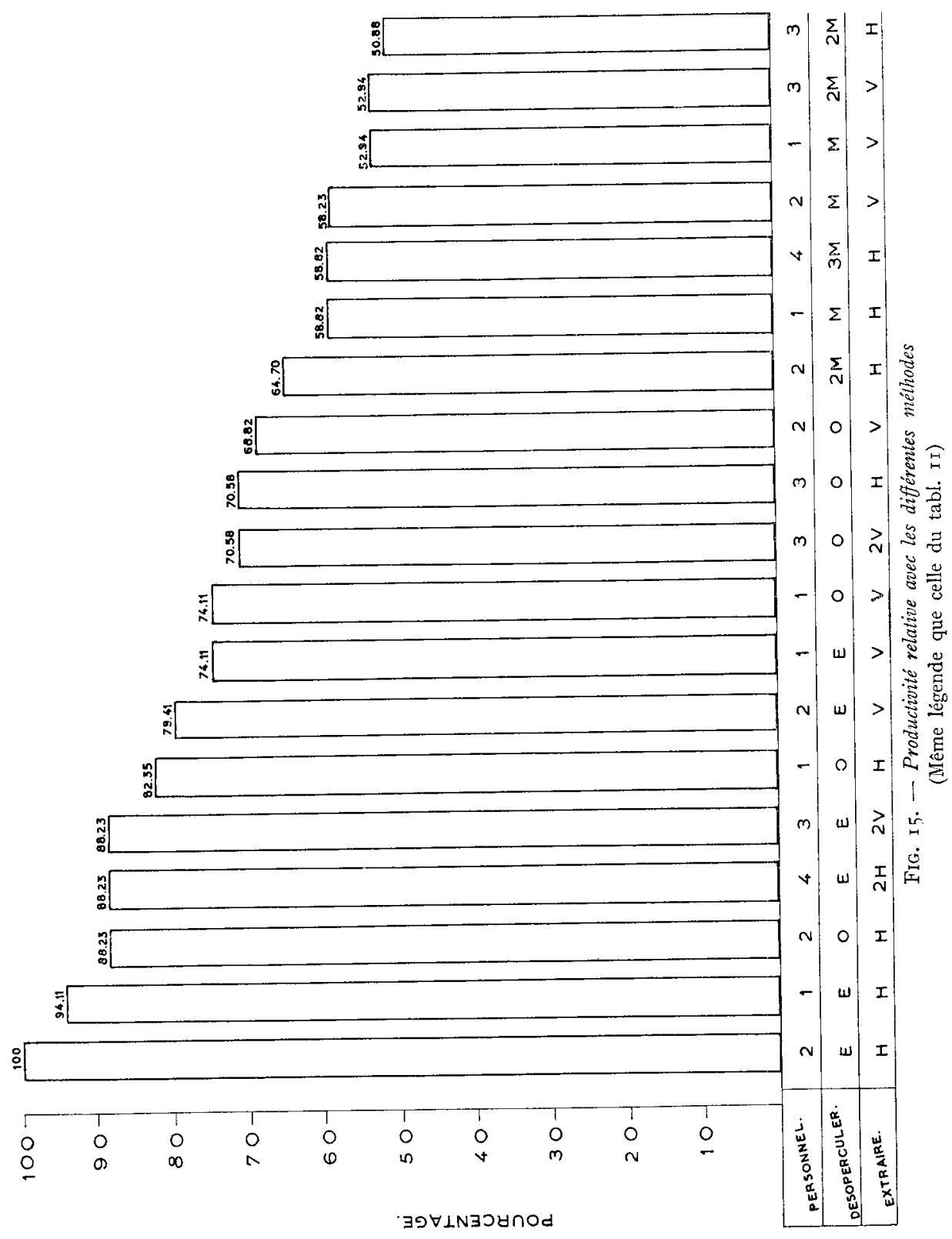


facteurs économiques d'acquisition et d'emploi : investissement, prix de revient, etc. Dans le cas étudié, il est difficile de procéder à une telle comparaison, l'extracteur à axe horizontal n'étant pas actuellement construit en série, comme l'est l'extracteur à axe vertical.

\section{TABLEAU I 3}

Produclivité du travail humain

Nombre de cadres et poids de miel exirait par homme et par jour

\begin{tabular}{|c|c|c|c|c|c|c|c|c|c|}
\hline \multicolumn{2}{|c|}{ Personnel } & \multicolumn{2}{|c|}{ Matc̈riel } & \multirow{2}{*}{$\begin{array}{l}\text { Sombre } \\
\text { de } \\
\text { cadres }\end{array}$} & \multicolumn{4}{|c|}{ Poids de miel extrait avec cadres } & \multirow{2}{*}{$\begin{array}{c}\text { Rapport } \\
100\left({ }^{1}\right)\end{array}$} \\
\hline Désop. & Extrait & Désop. & Extrait & & $1,5 \mathrm{~kg}$ & $2 \mathrm{~kg}$ & $2,5 \mathrm{~kg}$ & $3 \mathrm{kgr}$ & \\
\hline 1 & & 0 & V & $50 / 4$ & 756 & 1008 & 1260 & 1512 & $7 !, 11$ \\
\hline 1 & 1 & 0 & V & 468 & 702 & 936 & 1170 & 1404 & 68,82 \\
\hline 2 & 1 & 0 & $2 \mathrm{~V}$ & 480 & 720 & 960 & 1200 & 1410 & $70, ; 8$ \\
\hline 1 & & $\mathrm{E}$ & $\mathrm{V}$ & $50 \%$ & 750 & 1008 & 1260 & 1512 & 74,11 \\
\hline 1 & 1 & E & V & $\left.5^{\prime} \mathbf{1}\right)$ & 810 & 1080 & $1: 500$ & 1620 & 79,11 \\
\hline 2 & 1 & IE & $2 \mathrm{~V}$ & 600 & 900 & 1200 & 1500 & 1800 & 88,23 \\
\hline 1 & & M & V & 360 & $5: 0$ & 720 & 900 & 1080 & $5:, 94$ \\
\hline 1 & 1 & M & V & 396 & $59^{\prime}$ & 792 & 990 & 1188 & 58,23 \\
\hline 2 & 1 & $2 \mathrm{M}$ & $\mathrm{V}$ & 360 & $5^{\prime} 0$ & $7: 0$ & 900 & 1080 & $52,9 '$ \\
\hline 1 & & 0 & $\mathrm{H}$ & 560 & $8: 0$ & 1120 & 1400 & 1680 & 82,35 \\
\hline 1 & 1 & 0 & $\mathrm{H}$ & 600 & 900 & 1200 & 1500 & 1. 800 & 88,23 \\
\hline 2 & 1 & 0 & H & 480 & 720 & 960 & 1200 & $1\}_{1}^{\prime} 0$ & 70,58 \\
\hline 1 & & $\mathrm{E}$ & HI & 640 & 960 & 1280 & 1600 & 1920 & 94,11 \\
\hline 1 & 1 & $\mathrm{~F}$ & $\mathrm{H}$ & 680 & 1020 & 1360 & 1700 & 2040 & 100 \\
\hline 3 & 1 & $\mathrm{E}$ & $2 \mathrm{II}$ & 600 & 900 & 1200 & 1500 & 1800 & 88,23 \\
\hline 1 & & $M$ & $\mathrm{H}$ & 400 & 600 & 800 & 1000 & 1200 & 58,82 \\
\hline 1 & 1 & M & $\mathrm{H}$ & 440 & 660 & 880 & 1100 & 1320 & $63^{\prime}, 70$ \\
\hline 2 & 1 & $2 \mathrm{M}$ & II & $3 \div 6$ & 519 & 792 & 865 & 1038 & 50,88 \\
\hline 3 & 1 & $3 \mathrm{M}$ & $\mathrm{H}$ & 400 & 600 & 800 & 1000 & 1200 & 58,82 \\
\hline
\end{tabular}

O couteau ordinaire, E couteau électriqü, II machine à désoperculer, V extracteur à axe vertical, II extracteur à axe horizontal.

(1) Indice par rapport à 100 pour la méthode la plus rapide.

\section{IV. - AMÉNAGEMENT DES LOCAUX}

Ie rendement qualitatif et quantitatif d'un travail dépend de trois facteurs : le personnel, l'organisation adoptée et l'aménagement des locaux. Nous n'aborderons pas le premier facteur : le personnel. Il sera intéressant dans une étude spéciale de considérer les problèmes qu'il pose : sélection, formation, intéressement et sécurité de la main-d'œuvre en apiculture.

L'aménagement du magasin de stockage des hausses pleines et vides a été traité au premier chapitre concernant le problème du stockage.

L'installation de la miellerie oì se déroulent des opérations de déplacements, de manipulations et de transports de hausses et la mise en ceuvre de matériels divers, exige une étude particulière afin qu'elle réponde à des principes rationnels. 
A. Principes de l'aménayement

Nous retiendrons quatre principes fondamentaux dans l'aménagement de la miellerie.

Io Réduction des déplacements.

Les hausses et les cadres devant être fréquemment manipulés au cours du travail, il est nécessaire d'envisager des circuits aussi courts que possible entre les emplacements de stockage ou d'attente et les postes de travail et de disposer d'un matériel permettant de réduire le nombre des opérations de transport.

$2^{\circ}$ Faciliter les manutentions.

I,e matériel de transport doit pouvoir circuler facilement d'un lieu à un autre sans gêner les autres travaux et sans provoquer d'encombrement. Il faut donc prévoir des dimensions de voies de circulation suffisantes et établir un circuit évitant les croisements et les retours en arrière du matériel.

$3^{\circ}$ Économie de place.

L'aménagement des postes de travail doit être réalisé avec un souci d'économie de place, tout en envisageant des possibilités éventuelles d'extension sans avoir à apporter d'importantes modifications dans l'aménagement initial.

$4^{\circ}$ Faciliter le travail.

Le personnel doit travailler avec le maximum d'aisance et de confort en évitant en particulier les inconvénients résultant d'une position pénible du corps pendant le travail et en supprimant les opérations ou les gestes susceptibles d'engendrer une fatigue anormale.

\section{B. Analyse du travail}

En vue de réaliser une implantation fonctionnelle des postes de travail, il est nécessaire de définir la nature de ces postes et le déroulement chronologique des opérations dont ils sont le siège.

Deux cas doivent être envisagés suivant la nature du matériel d'extraction utilisé.

a) Cas de l'extracteur à axe horizontal.

Le diagramme de la figure 16 représente le déroulement du travail lorsqu'on utilise l'extracteur à axe horizontal.

Trois postes sont prévus :

- le magasin de stockage des hausses avant et après extraction;

- le poste d'enlèvement des opercules où les hausses sont vidées, les cadres désoperculés et les hausses remplies de cadres désoperculés ; pompé.

- le poste d'extraction oì les hausses sont centrifugées, le miel extrait et

On remarque sur le diagramme quatre opérations de déplacement des hausses et une opération d'attente entre le poste d'enlèvement des opercules et l'extracteur. 
b) Cas de l'extracteur à axe vertical.

Ici le travail est un pet1 plus compliqué (voir fig. I7), car on observe sur le graphique deux matériels manipulés : les hausses et les cadres que l'on sépare au moment de l'enlèvement des opercules et que l'on réunit après l'extraction.

Nous retrouvons les trois mêmes postes que dans le premier cas.

Ici les hausses sont déplacées trois fois et les cadres ne sont manutentionnés que sur de très courtes distances. Par contre on observe trois attentes: deux pour les hausses, avant enlèvement des opercules et entre cette opération et l'extraction: et une attente des cadres pleins sur le tourniquet avant l'extraction.

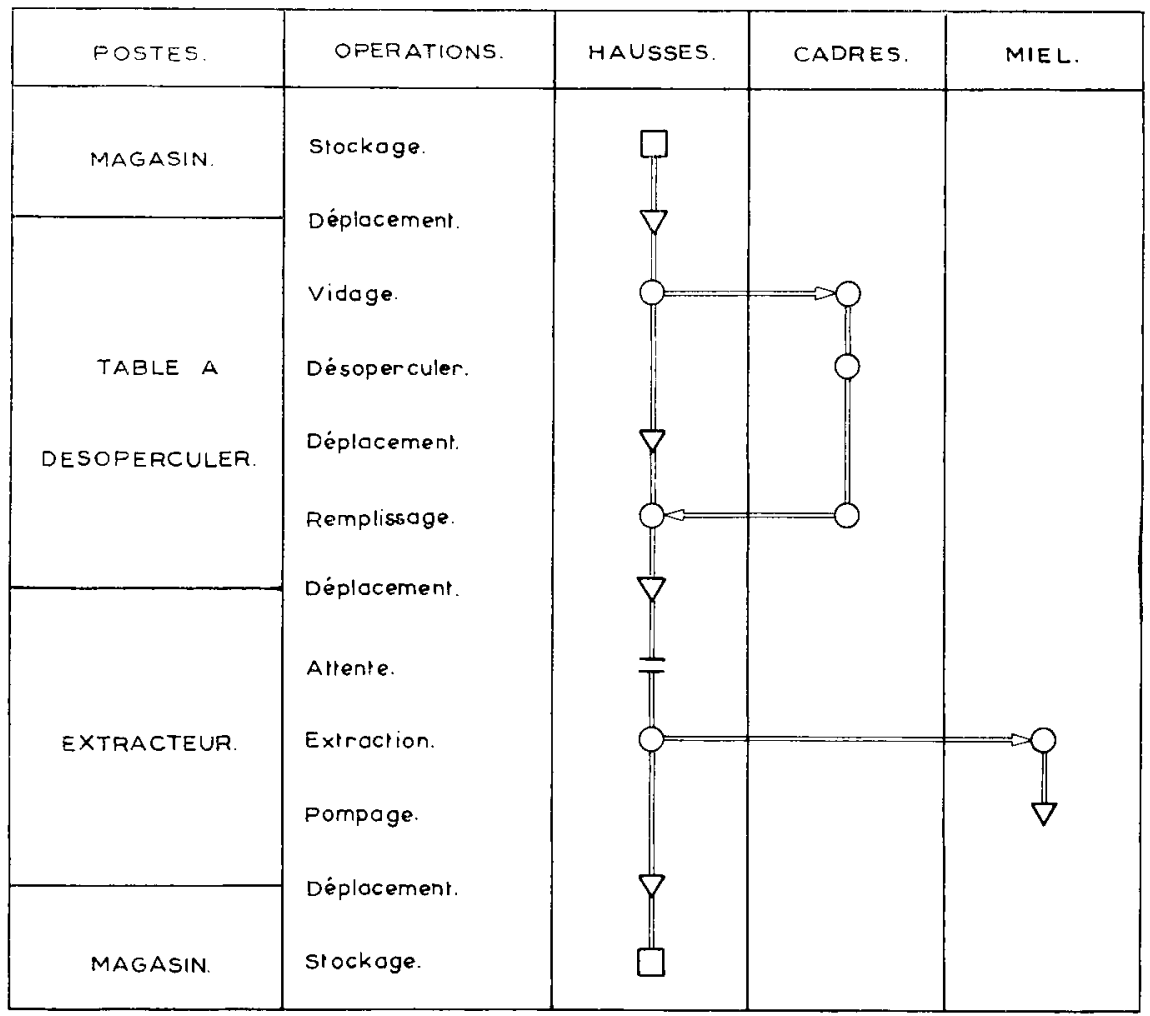

\section{Stockage $\nabla$ Déplacement $\bigcirc$ Opérations $=$ Attente}

FIG. 16. -- Diagramme du travail avec exiracteur à axe horizontal

Une opération supplémentaire doit être exécutée dans ce cas : le garnissage des hausses vides à l'aide des cadres vides sortant de l'extracteur.

Compte tenu de cette analyse du déroulement du travail, les postes doivent être implantés en ligne ou en $U$ suivant que le stockage des hausses pleines et des hausses vides se fait dans un même local ou dans des locaux distincts.

On remarque sur les figures I8 et Ig que dans tous les cas les déplacements sont réduits au minimum par suite du rapprochement des postes complémentaires, 
c'est-à-dire les lieux de stockage ou d'attente du bac d'enlèvement des opercules ou de l'extracteur. De plus, dans les quatre cas, le travail se déroule dans l'espace suivant l'ordre chronologique des opérations, sans retour en arrière.

Les deux méthodes proposées d'implantation en ligne et en U pour chaque type de matériel répondent bien aux principes énoncés ci-dessus.

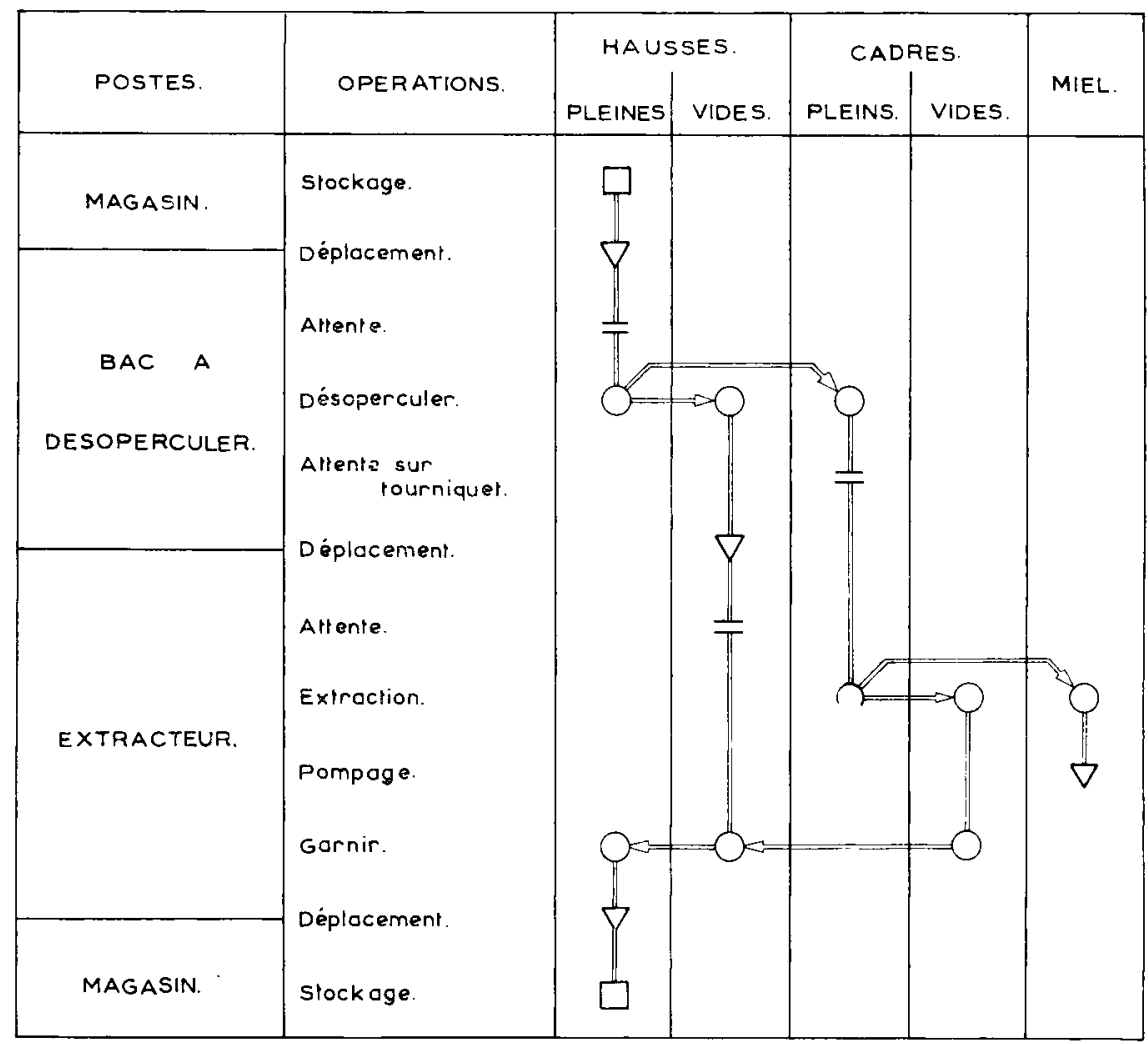

Stockage $\nabla$ Déplacement $\bigcirc$ Opérations $=$ Attente

FIg. 17. - Diagramme du travail avec extracteur à axe vertical

\section{Calcul des dimensions}

L a surface et les dimensions à donner à la miellerie dépendent :

de la surface brute d'encombrement du matériel;

de la disposition des postes en ligne ou en $U$;

de l'importance des zones de circulation et de manutention.

a) Surfaces brutes d'encombrement.

Le tableau I4 indique pour le matériel susceptible d'être utilisé dans une ins. tallation de miellerie les dimensions et les surfaces brutes d'encombrement. 


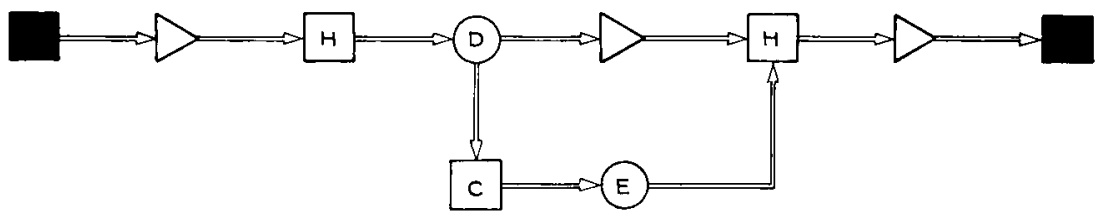

IMPLANTATION EN LIGNE

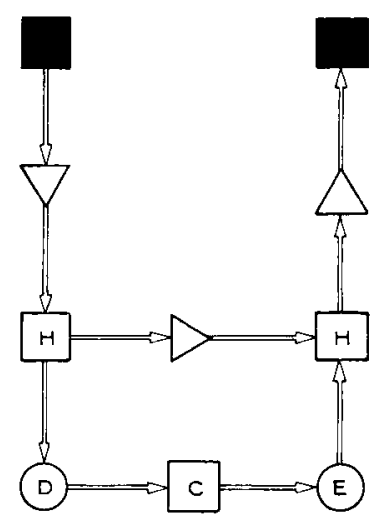

IMPLANTATION EN U.

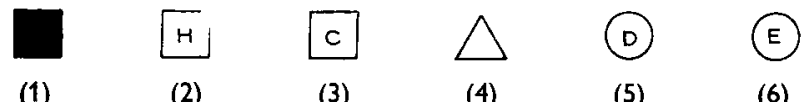

(1)

(2)

(3)

(5)

(6)

I : Stockage, 2: Hausses, 3 : Cadres, 4 : Déplacement, 5 : Désoperculer, 6 : Extraire

FIG. 18. - Implantation des postes avec extracteur a axe vertical

TABLEAU I4

Normes dimensionnelles du matériel

\begin{tabular}{|c|c|c|c|c|}
\hline Matériel & $\begin{array}{c}\text { Iong. } \\
\text { (cm) }\end{array}$ & $\begin{array}{l}\text { Jarg. } \\
(\mathrm{cm})\end{array}$ & $\begin{array}{c}\text { Haut. } \\
(\mathrm{cm})\end{array}$ & $\begin{array}{c}\text { Surface } \\
\left(\mathrm{m}^{2}\right)\end{array}$ \\
\hline Hausse & 50,2 & 42,8 & 17 & \\
\hline Petite palette vide . . . . . . . & 85 & 65 & 20 & 0,55 \\
\hline Petite jalette +18 hausses ... & 85 & 65 & 173 & 0,55 \\
\hline Grande palette vide $\ldots . \ldots \ldots$ & 102 & 102 & 15 & 1,04 \\
\hline Grande palette $+28 \mathrm{~h}$. pleines.. & 102 & 102 & 134 & 1,04 \\
\hline Grande palette $+36 \mathrm{~h}$. vides... & 102 & 102 & 168 & 1,04 \\
\hline Tablette mobile ........... & 55 & 47,5 & 70 & \\
\hline Table à désoperculer ......... & 180 & 80 & 78 & \\
\hline Bac à désoperculer ........... & 115 & 100 & 80 & \\
\hline Extracteur axe horizontal ...... & 140 & 120 & 110 & 1,68 \\
\hline Extracteur axe vertical ....... & 92 & 92 & 146 & 0,66 \\
\hline
\end{tabular}


b) Surfaces de circulation.

Pour permettre la station d'un ouvrier en face d'un matériel et permettre la circulation d'une personne il faut prévoir une largeur de passage de $\mathrm{I} \mathrm{m}$. Cette largeur permet également la circulation d'une tablette mobile qui ne mesure que $47,5 \mathrm{~cm}$ de large.
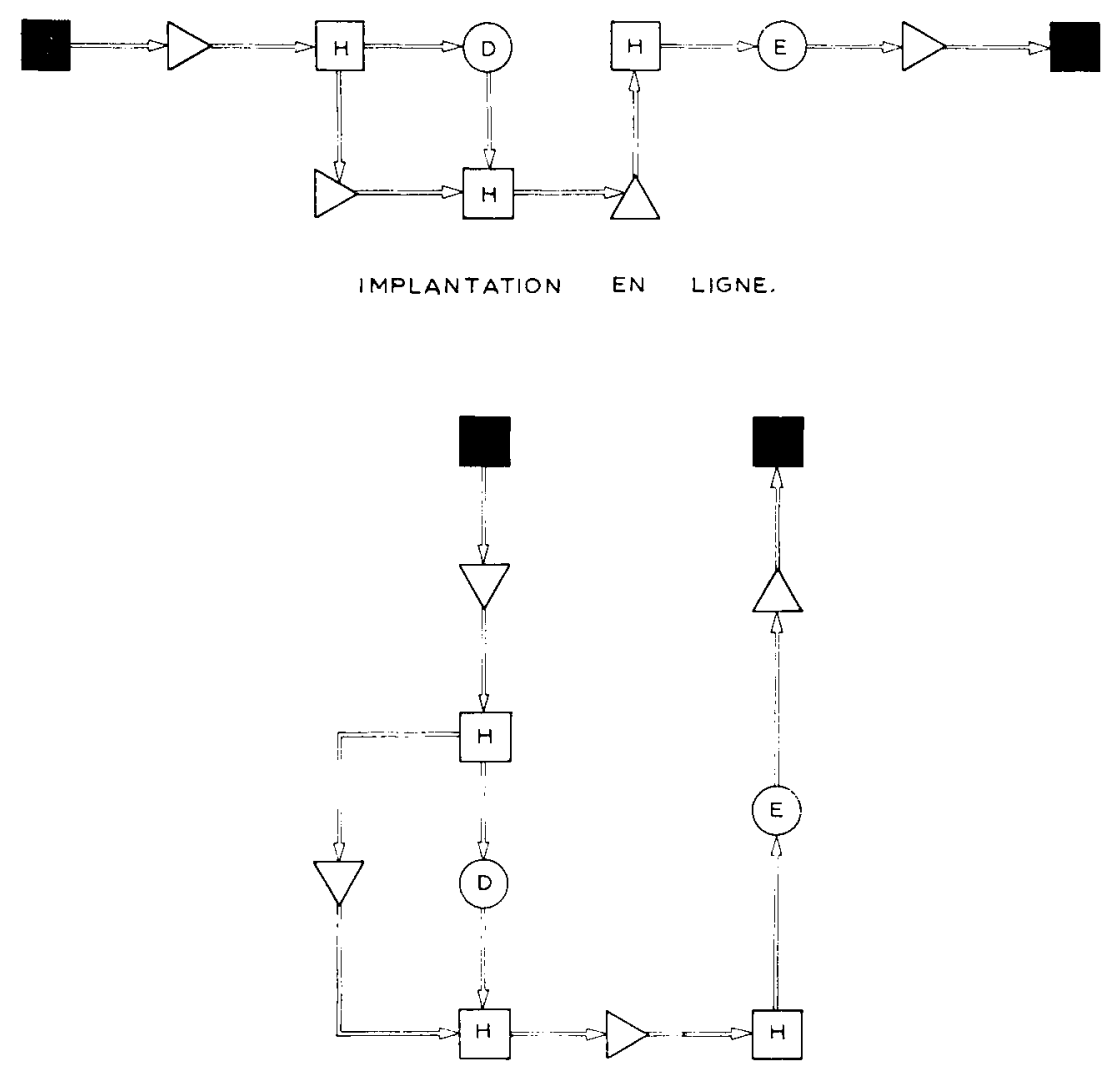

IMPLANTATION EN U.

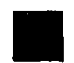

(1)

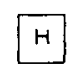

(2)

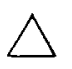

(3)

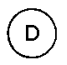

(4)

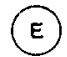

(5)

1: Stockage, 2: Hausses, 3: Déplacement, 4 : Désoperculer, 5 : Extraire

FIG. I9. - Implantation des postes avec extracteur à axe horizontal

I a manutention des petites palettes exige une largeur de circulation de $\mathrm{I}, 50 \mathrm{~m}$ et les grandes palettes déplacées à l'aide d'un transrouleur-élévateur nécessitent une voie de circulation de $2,50 \mathrm{~m}$ de large lorsqu'il n'y a pas de manouvres ni de virages à effectuer et $3 \mathrm{~m}$ dans le cas contraire. 


\section{1). Implantation du matériel}

a) Ateliers équipés d'extracteurs à axe vertical.

Quelle que soit la méthode d'enlèvement des opercules, c'est-à-dire indépendamment du matériel utilisé à cette opération, le travail peut être exécuté avec le personnel suivant :

- un homme travaillant seul alternativement au poste d'enlèvement des opercules et à l'extracteur ;

- un homme à désoperculer, un honıme à l'extracteur ;

- deux hommes à désoperculer, un homme servant un ou deux extracteurs.

Au point de vue de la manutention des hausses et des cadres, la meilleure organisation consiste à utiliser :

- des grandes palettes pour approcher les hausses du poste d'enlèvement des opercules ;

- un tourniquet pour stocker les cadres désoperculés entre le bac et le ou les extracteurs ;

- des petits chariots mobiles d'une capacité de 4 hausses pour le remplissage des hausses vides de cadres vides sortant de l'extracteur.

L'aménagement du matériel d'extraction et les dimensions du poste sont les mêmes suivant que les magasins de stockage des hausses pleines et des hausses vides sont disposés de part et d'autre du poste d'extraction (disposition en ligne) ou qu'ils se trouvent situés du même côté (disposition en U).

$1^{\text {er }}$ cas : travail effectué par un ou deux ouvriers.

Que le travail soit effectué avec un ouvrier travaillant seul ou avec deux personnes, le poste est aménagé suivant la disposition indiquée sur la figure 20 à gauche, le matériel est installé en lignes avec la palette supportant les hausses chargées de cadres pleins à une extrémité et en bout du bac à désoperculer. Entre le bac et l'extracteur, le tourniquet d'attente des cadres désoperculés, enfin à l'autre extrémité du poste le chariot mobile supportant les hausses vides à garnir de cadres vides sortant de l'extracteur.

Ce poste nécessite une allée de circulation de I $\mathrm{m}$ de large du côté des ouvriers et une allée de $60 \mathrm{~cm}$ de large du côté opposé.

La surface totale occupée par le matériel, le personnel et les allées de circulation est de $\mathrm{I0}, 40 \mathrm{~m}^{2}$ soit une longueur de $4 \mathrm{~m}$ et une largeur de 2,60 $\mathrm{m}$.

Entre ce poste d'extraction et le lieu de stockage des palettes chargées de hausses pleines ou vides, il est nécessaire de ménager un espace de $2,50 \mathrm{~m}$ de large pour effectuer les manœuvres de palettes.

$2^{e}$ cas : Trois hommes travaillant avec un ou deux extracteurs.

La disposition du poste est la même que dans le cas précédent mais les ouvriers chargés de l'enlèvement des opercules devant stationner de part et d'autre du bac à désoperculer et se servant à la même palette de hausses pleines, il est nécessaire de prévoir de chaque côté du poste une zone de passage de I m de large. La surface est alors de $\mathrm{I} 2 \mathrm{~m}^{2}$ soit une longueur de $4 \mathrm{~m}$ et une largeur de $3 \mathrm{~m}$ (fig. 20 à droite)

Lorsqu'on utilise deux extracteurs côte à côte, on dispose de part et d'autre des appareils d'une largeur de passage de $0,60 \mathrm{~m}$ suffisante pour la circulation du

Amales de l'Abeille. - 1965 . 
personnel et le passage des hausses vides qui se fait manuellement de la palette aux chariots mobiles.

Comme dans le cas précédent, il faut ménager entre le poste d'extraction et le magasin de stockage des palettes une zone de manœuvre de $2,50 \mathrm{~m}$ de largeur.

Dans une miellerie équipée d'un seul extracteur à axe vertical, il est nécessaire de prévoir une largeur de poste de $3 \mathrm{~m}$ ce qui permet de pouvoir éventuellement travailler avec trois hommes sans avoir à apporter de modification à l'aménagement du matériel.

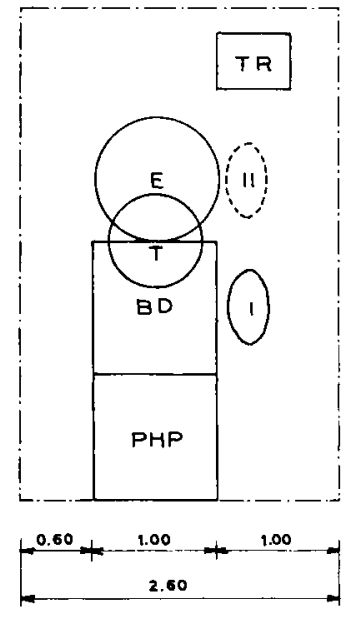

POSTE AVEC 1 OU 2 OUVRIERS.
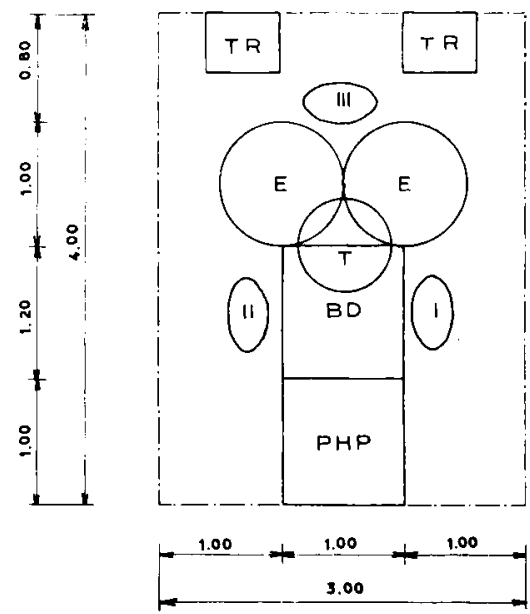

POSTE AVEC 3 OUVRIERS

ET 2 EXTRACTEURS.

FIG. 20. - Implantation avec extracteur d axe vertical

$\mathrm{BD}$ bac à désoperculer, $\mathrm{E}$ extracteur, PHP palette hausses pleines, $\mathrm{T}$ tourniquet d'attente, TR transporteur, I II III opérateurs

b) Ateliers équipés d'extracteurs à axe horizontal.

Dans ces ateliers, il est nécessaire d'utiliser au poste d'enlèvement des opercules des palettes supportant les hausses avant enlèvement des opercules et des chariots roulants pour recevoir et manutentionner les hausses chargées de cadres désoperculés.

L'organisation dépend du nombre d'ouvriers et de la méthode d'enlèvement des opercules, cinq cas doivent être envisagés :

Io un ouvrier travaille seul alternativement à l'enlèvement des opercules et à l'extracteur ;

$2^{0}$ deux hommes travaillent ensemble aux deux postes;

$3^{0}$ trois ouvriers : deux à l'enlèvement des opercules et un à l'extracteur ;

$4^{0}$ quatre ouvriers : trois à l'enlèvement des opercules avec le couteau ordinaire ou la machine à désoperculer et un homme à l'extracteur ;

$5^{\circ}$ quatre ouvriers : trois à l'enlèvement des opercules au couteau électrique et un homme servant deux extracteurs. 
$1^{\text {er }}$ cas : un ouvrier travaille seul.

La figure $2 \mathrm{I}$ en haut, représente l'implantation du poste qui exige une surface de $\mathrm{II}, 76 \mathrm{~m}^{2}$ avec une longueur de 4,20 m et une largeur de $2,80 \mathrm{~m}$. La zone de circulation occupe un côté du poste permettant la manutention des chariots roulants et le chargement de l'extracteur.

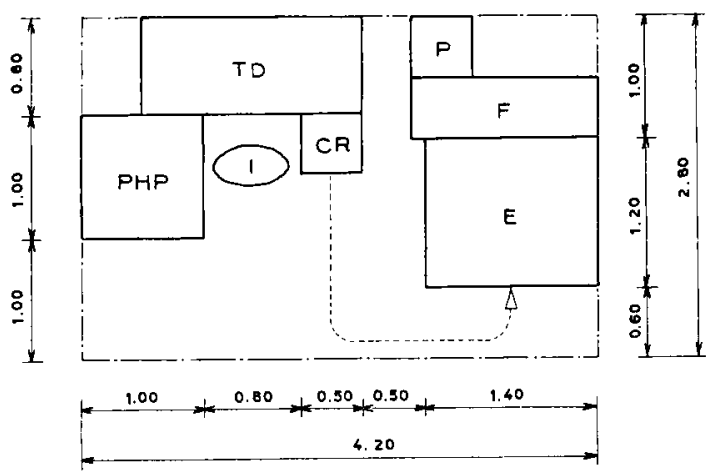

POSTE AVEC 1 OUVRIER

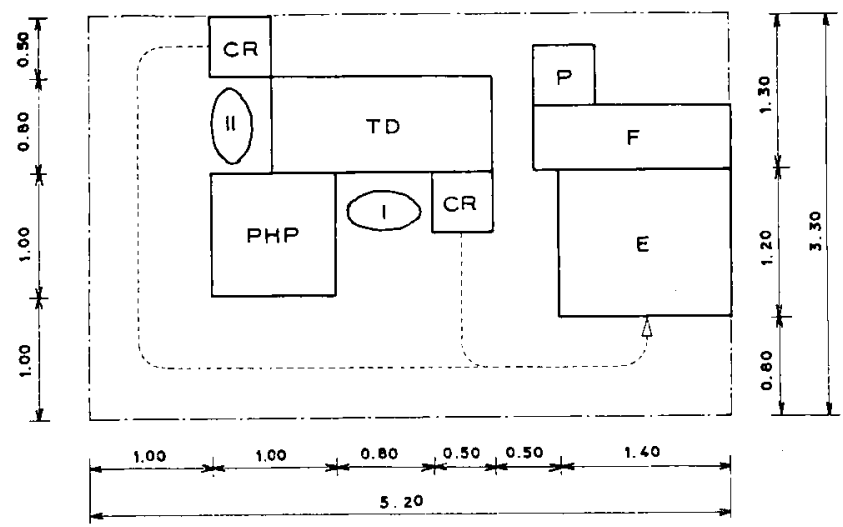

POSTE AVEC 2 OU 3 OUVRIERS

FIG. 21. - Implantation avec extracteur à axe horizontal.

CR cadres désoperculés, $\mathbf{E}$ extracteur, $\mathbf{F}$ fosse, $\mathrm{P}$ pompe, PHP palette hausses pleines, TD table à désoperculer, I II III opérateurs

2e cas : deux ouvriers travaillent simultanément.

L'ouvrier occupé en permanence à l'enlèvement des opercules prend place à l'extrémité de la table à désoperculer (fig. 2I en bas) et l'ouvrier travaillant alternativement à l'enlèvement des opercules et à la manœuvre de l'extracteur, prend place le long d'un des grands côtés de la table à désoperculer. I,es deux ouvriers prennent les cadres à désoperculer sur la même palette disposée entre les deux postes. 
L'ensemble des postes occupe une surface de $17,16 \mathrm{~m}^{2}$ avec une longueur de $5,20 \mathrm{~m}$ et une largeur de 3,30 $\mathrm{m}$ et deux zones de circulation de I $\mathrm{m}$ de large pour la manutention des chariots roulants et la manouvre de l'extracteur.

3e cas : trois ouvrıers travaillent simultanément.

Dans ce cas, deux ouvriers sont employés en permanence à désoperculer et le $3^{\text {e }}$ est affecté à l'extracteur.

Le poste a la même disposition (fig. $2 \mathrm{I}$ en bas) que dans le cas précédent et présente les mêmes dimensions.

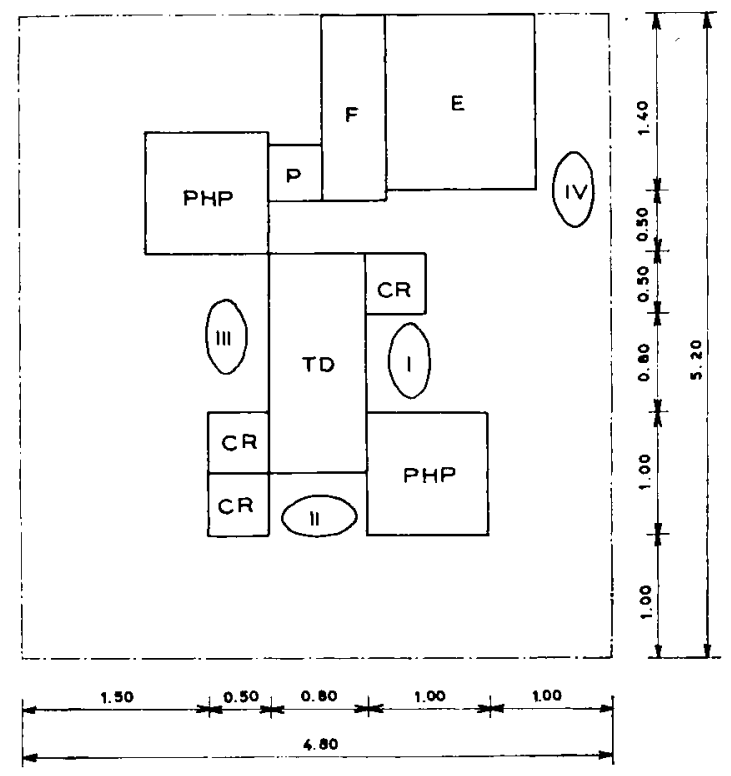

POSTE AVEC 4 OUVRIERS,

1 EXTRACTEUR A AXE HORIZONTAL.

FIG. 22. - Poste avec 4 ouvriers et un extracteur d axe horizontal (Même légende que celle de la fig. 21)

$4^{\text {e }}$ cas : quatre ouvriers et un extracteur.

Lorsque trois ouvriers désoperculent en permanence à l'aide du couteau ordinaire ou de la machine à désoperculer, il faut affecter un homme à l'extracteur. Il est alors nécessaire de prévoir l'emplacement de deux palettes chargées de hausses à désoperculer et 3 zones de circulation disposées le long de 3 côtés du poste (Fig. 22).

La surface nécessaire est de $24,96 \mathrm{~m}^{2}$ avec une longueur de 5,20 $\mathrm{m}$ et une largeur de $4,80 \mathrm{~m}$.

$5 \mathrm{e}$ cas : quatre ouvriers et deux extracteurs.

Lorsque trois ouvriers désoperculent à l'aide du couteau électrique il faut disposer de 2 extracteurs servis par un ouvrier. Ians ce cas (fig. 23) le poste occupe $26,40 \mathrm{~m}^{2}$ avec une longueur de $5,50 \mathrm{~m}$ et une largeur de 4,80 m. L es extracteurs 
sont alors disposés parallèlement à l'extrémité du poste d'enlèvement des opercules avec un passage de $0,80 \mathrm{~m}$ entre les deux appareils et deux allées latérales de circulation de $0,80 \mathrm{~m}$ pour la manœuvre des extracteurs.

Le tableau I6 permet de comparer les dimensions des différentes solutions d'aménagement de la miellerie.

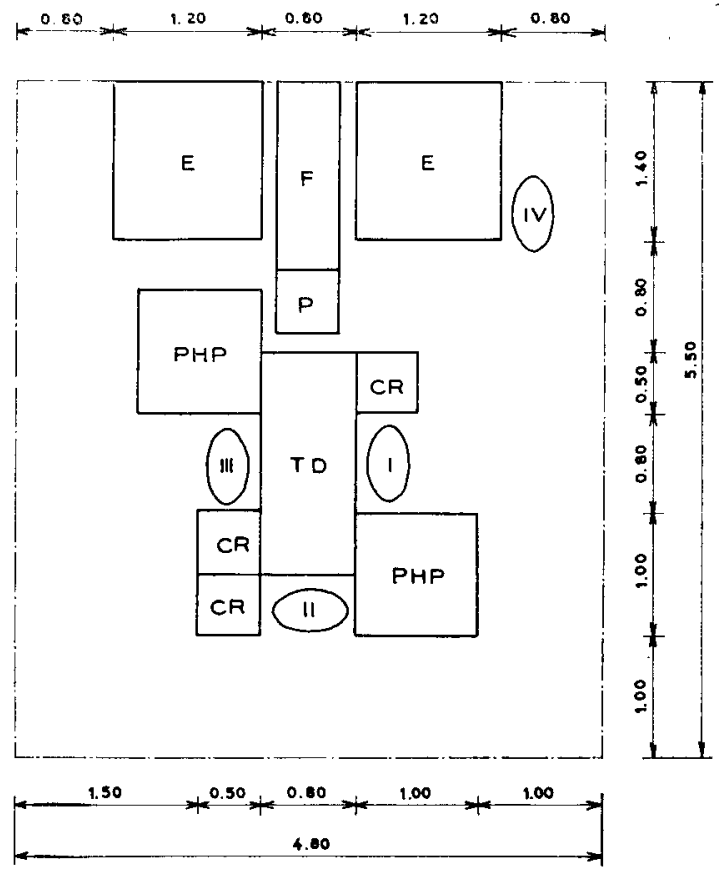

POSTE AVEC 4 HOMMES

ET 2 EXTRACTEURS A AXE HORIZONTAL.

FIG. 23. - Poste avec 4 hommes et deux extracteurs à axe horizontal (Même légende que celle de la fig. 2I)

TABL,A,AU I6

Dimensions comparées des postes d'extraction

\begin{tabular}{|c|c|c|c|c|}
\hline Extracteurs & Personnel & $\begin{array}{l}\text { Longueur } \\
(\mathrm{m})\end{array}$ & $\begin{array}{l}\text { Largeur } \\
(\mathrm{m})\end{array}$ & $\begin{array}{l}\text { Surface } \\
\left(\mathrm{m}^{2}\right)\end{array}$ \\
\hline $\begin{array}{l}1 \text { vertical } \ldots \ldots \\
1 \text { vertical } \ldots . . .\end{array}$ & $\left.\begin{array}{lll}1 & D & \text { et } \\
1 & D & \text { et } \\
E\end{array}\right\}$ & 4,00 & 2,60 & 10,40 \\
\hline $\begin{array}{l}1 \text { vertical } \ldots \ldots \\
2 \text { verticaux } \ldots . .\end{array}$ & \} $2 \mathrm{D}, 1 \mathrm{E}$ & 4,00 & 3,00 & 12,00 \\
\hline $\begin{array}{l}1 \text { horizontal .... } \\
1 \text { horizontal .... } \\
1 \text { horizontal .... } \\
1 \text { horizontal ... } \\
2 \text { horizontaux... }\end{array}$ & $\begin{array}{l}1 \mathrm{D} \text { et } \mathrm{E} \\
2 \mathrm{D} \text { et } \mathrm{E} \\
2 \mathrm{D}, 1 \mathrm{E} \\
3 \mathrm{D}, 1 \mathrm{E} \\
3 \mathrm{D}, 1 \mathrm{E}\end{array}$ & $\begin{array}{l}4,20 \\
5,20 \\
5,20 \\
5,20 \\
5,50\end{array}$ & $\begin{array}{l}2,80 \\
3,30 \\
3,30 \\
4,80 \\
4,80\end{array}$ & $\begin{array}{l}11,76 \\
17,16 \\
17,16 \\
24,96 \\
26,40\end{array}$ \\
\hline
\end{tabular}


On remarque sur ce tableau que l'extracteur à axe vertical exige le moins de surface, du fait du plus faible encombrement de l'appareil que l'extracteur à axe horizontal et qu'il ne nécessite pas l'emploi de la table à désoperculer qui est elle-même plus encombrante que le bac. La différence de surface nécessaire est faible dans les petites installations employant un ou deux ouvriers. A partir du poste de 3 personnes, la différence de surface nécessaire est de $40 \mathrm{p}$. Ioo plus importante avec l'extracteur à axe horizontal.

Pour les petites installations dans lesquelles un ou deux hommes seulement sont employés, c'est la solution du poste équipé avec extracteur à axe vertical qui exige le moins de surface, mais on obtient un rendement de travail journalier nettement plus faible, par exemple avec le couteau à désoperculer électrique, le rendement d'un homme seul est de 504 hausses avec l'extracteur à axe vertical et 640 hausses ( 27 p. Ioo en plus) et avec deux ouvriers le rendement passe de I o80 à I 360 (26 p. roo en plus). Il semble donc que la perte de place réalisée avec l'extracteur à axe horizontal soit largement compensée par l'amélioration du rendement du travail.

\section{E. Stockage du miel}

A la miellerie doit être adjointe un local de stockage du miel.

Le miel est acheminé par pompage, à travers des canalisations en verre Pyrex de $40 \mathrm{~mm}$ de diamètre dans des récipients appelés improprement maturateurs. Dans ces récipients en effet, le miel ne subit pas une maturation mais simplement une épuration, une clarification par remontée à la surface des bulles d'air et des corps étrangers et en particulier des débris de cire qu'il contient. Pour permettre cette remontée par différence de densité, le miel doit être porté et maintenu à une température de 30 à $35^{\circ}$ qui entraîne une diminution de sa viscosité. Les récipients doivent pouvoir être chauffés à l'aide de radiateurs électriques de I ooo watts, réglés à 1'aide de thermostats plongeant dans le miel à $50 \mathrm{~cm}$ du bord des récipients et réglés à $30^{\circ}$ ou $35^{\circ}$ et des thermostats montés en série avec les premiers et qui sont installés à l'extérieur des cuves et réglés à $40^{\circ}$. Il faut d'autre part que les cuves soient logées dans des habitacles isolés thermiquement par des cloisons de polystyrène expansé de $4,5 \mathrm{~cm}$ d'épaisseur.

Les cuves sont surélevées à une hauteur de $0,80 \mathrm{~m}$ à I $\mathrm{m}$ au-dessus du sol pour permettre le soutirage au moment de l'expédition. Pour obtenir une remontée rapide des impuretés, il est préconisé de ne pas utiliser des cuves présentant une hauteur supérieure à $I, 50 \mathrm{~m}$, dimension qui facilite également les aménagements de chauffage et d'isolement.

Une cuve cylindrique de $\mathrm{I}, 50 \mathrm{~m}$ de hauteur et de $\mathrm{I} \mathrm{m}$ de diamètre offre un volume de I I77 litres soit un poids de I $694 \mathrm{~kg}$ de miel $(d=\mathrm{I}, 44)$.

La surface d'encombrement d'une telle cuve, y compris l'épaisseur des cloisons isolantes est de $I$, Io $\times I$, Io $\mathrm{m}$ soit une surface de $I, 2 I \mathrm{~m}^{2}$.

Lorsque les cuves sont installées sur un seul niveau, il faut disposer d'une hauteur de 3,50 $\mathrm{m}$ soit $\mathrm{I} \mathrm{m}$ de soubassement, I,50 $\mathrm{m}$ de hauteur de cuve et $\mathrm{I} \mathrm{m}$ de débattement supérieur.

Il est possible dans les locaux ayant une hauteur de $5,50 \mathrm{~m}$ prévue pour le gerbage des palettes de hausses vides sur trois niveaux, d'aménagerles cuves de stockage du miel sur deux hauteurs superposées. 
I,e magasin de stockage du miel doit présenter une surface de circulation et de manutention d'une largeur minimum de $2,50 \mathrm{~m}$ pour permettre les opérations de soutirage au moment des expéditions.

\section{F. Exemple de projet d'installation}

Soit une entreprise apicole de 600 colonies exploitée par deux personnes et susceptible de produire au maximum 20 tonnes de miel. Comment doit-on envisager l'aménagement rationnel de la miellerie et de ses annexes, le miel n'étant pas conditionné en emballages de détail, mais expédié en vrac à un organisme de vente par fûts de $300 \mathrm{~kg}$ ?

Une production de Io à 20 tonnes de miel correspond à l'emploi de 7 ooo à 8 ooo cadres si l'on considère une charge de $1,5 \mathrm{~kg}$ par cadre en année de récolte normale et de $2,5 \mathrm{~kg}$ par cadre en année de très bonne récolte. Nous adoptons le nombre de 8 ooo cadres, ce qui représente un matériel théorique de 800 hausses et pratiquement de I ooo à I 200 hausses en raison de 1'hétérogénéité des charges unitaires.

L'installation doit comprendre : un local de déchargement des hausses provenant des ruchers, un magasin permettant de stocker I ooo hausses vides, un poste d'extraction et un magasin de stockage de 20 tonnes de miel en maturateurs capables de recevoir les plus fortes récoltes.

Le poste de déchargement du véhicule de transport des hausses doit avoir une longueur de $6 \mathrm{~m}$ et une largeur de $3 \mathrm{~m}$.

Si l'on utilise pour le stockage des hausses vides des grandes palettes et qu'on les gerbe sur 3 niveaux, le tableau 3 indique que pour I ooo hausses, il faut disposer les palettes sur 2 rangs $(2,20 \mathrm{~m})$ et une longueur de $5,50 \mathrm{~m}$ soit une surface brute de I2, Io $\mathrm{m}_{2}$. Il est nécessaire de prévoir une allée de $3 \mathrm{~m}$ de large pour permettre l'évolution d'un transrouleur-élévateur et une hauteur sous plafond de $5,50 \mathrm{~m}$.

On utilise pour désoperculer les cadres le moyen le plus rapide, c'est-à-dire le couteau électrique. L'examen du tableau I I montre que deux hommes utilisant un couteau électrique peuvent traiter I 080 cadres par jour avec un extracteur à axe vertical et I 360 cadres avec un extracteur à axe horizontal. Nous adoptons cette deuxième formule, solution permettant d'effectuer le travail en $\frac{8 \text { ooo }}{360}$ soit un peu plus de 5 jours au ileu de $\frac{8 \text { ooo }}{\text { I } 080}$ soit 7 jours et demi avec 1'extracteur à axe vertical $\left({ }^{1}\right)$.

Le poste d'extraction pour deux ouvriers travaillant avec un extracteur à axe horizontal exige un emplacement de 5,20 $\mathrm{m}$ de long et $3,30 \mathrm{~m}$ de large (voir fig. $2 \mathrm{I}$ en bas).

Le stockage du miel étant réalisé dans des maturateurs de I,50 $\mathrm{m}$ de haut et de I m de diamètre, d'une capacité de I $694 \mathrm{~kg}$ de miel, il faut prévoir $\frac{20}{\mathrm{I}} \frac{000}{694}$ soit

(1) Le gain de deux jours et demi grâce à l'emploi d'un appareil par rapport à un autre peut sembler négligeable, en fait il s'agit de réaliser un travail qui se situe généralement à une période de pointe et une telle économie de temps peut constituer un intérêt certain pour l'exploitation. 
I2 unités de stockage dont chacune occupe une surface carrée de $\mathrm{I}, \mathrm{IO} \mathrm{m}$ de côté soit $\mathrm{I}, 2 \mathrm{I} \mathrm{\textrm {m } ^ { 2 }}$.

Nous avons la possibilité de prévoir deux niveaux de maturateurs exigeant une hauteur sous plafond de $5,25 \mathrm{~m}$ correspondant à celle prévue dans le magasin
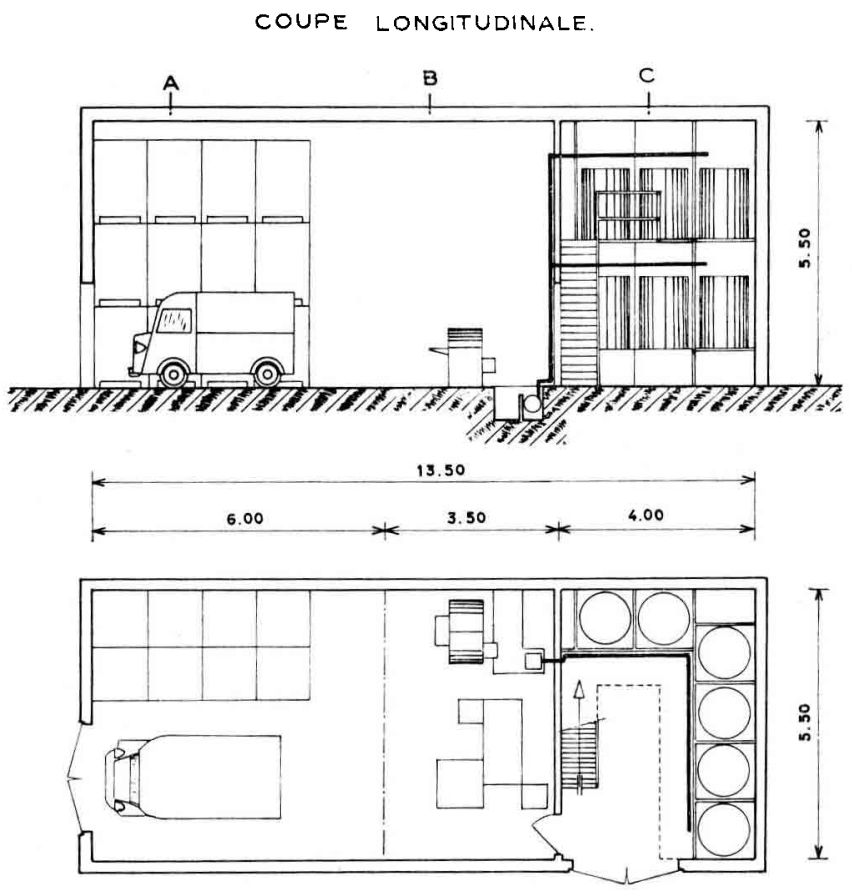

PLAN.
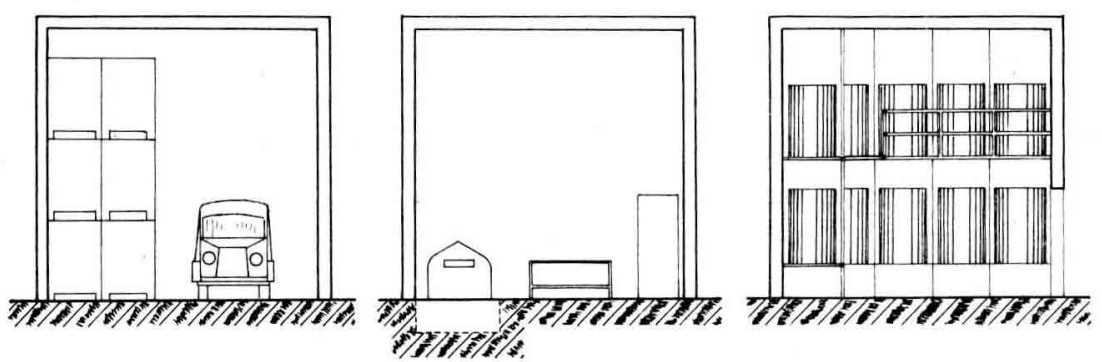

COUPE A

COUPE $\mathrm{B}$.

COUPE $C$.

FIG. 24. - Projet d'aménagement d'une installation pour 20 tonnes de miel

de stockage des hausses vides $(5,50 \mathrm{~m})$. La surface brute nécessaire pour les I2 maturateurs disposés sur deux niveaux est de $\frac{\mathrm{I}, 2 \mathrm{I} \times \mathrm{I} 2}{2}=7,26 \mathrm{~m}^{2}$, surface à laquelle il faut ajouter une zone de manutention de $2,50 \mathrm{~m}$ de large. 
Le plan de la figure 24 montre qu'avec un local de I3,50 $\mathrm{m}$ de long et $5,50 \mathrm{~m}$ de large, soit d'une surface de $74,25 \mathrm{~m}^{2}$, il est possible d'implanter rationnellement les locaux nécessaires à l'entreprise, en prévoyant pour chaque poste des dimensions et des surfaces répondant largement aux besoins théoriques calculés.

L'aire de déchargement des hausses mesure $6 \mathrm{~m}$ de long et $3,30 \mathrm{~m}$ de large, soit une surface de $\mathrm{I} 9,8 \mathrm{~m}^{2}$ pour un besoin de $18 \mathrm{~m}^{2}$.

L,e magasin de stockage des hausses a la même longueur que l'aire de déchargement, cette dernière servant d'allée de circulation du magasin. L'emplacement réservé aux palettes a une longueur de $6 \mathrm{~m}$ et une largeur de 2,20 $\mathrm{m}$ soit $\mathrm{I}_{3}, 2 \mathrm{~m}^{2}$ pour un besoin de $9,68 \mathrm{~m}^{2}$.

L'atelier d'extraction mesure 5,50 $\times 3,50 \mathrm{~m}$ alors qu'il est nécessaire de disposer d'une surface de $5,20 \times 3,30 \mathrm{~m}$.

Enfin le magasin de stockage du miel qui mesure $5,50 \times 4 \mathrm{~m}$ permet de loger les 2 maturateurs sur deux niveaux et de disposer d'une surface de manutention des fûts d'expédition de $4,40 \times 2,90 \mathrm{~m}$.

On ne prévoit pas de cloison entre le magasin des hausses et l'atelier d'extraction afin de donner plus de souplesse d'évolution entre le poste d'enlèvement des opercules et l'entrée de l'extracteur.

On remarque la simplicité et la réduction de longueur du circuit de pompage du miel grâce à l'emplacement de la pompe par rapport aux maturateurs.

Dans le magasin à miel, une passerelle avec escalier d'accès est aménagée à $3 \mathrm{~m}$ du sol, le long des maturateurs pour circuler à la hauteur des bacs supérieurs.

Les accès sont constitués par une porte de $3 \mathrm{~m}$ de large permettant l'entrée du véhicule de transport des hausses au poste de déchargement, une porte de service entre le poste d'enlèvement des opercules et le magasin à miel et enfin une porte de $2,50 \mathrm{~m}$ de large permettant le passage des fûts au moment des expéditions.

\section{CONCLUSION}

Cette étude fait apparaître les avantages que les apiculteurs peuvent retirer de l'application d'une meilleure organisation du travail.

Devant le grand nombre de modèles d'outils et d'appareils, il est nécessaire de faire un choix basé sur des études systématiques démontrant les avantages de ceux qui permettent d'effectuer un travail de meilleure qualité, dans le temps le plus court et avec le moins de fatigue pour les opérateurs. C'est ainsi qu'on a pu démontrer dans cette étude l'avantage du couteau électrique sur les autres matériels pour l'enlèvement des opercules des cadres.

L'organisation du travail permet de répartir judicieusement les tâches dans le temps. Que l'apiculteur travaille seul ou en équipe, il est nécessaire d'organiser le déroulement du travail de manière à éliminer les temps morts occasionnés par les attentes en particulier et de réduire les temps consacrés à l'exécution d'opérations accessoires telles que les transports et les manutentions. Il est intéressant de remarquer, à la suite des observations faites sur des chantiers d'extraction de miel, que ce ne sont pas ceux où l'effectif de travailleurs permet d'obtenir le plus haut 
rendement qui fournissent la meilleure productivité, c'est-à-dire le meilleur rendement individuel.

Nous avons remarqué que l'effectif des équipes de personnel dépend de la nature du matériel utilisé et en particulier des outils d'enlèvement des opercules, des modèles d'extracteurs et des moyens de manutention des cadres et des hausses.

Enfin l'étude a permis de définir les types d'implantation les plus rationnels, compte tenu du matériel utilisé et de l'effectif de main-d'œuvre employée. Dans chaque cas, on a pu déterminer la disposition respective des éléments humains et mécaniques qui interviennent dans le poste de travail.

On peut ainsi réduire au minimum la surface de local à utiliser, la fréquence et la distance des déplacements et des transports tout en assurant au personnel le maximum de confort et de sécurité.

Reçu pour publication en mars 1965.

\section{REMERCIEMEN'TS}

Les études de chantiers ont été réalisées à la Station expérimentale d'Apiculture del'I. N. R.A à Montfavet (Vaucluse) et aux Établissements Robin à Chézelles (Indre). Il nous est particulièrement agréable d'exprimer nos remerciements à MM. LAvie, RoBIN, FEINTRENIE et MARY, ainsi qu'à leurs collaborateurs, qui ont accepté, avec beaucoup de complaisance et de compréhension les contraintes qu'entrainent les observations et les mesures de travail. Nous sommes vivement reconnaissants envers M. J. Louveaux, directeur de la Station de Recherches sur l'Abeille et les Insectes sociaux, pour les précieux conseils qu'il nous a aimablement prodigués pour la réalisation de cette étude.

\section{SUMMARY}

\section{WORK ORGANIZATION OF HONEY EXTRACTION}

The study on the organisation of the honey crop deals with the problems of manipulation and stocking of the supers at the time of the crop and between the crops. The use of pallets which can be stacked on two or three levels by means of fork lift allows to save space and reduce the manipulation timings as compared with the method of stocking on the ground and hand manipulation.

The comparative study of the maintools used for the operation of uncapping was carried out by one single manipulator working on frames with the same stock of honey. It was found that an electrically heated knife gives the best results, that the traditional knife requires a timing 22 p. 100 longer than the former and bastby, that the uncapping machine with a vibrating and heated blade takes a percentage of time $67 \mathrm{p}$. roo longer than the first one.

The study of the apparatus used for the extraction by centrifugal force allowed to compare the two apparatuses best adapted to a semi-industrial work : the vertical axis extractor into which the frames are inserted and the horizontal axis extractor into which the frames, in the supers, are put. Whereas with the first apparatus, which has a capacity of 36 frames for a machine work of to minutes, six minutes are needed for the loading and unloading, the second one, which has a capacity of 40 frames for the same machine work time, only requires 2 minutes for the manipulations.

Taking into account the time needed for the uncapping and the extraction, the study dealt with the organization of the work, carried out by a labour force varying from one labour hand working alone to 4 people, specialized in the execution of the different basic operations. In each case, we worked out the time required for a sequence of work corresponding to a complete cycle of operations, and consequently, the number of sequences which can be carried out in one day and the performance realized (which is influenced by the importance of the crop). 
This factor once established, it is then easy to determin which apparatus should be used, and the labour force to be provided for, so as to carry out the extraction work in a reasonable length of time. One man operating alone can extract in a day from 400 to 640 frames, or 600 to I $600 \mathrm{~kg}$ of honey, according to the importance of the crop. Four inen, three of whom uncap with an electrical knife, the fourth one managing two horizontal axis extractors, can treat daily 2400 frames or 3600 to $6000 \mathrm{~kg}$ of honey.

The best productivity, i.e. the highest performance per labour and is obtained by a team of 2 men using the electrical knife and the horizontal axis extractor which allows to deal with 680 frames or 1020 to $1700 \mathrm{~kg}$ of honey per workman and per day.

For the fitting out of the rooms and the installation of the equipment, the $U$ shaped disposition i.e. the stocking of the full supers at the same place as that of the empty ones, relatively to the working posts, proved more economical than the implantation in a row.

The post equiped with a horizontal axis extractor requires a larger net surface (place for the apparatus and for moving about) than that required by a post with a vertical-axis extractor : for instance, with 3 labour hands, one must dispose of $17 \mathrm{~m}^{2}$ in the first case and of $12 \mathrm{~m}^{2}$ in the second one, which means an economy of surface of $40 \mathrm{p}$. 100; but the advantages registered in the first case largely compense this disadvantage.

\section{RÉFÉRENCES BIBLIOGRAPHIQUES}

Barnes R. M. 1960. Étude des mouvements et des temps. Les Éditions d'organisation.

Binielli J. 1956. Pratique de la simplification du travail. Éditions Entreprise moderne.

Boursset S. 1962. Problème posé par l'aménagement des postes de travail. Le travail humain 14, 28:304 .

Faverge J. M., Leplat J., Guiguet B. 1958. L'adaptation de la machine à l'homme. Presses universitaires de France.

Lavie P., Louveaux J. 1961. La station expérimentale d'apiculture de l'I. N. R. A. Annales Abeille, 4, 297-360.

LehmanN G. 1955. Physiologie pratique du travail. Les Éditions d'organisation.

LouvEaux J. et coll. ig64. Les techniques de conditionnement et de commercialisation du miel au Canada et aux U.S.A. Annales Abeille, 7, 103-159.

Mrchel P. г96r. Implantation et manutentions, méthodes d'études. Dunod.

Piel-DesruisseauX J. ${ }^{96} 3$. L'organisation du travail en agriculture, $\left(2^{\circ}\right.$ édition). Les Éditions d'organisation. 